\title{
Assessing the Life Cycle Benefits of Recycled Material in Road Construction
}

\author{
Eleanor Frances Bloom
}

A thesis submitted in partial fulfillment of the requirements for the degree of

\author{
Master of Science
}

Geological Engineering

At the

University of Wisconsin-Madison

Summer 2016 


\title{
Assessing the Life Cycle Benefits of Recycled Material in Road Construction
}

By

\author{
Eleanor Frances Bloom
}

Approved by

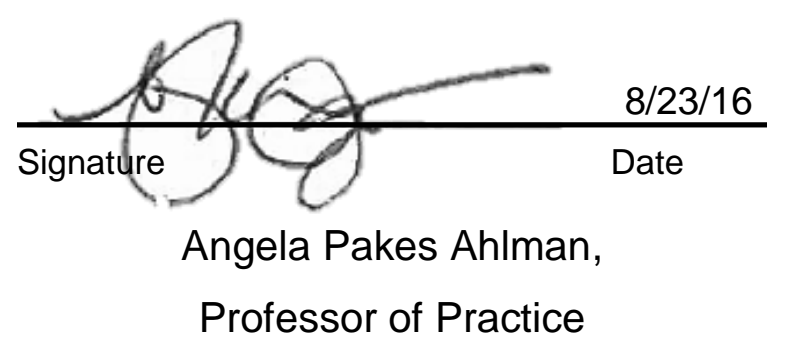
$\frac{\text { WN/.LIKOS FOR EDEL 8/23/16 }}{\text { Signature }}$
Tuncer B. Edil,
Professor Emeritus

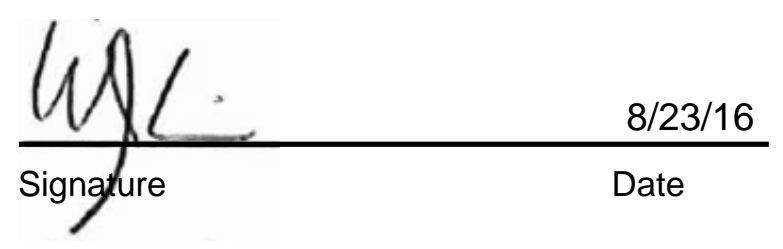

William J. Likos,

Professor

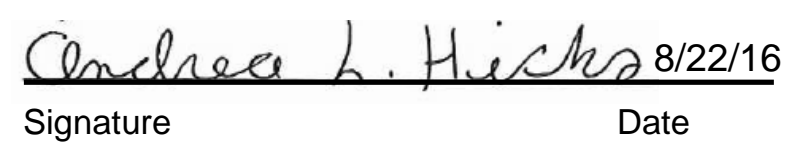

Andrea Hicks, Assistant Professor 


\section{Executive Summary}

There is interest in determining and validating the environmental and economic benefits of incorporating recycled materials into road construction using life cycle assessments (LCA) and life cycle cost analysis (LCCA) tools. However, the process of collecting the necessary data for LCAs and LCCAs from departments of transportations (DOTs) and road construction contractors is not well defined. This thesis provides a study of real-time data collection to compare with the results of pre-construction estimated LCA data. The goal of this comparison is to determine a data collection precedent for environmental analyses of future transportation projects. Additionally, two prominent LCA tools were used in conducting the assessment and the results were compared to validate the predicted impacts.

The primary body of this thesis focuses on a specific, project-based LCA and LCCA of the reconstruction and expansion of a 2.4-km (1.5-mi) stretch of the eastbound Beltline Highway in Madison, Wisconsin. Recycled materials used in this reconstruction include: fly ash, slag, recycled asphalt shingles (RAS), recycled asphalt pavement (RAP), and recycled concrete aggregate (RCA). Fly ash and slag were used as a partial replacement of cement in the ready-mix concrete. RAP was used in both hot mix asphalt (HMA) pavement as well as a base course material. RAS was substituted for binder and aggregate material in some HMA mix designs. RCA, both recycled onsite and imported, was substituted for base and subbase material.

Two data collection methodologies were employed to gather the necessary inputs for the LCA of the reconstruction: 1) material quantities estimated from designs and specifications as planned prior to construction (referred as Planned), and 2) material quantities explicitly tracked and collected while construction was on-going (referred as Constructed). In the Planned data collection methodology, quantities were calculated using plan drawings and average mix designs. In the Constructed data collection methodology, key site-specific Wisconsin DOT (WisDOT) and contractor files were accessed for material quantity information. 
Two prominent tools were used to conduct the LCAs with the objective of validating impact results. The Pavement Life-cycle Assessment Tool for Environmental and Economic Effects (PaLATE) is an open-source LCA and LCCA program specifically developed for highway construction. Environmental outputs include energy and water consumption, carbon dioxide $\left(\mathrm{CO}_{2}\right)$ emissions, and more. The second LCA tool, SimaPro, is a professional LCA software used to collect, analyze, and monitor the sustainability performance data of products and services. Some of the SimaPro impact categories used in this analysis include fossil fuel depletion, global warming, energy demand, and $\mathrm{CO}_{2}$ emissions.

When comparing the LCAs of two or more products, a relative ranking of alternatives can be analyzed as well as the absolute impacts. For this study, the design of the actual roadway that incorporated recycled material (referred to as Recycled) was compared to a hypothetical design comprised of no recycled material (referred to as Virgin). In the Virgin design, recycled material quantities were replaced with equivalent virgin materials. This method demonstrates the impact reductions from the use of recycled material. To validate the LCA results, impacts predicted by PaLATE versus SimaPro were compared, with the primary focus on the common impact categories of energy and $\mathrm{CO}_{2}$ emissions.

Results show that the material quantities obtained from the two data collection methods are within one order of magnitude for all categories, demonstrating general agreement regardless of Constructed or Planned data. Generally, the Constructed data predicts slightly greater (1.2x to 2.2x) material use as compared to the Planned data. Impact reductions were seen in all PaLATE categories from the use of recycled materials, regardless of data collection methodology. However, most impact categories saw greater reductions using the Planned data as compared to the Constructed data. The greater reductions are due to a greater ratio of recycled to virgin material use in the quantities found by using the Planned data collection method. A comparison of absolute impact predictions, rather than reductions, revealed that the Planned data quantities saw lower impacts than the Constructed data. The Constructed data quantities have greater 
absolute impacts because this collection methodology found that more materials were used overall than as predicted by the Planned data collection method. Similar results are seen for the SimaPro analysis, but in different environmental impact categories.

Overall, the Planned and Constructed data produced relatively comparable results. In the particularly relevant categories of energy and $\mathrm{CO}_{2}$ emissions, the two data sets' results had a difference of only $7-8 \%$ according to the PaLATE analysis. In SimaPro's global warming and fossil fuel depletion categories, the Constructed data results predicted a $5-6 \%$ difference from the Planned data impacts reductions. When validating the impacts across PaLATE and SimaPro, the predictions from both tools for energy and $\mathrm{CO}_{2}$ emissions appear to have minor variability (within $10 \%)$. The trends explored in this thesis indicate that the data collection methodology and resulting LCA inputs have a greater influence in environmental impact predictions as compared to the analysis tools, particularly for energy and $\mathrm{CO}_{2}$ emissions.

Additionally, an LCCA was conducted using a simple cost-savings based on material unit prices. To calculate the savings, the cost for a recycled material was compared to the cost for an equivalent virgin material (e.g. fly ash vs. cement). Planned data lifetime savings for the project were estimated at approximately $\$ 209,800$, while the Constructed data predicted a lifetime savings of $\$ 267,000$. In general, the Constructed data quantities resulted in more cost savings because more recycled materials quantities were found by this collection methodology. The grand total savings differ by approximately $\$ 57,000$. While this may seem like a small number compared to typical DOT budgets, it becomes significant when considering the savings are for only 3 lanemiles. This stresses why explicit tracking may be important to accurately determine cost reductions from recycled material use.

Based on the LCAs and LCCA, similar economic and environmental impacts and reductions were predicted using the two data collection methodologies. However, the Constructed data collection was able to capture more accurate material quantities, as well as a greater variety of material types and mix designs. Although this in-depth tracking of material may have resulted 
in more accurate life cycle impact predictions, the Planned data quantities resulted in similar enough impacts to suggest that this methodology could be an acceptable method for estimating future LCA inputs. Additionally, based on comparable impact assessment parameters, the two LCA software tools provided similar results in terms of energy use and $\mathrm{CO}_{2}$ emissions. Therefore, DOTs should attempt to focus future efforts on material tracking for the purpose of LCAs and LCCAs when these issues are critical.

Additional studies are included in Appendix A and B. Appendix A discusses a case study conducted prior to the analysis included in the main thesis. For the Appendix A study, data was collected post-construction from designs and plans, i.e. data was not explicitly tracked. The assumptions and concerns generated by this first case study prompted the data collection methodology research question posed by the main thesis. Appendix B includes a report on the development of an environmental impact tool used to assess the sustainable management of pavements in poor condition. For this impact tool, different rehabilitation and management methods are analyzed for economic and environmental costs. The environmental impact of each management strategy was calculated using LCAs, and the results were incorporated in a more in-depth evaluation tool. This paper demonstrates an application of road-related LCAs that differs from the two case studies. 


\section{Acknowledgements}

I would like to thank my research advisors, Professor Tuncer Edil and Angela Pakes Ahlman, for their guidance and support during my studies in the Geological Engineering (GLE) program at the University of Wisconsin-Madison. I cannot image how my academic career may have unfolded if I had not met Angela in my first year as an undergraduate. Angela has served as not only an advisor, but as a mentor and role model for the challenging career of a woman engineer. Through Tuncer's wisdom and instruction, my simple analysis grew into a fully-formed thesis. My excellent experience as an undergraduate researcher with Angela and Tuncer provided the inspiration for my graduate studies and future career.

I would also like to thank my other committee members, Professors Bill Likos and Andrea Hicks. Through Professor Likos's courses, I have gained a strong foundation in geotechnical knowledge. With her LCA expertise, Professor Hicks has provided crucial advice on my research. Furthermore, I have the greatest appreciation for everyone affiliated with the GLE program. This tight-knit group of faculty and staff provide an exceptional environmental in which students such as myself can excel. In particular, thank you to Sabrina Bradshaw, who I have worked with for a number of years and who aided in my thesis editing. Additional thanks to other UW-Madison affiliates, including Gary Whited and many of the Civil and Environmental Engineering Department who provided transportation-related advice, access to software, or taught many of my classes.

My immense gratitude towards all of the students who have worked alongside me with the Recycled Materials Resource Center (RMRC). Thank you to Kelly Del Ponte, who worked with me as I moved from undergraduate to graduate student. Thank you to Bharat Madras Natarajan, who has been a near constant source of help and feedback. Thank you to Greg Horstmeier for perhaps my most productive summer. Thank you to the three newest RMRC students, Aaron Canton, Andrew Baker, and Erik Elliott. I look forward to seeing your future research. Additionally, I'd like to thank all of the GLE graduate students (especially those in the "loud" grad office) for 
being such a welcoming group. My best wishes to future graduates and future Gneiss Servers. Thank you to all my GLE undergraduate peers, most of whom have already started their exciting careers. I cannot express enough how amazing my time in the GLE program has been.

I want to thank all of those with whom I am not at academically affiliated, but who, nonetheless, have been absolutely crucial to my achievements. Thank you mom and dad for your love and encouragement all my life. Thank you to my boyfriend and partner, Tom Bryan, with whom I share so much that he could probably write my thesis for me at this point. Thank you to my brother and his wife, Samuel and Chika Bloom, my Aunt Dawn, and all my cousins who have become true Badgers in their support. My sincerest thanks to the amazing group of friends I have found over the past five years, especially Tessa Sliwa, Annamarie Bjorkland, Mark Engel, and Bethany Steive. Thank you to the beautiful ladies who started their careers like me at the Office of Sustainability, Sarah Olson, Laura Linde, and Emmy Burns. All of you helped me to balance work with play and enriched my experience in Madison.

Thank you to the RMRC and its member states, who provided research opportunities and much of my funding. In particular, funding for the Beltline case study was provided by the Wisconsin Department of Transportation (WisDOT) through the Construction Materials Support Center (CMSC) at UW-Madison. Thank you to Steve Krebs and Barry Paye of WisDOT for provided essential feedback on my case study reports. I would also like to acknowledge all those who helped me conduct the I-94 and Beltline case studies, including Dr. Jin Lee, Nate Schlegal and Brad Blum of CH2MHill, Art Covi of We Energies, Kevin McMullen of the Wisconsin Concrete Pavement Association, Brandan Strand of the Wisconsin Asphalt Pavement Association, and Kent Hansen of the National Asphalt Pavement Association. Thank you to those folks who worked with me at the Beltline construction site, including Chris Fredrick, Joe Jirsa, Mary Gherke, and Greg Courter and Kevin Kaufman of Hoffman Construction. Additionally, funding for the development of the environmental impact tool for sustainable management of pavements in poor condition was provided by the Minnesota Department of Transportation (MnDOT) through MnDOT 
Contract No. 89265 Work Order No.5. Professor Teresa Adams and Dr. Andrew Hanz of the National Center for Freight \& Infrastructure Research \& Education assisted in this analysis and the development of the final tool. Any opinions, findings, and conclusions or recommendations expressed in this material are those of the author and do not necessarily reflect the views of the sponsoring organizations. 


\section{Table of Contents}

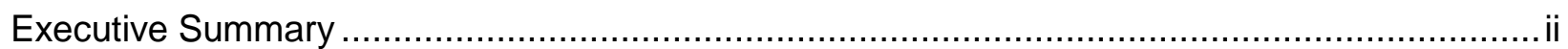

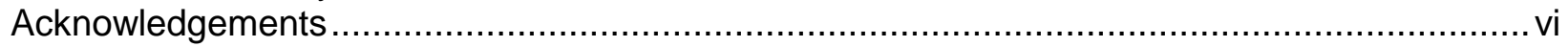

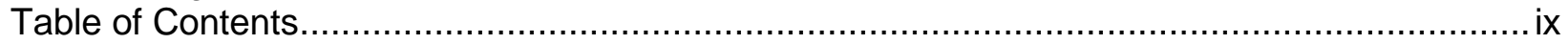

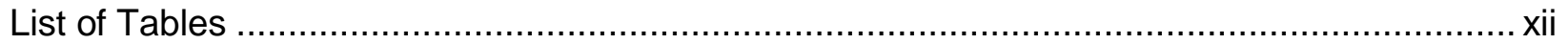

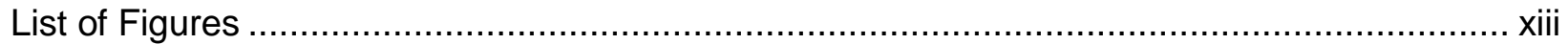

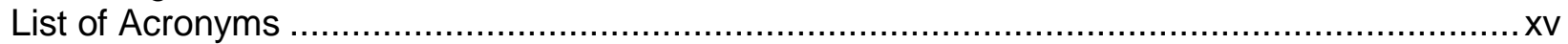

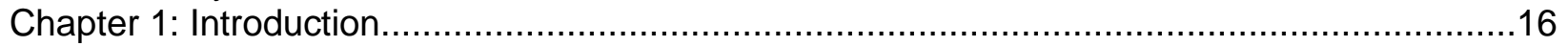

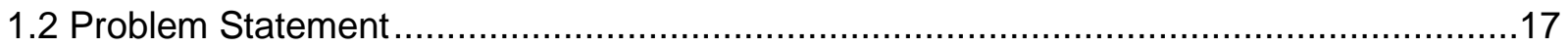

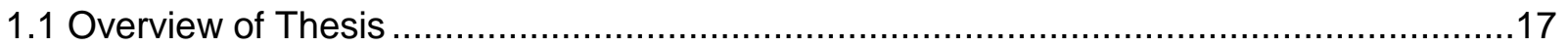

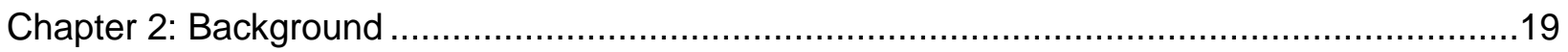

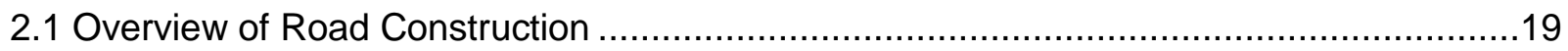

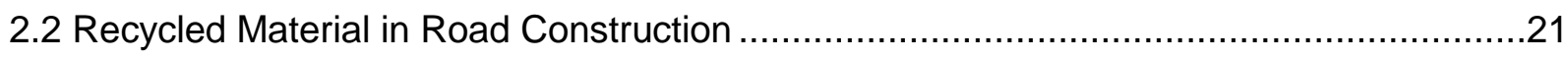

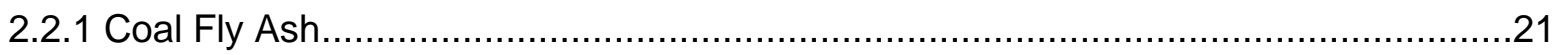

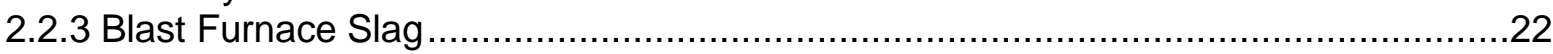

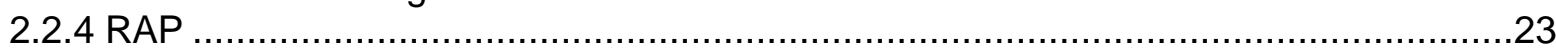

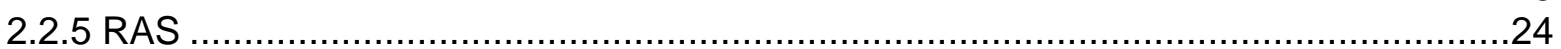

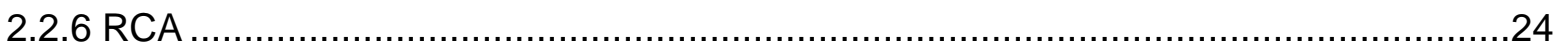

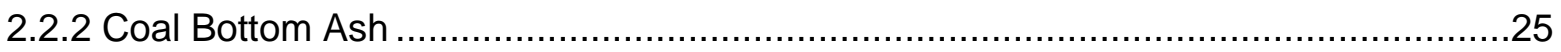

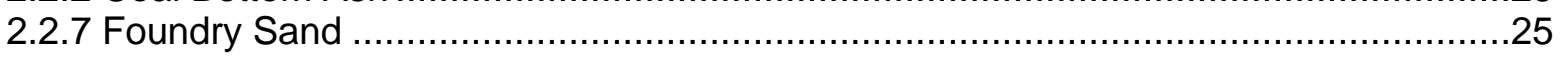

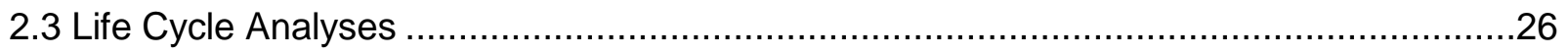

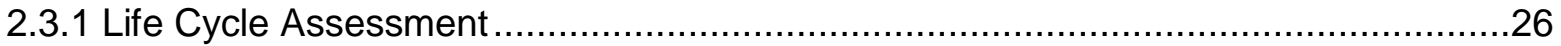

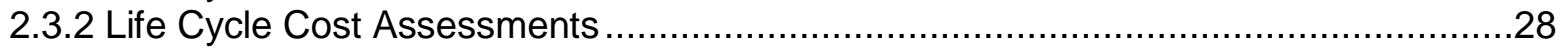

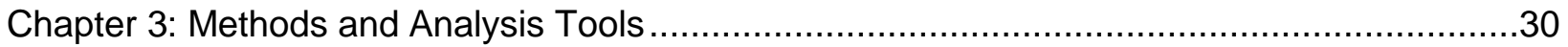

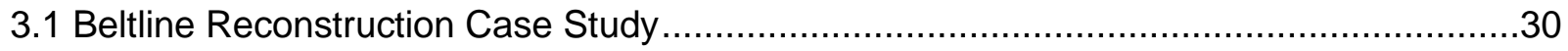

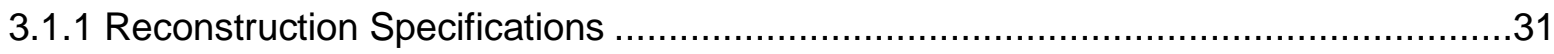

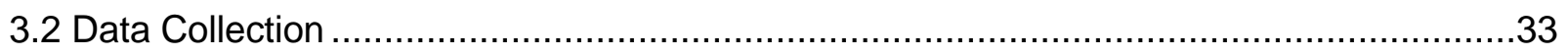

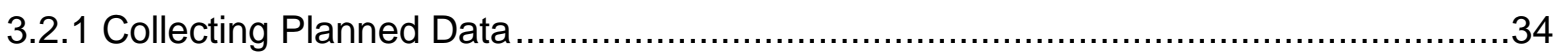

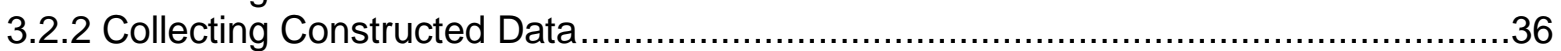

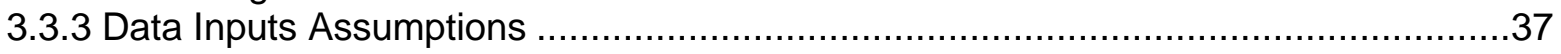

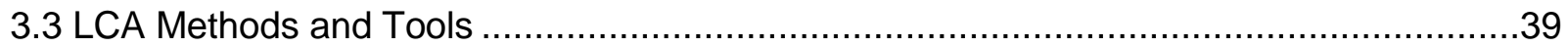

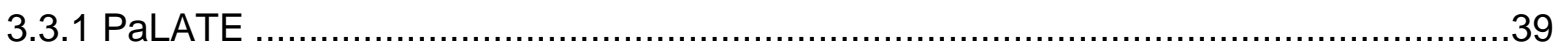

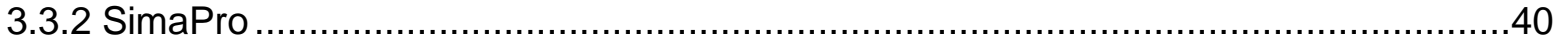

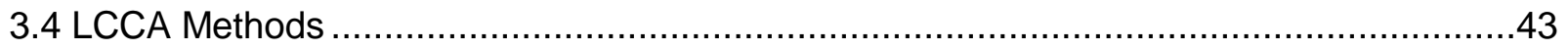

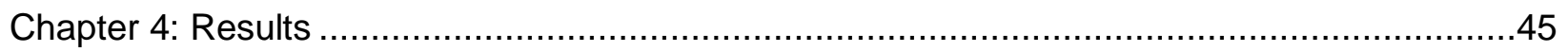

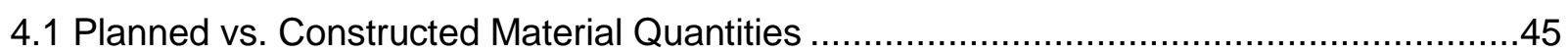

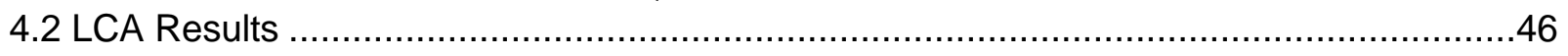

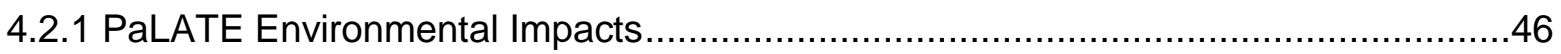

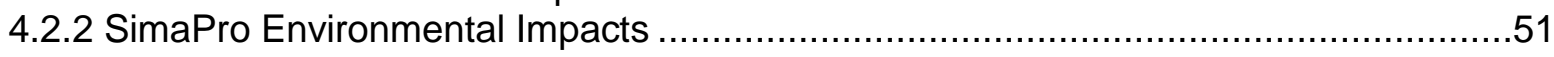

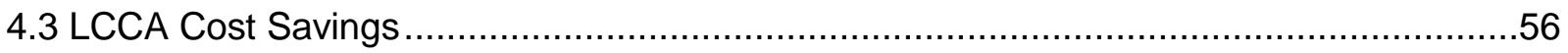

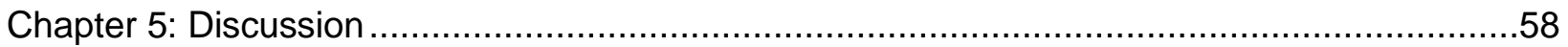




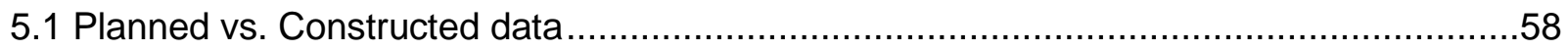

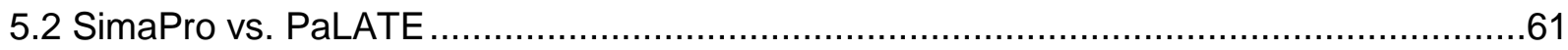

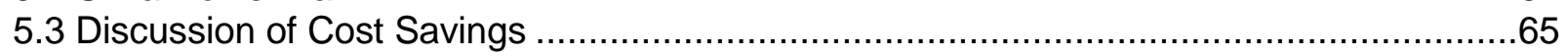

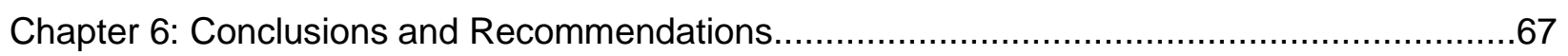

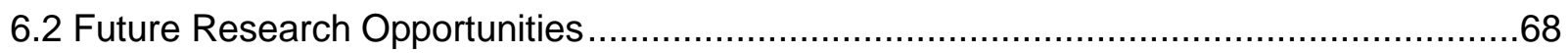

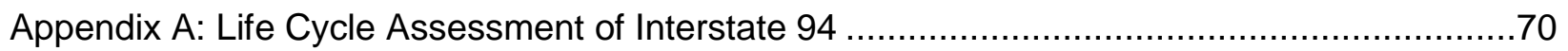

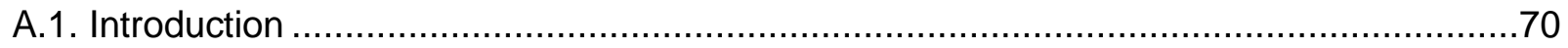

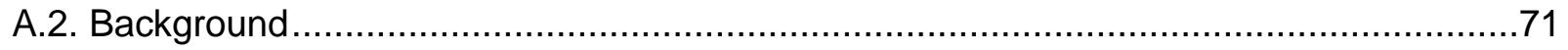

A.2.1 The I-94 North-South Freeway Project.................................................... 71

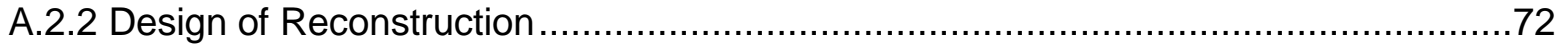

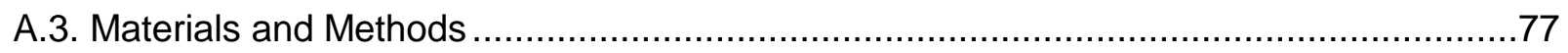

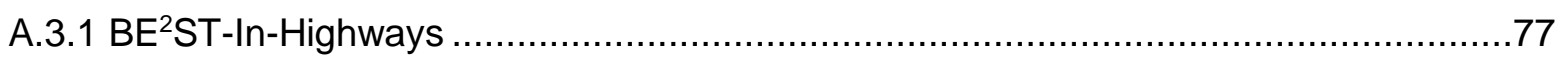

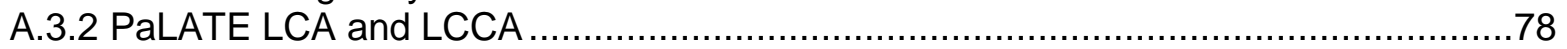

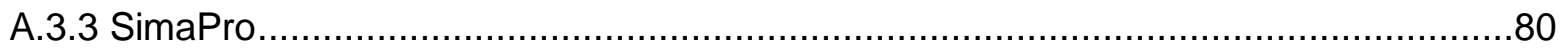

A.3.4 WisDOT Analysis for Service Life and Rehabilitation ..................................... 83

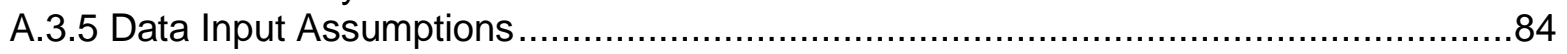

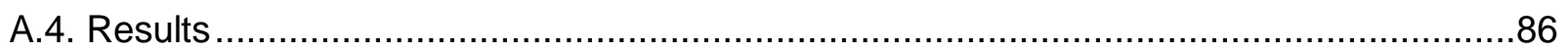

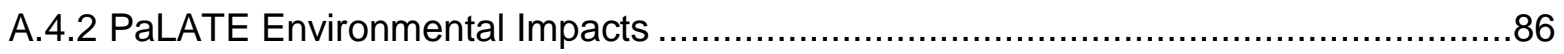

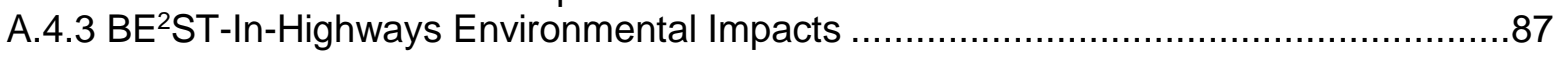

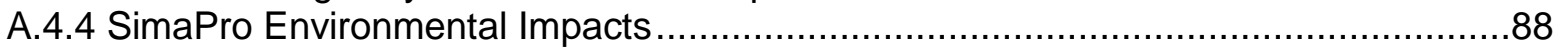

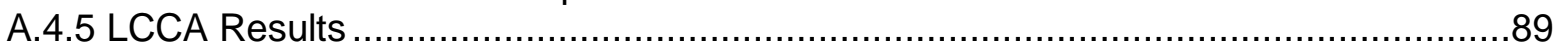

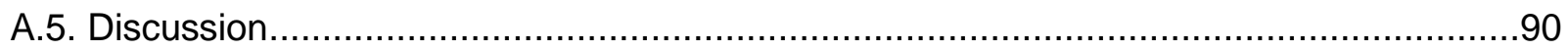

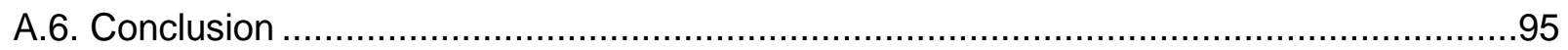

Appendix B: Development of Environmental Impact Tool to Assess the Sustainable Management

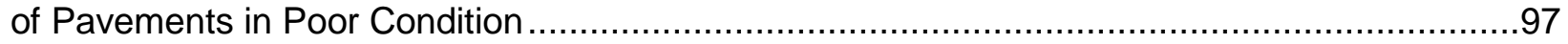

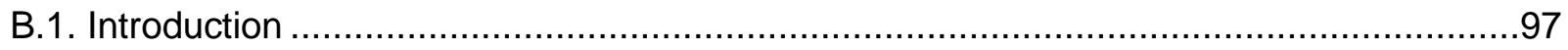

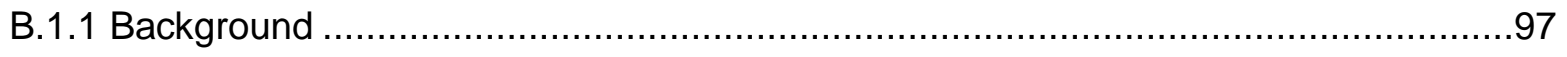

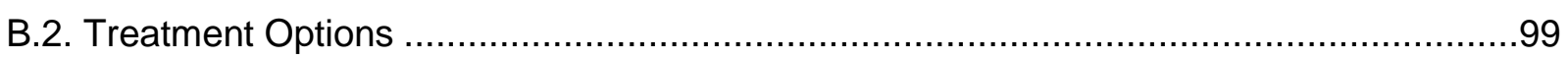

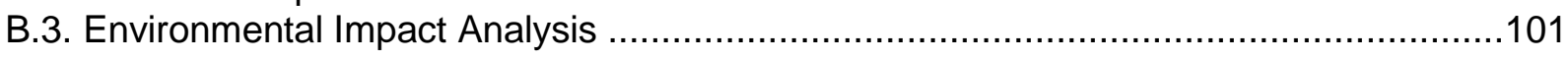

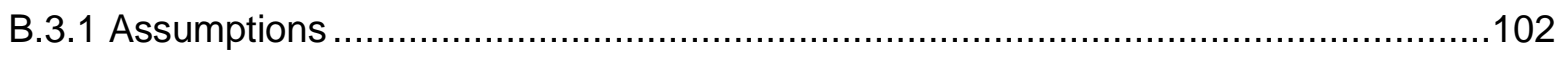

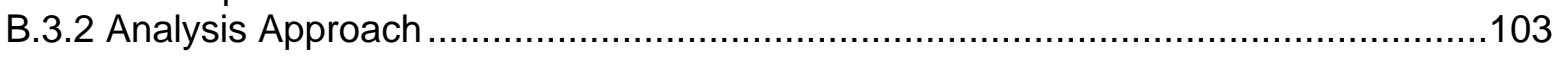

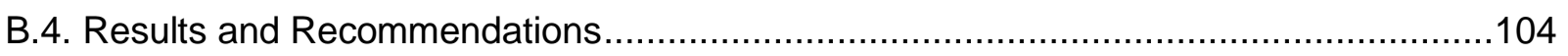

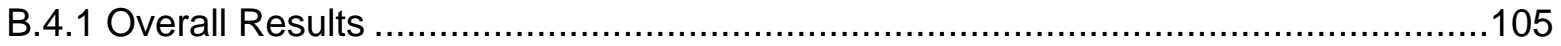

B.4.2 Environmental Results by Category .........................................................107

B.4.3 Annualized Environmental Impacts ...................................................... 109

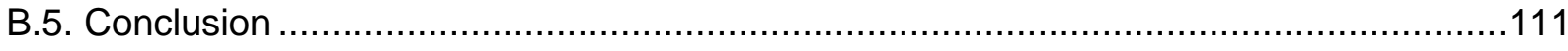

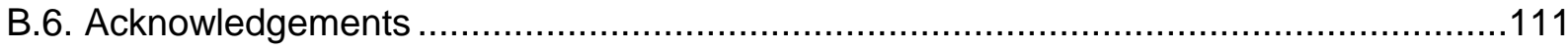

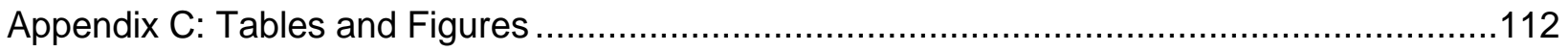

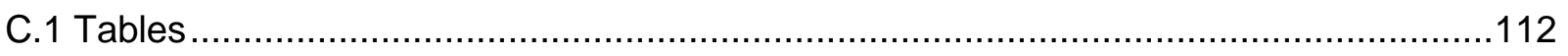

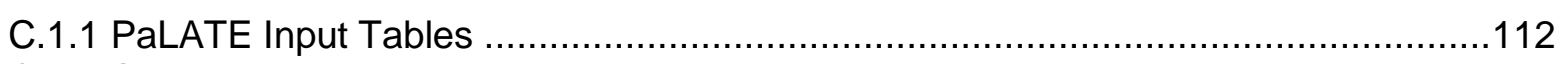

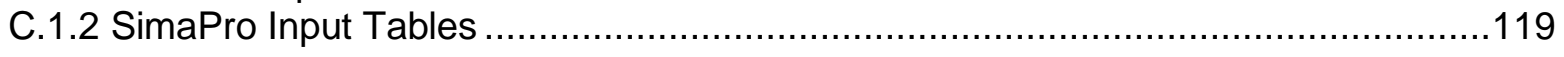

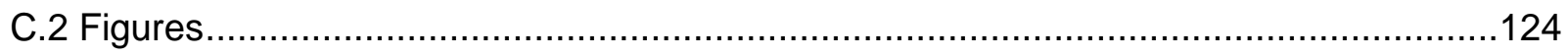




\section{Table of Contents}

C.2.1 SimaPro Networks.

124

C.2.2 Site Photos .

126

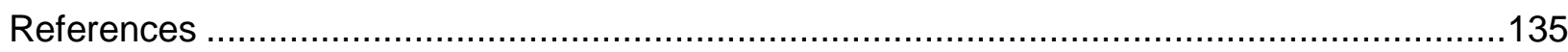




\section{List of Tables}

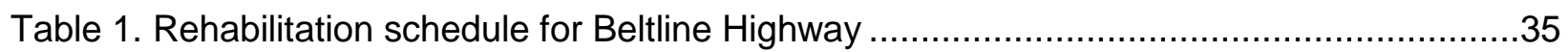

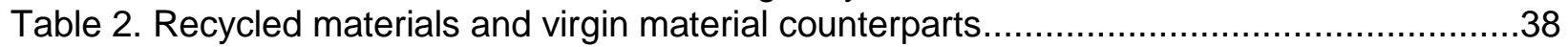

Table 3. Typical unit weights for road consturction materials.............................................38

Table 4. Materials and unit costs for $2.4-\mathrm{km}$ of highway construction ....................................44

Table 5. Summary of initial construction material quantities found from Planned and Constructed

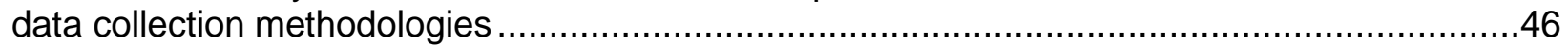

Table 6. PaLATE results of the Planned Beltline material .................................................48

Table 7. PaLATE results of the Constructed Beltline material ............................................48

Table 8. Normalized PaLATE results for the four analyzed designs, including the Recycled and

Virgin designs using both the Planned and Constructed data................................................50

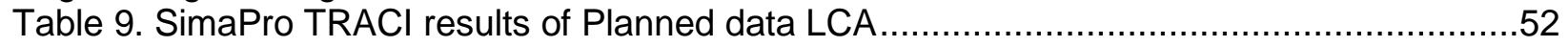

Table 10. SimaPro TRACI results of Constructed data LCA ...........................................52

Table 11. Normalized SimaPro results for the four analyzed designs, including the .................54

Table 12. Comparison of Constructed data results for PaLATE and SimaPro .........................56

Table 13. Summary of cost savings from Planned and Constructed data sets ........................57

Table A1. Mainline materials by layers with dimensions and sources...................................76

Table A2. Ramp materials by layers with dimensions and sources ....................................76

Table A3. STH 142 materials by layers with dimensions and sources ..................................77

Table A4. Embankment materials with approximate proportions and sources .......................77

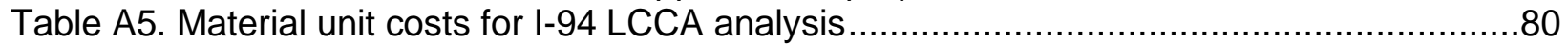

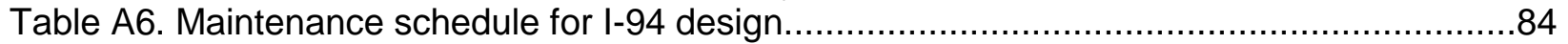

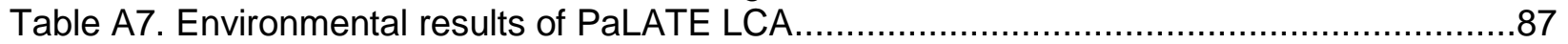

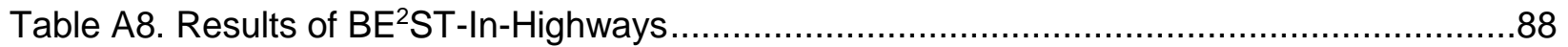

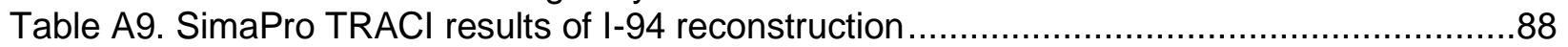

Table A10. Comparison of PaLATE and SimaPro results............................................... 89

Table A11. Summary of life cycle cost savings ....................................................... 90

Table B1. List of treatments with their corresponding type and thickness..........................100

Table B2. Estimated service lives for treatment options based on pavement condition ...........101

Table B3. Dimensions and frequencies used to calculate the volume of localized treatments in

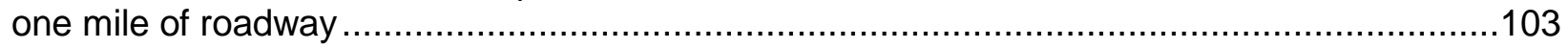

Table B4. Total environmental results for each treatment - non-annualized .........................105

Table B5. Rank of treatment options based on all four impact categories ...........................107

Table B6. Annualized environmental results per treatment per pavement initial condition for the

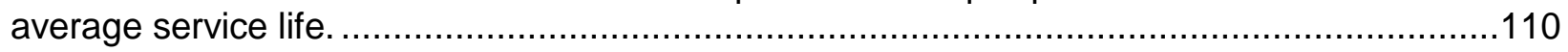

Table C1. I-94 Analysis: PaLATE inputs for Recycled design.............................................112

Table C2. I-94 Analysis: PaLATE inputs for Virgin design .............................................112

Table C3. Beltline Analysis: PaLATE inputs for Planned data Recycled Design.....................113

Table C4. Beltline Analysis: PaLATE inputs for Planned data Virgin design ..........................114

Table C5. Beltline Analysis: PaLATE inputs for Constructed data Recycled design ................115

Table C6. Beltline Analysis: PaLATE inputs for Constructed data Virgin design .....................117

Table C7. Beltline Analysis: SimaPro inputs for Planned data Recycled design ....................119

Table C8. Beltline Analysis: SimaPro inputs for Planned data Virgin design .........................120

Table C9. Beltline Analysis: SimaPro inputs for Constructed data Recycled design ................121

Table C10. Beltline Analysis: SimaPro inputs for Constructed data Virgin design ...................122

Table C11. I-94 Analysis: SimaPro inputs for Recycled design ...........................................123

Table C12. I-94 Analysis: SimaPro inputs for Virgin design..............................................123 


\section{List of Figures}

Figure 1. Beltline project location 31

Figure 2. Schematic of existing pavement structure, not to scale (Strand Associates, 2014).....32

Figure 3. Schematic of reconstruction pavement structure (Strand Associates, 2014) .............33

Figure 4. Percent reduction of the Planned and Constructed Beltline material by using recycled versus virgin material; from PaLATE analyses ....

Figure 5. Graphical representation of normalized PaLATE results across all impact categories for four design scenarios. .50

Figure 6. Percent reduction of the collected and estimated Beltline material by using recycled versus virgin material; from SimaPro analyses .................................................................53 Figure 7. Graphical representation of normalized SimaPro results across all impact categories for four design scenarios.... .55

Figure 8. Results of sensitivity analysis for change in energy consumption impacts when certain inputs (base, surface, and binder material quantities) are doubled (2x)..... .63

Figure 8. Percent reductions from PaLATE and SimaPro analyses of Planned and Constructed data sets .64 Figure 9. Absolute impacts from PaLATE $(\mathrm{Pa})$ and SimaPro (S) analyses of Recycled (R) and Virgin (V) designs from Planned (PI) and Constructed (C) data sets. In the legend, the labels should be read as the initials for: LCA tool (Pa vs. S), Data set (PI vs. C), Design (R vs. V).....65

Figure A1. $1.6 \mathrm{~km}$ (1 mi) I-94 reconstruction location in Kenosha County. The red star on the state of Wisconsin (upper left) shows the location within the state.............................................73 Figure A2. Schematic of existing pavement structure, not to scale (N. Schlegal and Brad B. Blum, personal communication, August-January 2013-2014)....................................................74 Figure A3. Environmental impact reductions due to the use of recycled materials from PaLATE analysis. .92

Figure A4. Visualization of improvements in environmental impact and recycling from BE ${ }^{2}$ ST-In-

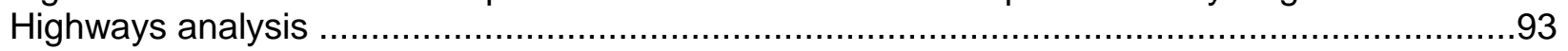

Figure B1. Environmental outputs compared to a base case, chip seal..............................106 Figure B2. Radar Plot of each treatment results per environmental output.........................108

Figure C1. Beltline Analysis: SimaPro network of energy flows for Planned data Recycled design

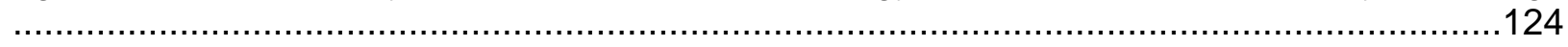
Figure C2. Beltline Analysis: SimaPro network of energy flows for Planned data Virgin design

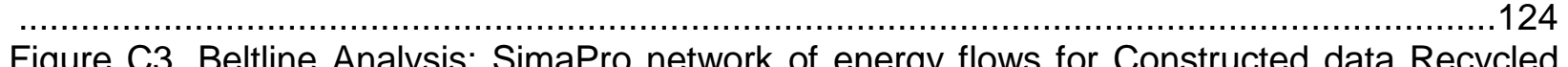
design..... 125 Figure C4. Beltline Analysis: SimaPro network of energy flows for Constructed data Recycled design ...... 125

Figure C5. Demolished concrete pavement stockpiled onsite (June 2013) ..........................126 Figure C6. Photo of on-going concrete crushing for RCA; RCA stockpiled onsite (June 2013)127 Figure C7. We Energies fly ash used in concrete mix; We Energies dug fly ash out from landfill nearby their coal power plant for use on the roadway (June 2013) ......................................128 Figure C8. Bottom ash stockpiled at We Energies coal power plant (June 2013) .................129 Figure C9. Base aggregate below concrete surface one-lane in width, consist of onsite RCA and RAP, imported RCA, and virgin aggregate (September 2015).... .130 Figure $\mathrm{C} 10$. Onsite recycled pavement stockpiles; rebar is removed from existing pavement and discarded (September 2015). 
Figure C11. Construction of base course on one of project's bridges; aggregate is stockpiled in the background (September 2015).

Figure C12. Recycled aggregate stockpiled onsite; space for stockpiling was sparse in urban environment and some piles were placed on bridge/ramp expansions (September 2015) ......133 Figure C13. Aerial photo of eastbound Beltline reconstruction; base course is being placed (April 2015) 


\section{List of Acronyms}

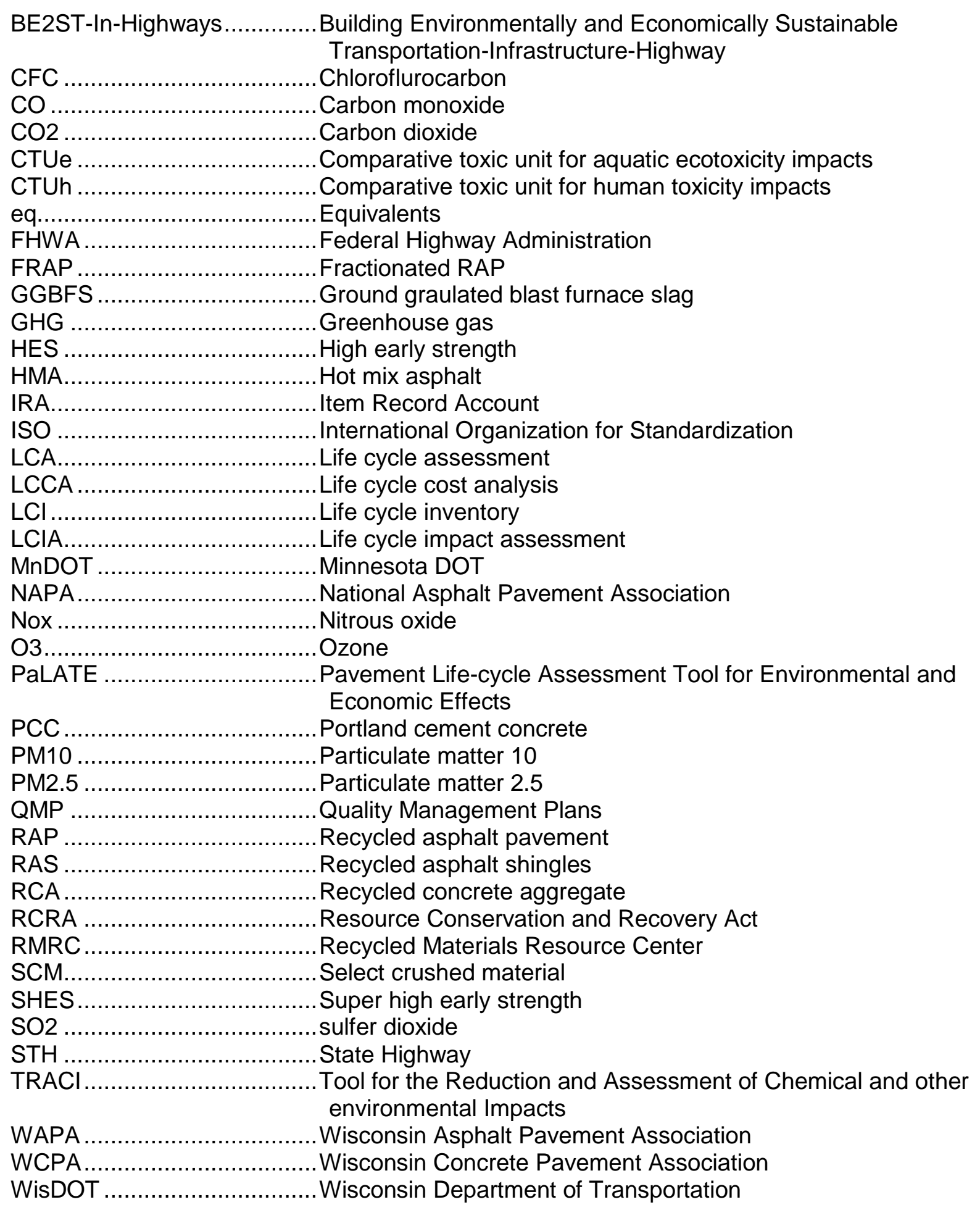




\section{Chapter 1: Introduction}

The construction of sustainable roads, or roads constructed with optimal use of resources and negligible environmental damage (Gambatese \& Rajendran, 2005), has become an increasingly popular topic because of the impacts on global climate change and rising costs of conventional virgin, or non-recycled, road materials (AASHTO, 2008). As of 2002, buildings and infrastructure utilized $40 \%$ of all materials extracted in the U.S. (Kibert, 2002), and in 2009, the construction industry emitted approximately $6 \%$ of total U.S. industry-related greenhouse gasses (GHGs) (Lee et al., 2013; Truitt, 2009). Additionally, the transportation sector contributes $26 \%$ of total U.S. GHG emissions (U.S. EPA, 2015b), and the GHG emissions associated with building roads can account for $10-20 \%$ of the emissions associated with lifetime usage of the road (Chester \& Horvath, 2009; Noland \& Hanson, 2015). To be sustainable, environmental impacts of highways must be reduced through planning, design, and construction processes that reduce the use of virgin materials, often by the substitution of recycled materials (Gambatese \& Rajendran, 2005). Production of materials commonly used in road construction, such as crushed rock aggregate or cement, consume significant energy, generate GHG emissions, are increasingly limited in supply, and often incur high transportation costs (AASHTO, 2008; Lee et al., 2010). After demolition, previously used concrete or asphalt pavement is either recycled or sent to a landfill, usually at a cost, and remains unused (Edil, 2013; FHWA, 2008; Guthrie et al., 2007). Sustainable road construction incorporates as much existing material on site as possible to reduce the cost of virgin aggregate use and landfilling of discarded materials. Additionally, recycled by-products such as fly ash, bottom ash, and slag are proven useful alternatives to using virgin materials. This study seeks to quantitatively and accurately determine the environmental and economic benefits of using recycled material through the reconstruction of a Wisconsin roadway project, thereby further demonstrating the viability of life cycle analyses in evaluating the advantages of sustainable road construction. 


\subsection{Problem Statement}

There is interest in determining and validating the environmental and economic benefits of incorporating recycled materials into road construction using life cycle assessments (LCA) and life cycle cost analysis (LCCA) tools. However, the process of collecting the necessary data for LCAs and LCCAs from departments of transportations (DOTs) and road construction contractors is not well defined. In previous case studies, life cycle data was estimated from planned design and average mix specifications gathered after the road construction was completed (Bloom et al., 2016; In press). Post-construction data led to issues such as over-generalization of mix designs and sourcing and lack of real-time data collection. For this study of a typical urban highway in Wisconsin, the Recycled Materials Resource Center (RMRC) was able to work with the Wisconsin Department of Transportation (WisDOT) and local contractors to explicitly track and quantify the material used in construction, identify material sources, and determine transportation distances. This project provided a study of real-time data collection to compare with the results of postconstruction estimated LCA data. The goal of this comparison is to determine a data collection precedent for environmental analyses of future transportation projects. Additionally, two prominent LCA tools were used in conducting the assessment and the results were compared to validate the predicted impacts.

\subsection{Overview of Thesis}

The primary body of this thesis focuses on a specific, project-based LCA and LCCA of the reconstruction of a typical Wisconsin highway that incorporated recycled materials. This case study was used to answer the research questions regarding data collection methodologies and the use of multiple LCA tools for impact validation. In Chapter 2, a general background on road construction practices, typical recycled material use in roads, and life cycle analyses is provided. Chapter 2 is intended to provide the reader with sufficient knowledge of the topics used in highway 
reconstruction analyses. Details on the reconstruction, data collection methodologies, and LCA tools are discussed in Chapter 3. In this thesis, the specific reconstruction serves as an analysis tool to answer more general questions on assessing recycled materials in road construction. The project provided a practical opportunity to study the two methods of data collection as well as the LCA tools. Results of the analysis are provided in Chapter 4 , and Chapter 5 consists of a more in depth discussion of the results as they relate to the research questions. Finally, concluding remarks and recommendations are included in Chapter 6.

Two minor reports are included in Appendices A and B. Appendix A discusses a case study conducted prior to the study included in the main thesis. For the Appendix A study, data was collected post-construction from designs and plans, i.e. data was not explicitly tracked. The assumptions and concerns generated by this first case study prompted the research question on data collection methodology posed by the main thesis. Appendix B includes a report on the development of an environmental impact tool used to assess the sustainable management of pavements in poor condition. For this impact tool, different rehabilitation and management methods are analyzed for economic and environmental costs. The environmental impact of each management strategy was calculated using LCAs, and the results were incorporated in an more in depth evaluation tool. This paper demonstrates an application of road-related LCAs that differs from the two case studies.

WisDOT and the Minnesota Department of Transportation (MnDOT) commissioned the case studies and environmental impact tool, respectively. Both Wisconsin and Minnesota are member-states of the RMRC, and as such dictate the topics of the RMRC's projects. Both states expressed interest in the quantitative assessment of the environmental and economic benefits of recycled material use in road construction. The research questions presented in this thesis were generated while conducting the quantitative assessments for RMRC member-states. Answers to the research questions ideally will benefit and enhance future material tracking efforts, LCAs, and LCCAs conducted by and for state DOTs. 


\section{Chapter 2: Background}

\subsection{Overview of Road Construction}

This thesis analyzes the reconstruction of a concrete highway in the state of Wisconsin. WisDOT favors rigid pavement for their highways due to harsh winter weather conditions and significant temperature variations throughout the year (Johanneck \& Khazanovich, 2010; WisDOT, 2016b). Rigid roads are paved with concrete as opposed to flexible, asphalt pavements. The properties of asphalt binder vary significantly with changes in temperature (Pavement Interactive Consortium, 2008). Since asphalt pavement deformation is closely related to its binder performance, asphalt is susceptible to rutting and bleeding when the binder is subject to extreme temperature change. Asphalt pavement performance can be compromised in cold weather as flexibility is lost and cracking increases (Flexible Pavements of Ohio, 2015).

The typical structure for rigid pavement includes a layer of concrete over base aggregate over subgrade (Y. H. Huang, 2003). In rigid pavements, the surface concrete assumes the bulk of the traffic load. Concrete is formed by blending cementitious material with water to create a paste that binds well-graded aggregates (Portland Cement Association, 2015). Traditionally, Portland cement is used to bind the aggregate material, thus rigid pavement is referred to as Portland cement concrete (PCC). However, cement can be expensive both economically and environmentally. Cement's raw materials are quarried, crushed to a very fine grade, and heated in a cement kiln to approximately $1,480^{\circ} \mathrm{C}\left(2,700{ }^{\circ} \mathrm{F}\right)$. This process requires a large amount of energy, usually supplied by fossil fuels, and has significant GHG emissions. A generally less expensive, environmentally friendly alternative is the substitution of industrial by-products (T. B. Edil, 2013). One of the most common cementitious by-products is coal fly ash from coal-fired electric utility generation (RMRC, 2010b). State DOTs regulate the percentage of Portland cement-fly ash replacement to maintain road performance. 
Base layers are usually divided into two sections: base and subbase (Huang, 2003). The base course is comprised of higher quality, more strictly specified aggregate as compared to the subbase course. As such, the subbase material, often referred to as select crushed material (SCM), is less expensive than base course. Cost is often lowered by using a thin, high-quality base layer over a thicker, lower-quality subbase. Virgin base aggregated is typically quarried sand and stone. However, to avoid landfilling and reduce costs, recycled pavements can be substituted for virgin aggregate (Edil, 2013; Edil et al., 2012). Often this pavement is recycled onsite from existing roadway material including recycled asphalt pavement (RAP) and recycled concrete aggregate $(R C A)$. WisDOT specifications do not limit the replacement of virgin aggregate with recycled pavement materials in bases (WisDOT, 2016c). As long as the RAP or RCA meets strength and gradation parameters for either base or subbase, as much material can be used as available. However, availability can be limited by the quantity of material in the existing roadway. In some cases, the existing soil and natural material has sufficient strength properties to serve as the base course (Huang, 2003). However, because surface sediments in Wisconsin are generally weak clays and sands left from past glaciations, the subgrade provides little support (Edil et al., 2002).

In the highways presented in this thesis, an asphalt base layer was included in the design. Although not common, asphaltic bases below concrete are advantageous because they provide a waterproof barrier to prevent water infiltration in the bases as well as additional support (Pavement Interactive Consortium, 2009). Asphalt pavement, or hot mix asphalt (HMA), is comprised of aggregates bound together with asphalt binder. In addition to the economic and environmental cost of quarrying the virgin aggregate, extracting and processing the bituminous material to produce binder is also an intensive process. To reduce the cost and environmental impacts, RAP or recycled asphalt shingles (RAS) can be used in HMA. RAP and RAS consist of high-quality, well-graded aggregated coated by asphalt cement (RMRC, 2010). They are substituted for virgin aggregate, and their asphalt content can be extracted to replace virgin 
binder.

DOTs generally seek to minimize roadway costs, therefore cost savings analyses are included in this thesis. Costs for road materials can vary significantly from project to project. Statewide average prices supplied by WisDOT and other Wisconsin agencies were used to estimate the project costs. Many average prices can be found in WisDOT's average unit price list, including virgin aggregate, salvaged asphaltic pavement, and SCM (WisDOT, 2015). The Wisconsin Concrete Pavement Association (WCAP) provided quotes average prices of cement, fly ash, and RCA (K. McMullen, personal communication, November 2015). The Wisconsin Asphalt Pavement Association (WAPA) provided quotes for average prices of HMA mix with and without RAP replacement (B. Stran, personal communication, November 2015). The National Asphalt Pavement Association (NAPA) recommended the cost estimates for RAS (K. Hansen, personal communication, November 2015). This cost data collection for each case study is discussed in more detail later in the thesis.

\subsection{Recycled Material in Road Construction}

A variety of recycled materials were used for the construction projects assessed in this thesis. Some of the materials are more traditionally used in practice, such as RAP and fly ash, while others are more unique to the specific reconstructions. The following sections discuss the pertinent recycled materials and industrial by-products in detail.

\subsubsection{Coal Fly Ash}

Fly ash is a fine-grained, powdery, particulate material produced from burning pulverized coal in a coal-fired boiler at electrical generation plants (RMRC, 2010). Fly ash for road applications is classified as either Class F or Class C (Chesner et al., 1998). Class F fly ash is produced from burning anthracite or bituminous coal. Class C fly ash is produced from burning lignite or subbituminous coal. Both classes are pozzolanic, meaning that when finely divided and 
in the presence of water, the fly ash will combine with calcium hydroxide to form cementitious compounds (ACAA, 2003). However, Class $C$ fly ash has self-cementing properties (i.e. ability to harden and gain strength in the presence of water alone) that make Class $\mathrm{C}$ a more valuable and common fly ash in road concretes.

According to the American Coal Ash Association (ACAA), fly ash has been used in road and highway construction projects since the early 1950s (ACAA, 2003). Fly ash is often used for cement replacement in concrete and less commonly as fill stabilization in base material (Edil, 2013). In 2014, approximately 11.9 million metric tons (13.1 million tons) of fly ash were use in concrete production (ACAA, 2015). Benefits of fly ash in PCC unrelated to environment or economics include higher ultimate strength, improved workability, reduced bleeding, reduced permeability, and more. However, disadvantages of fly ash substitution may include possible reduction in durability and reduced early strength (ACAA, 2003). In base courses, fly ash and lime can be combined with aggregate to improve the quality of the road layer. Although not as common a practice, studies have suggested many benefits of fly ash-improved base courses, including increased strength and extended service life of the roadway (ACAA, 2015; Lee et al., 2010; Wen et al., 2011). In this study, fly ash was used in most cement mixes but was not used in any base course applications.

\subsubsection{Blast Furnace Slag}

During iron production, iron ore, iron scrap, and fluxes (limestone and/or dolomite) are charged into a blast furnace where iron ore is reduced to a molten iron product (Chesner et al., 1998). Blast furnace slag is a nonmetallic coproduct of this process primarily consisting of silicates, alumnosilicates, and calcium-alumina-silicates. If the molten slag is rapidly cooled and solidified such that no crystallization occurs, it is referred to as granulated blast furnace slag. More specifically, when crushed to very fine particles, ground granulated blast furnace slag (GGBFS) has cementitious properties. When crushed to cement fineness, GGBFS can be used as a 
supplementary cementitious material in PCC (FHWA, 2016). GGBFS substitution produced concrete with properties alike to concrete with conventional cement. However, issues have occurred with loss of durability in PCC mixes with over $25 \%$ slag replacement. A small amount of slag was used in a few PCC mix designs in the main case study of this thesis.

\subsubsection{RAP}

Over $90 \%$ of U.S. highways and roads are paved with HMA (Copeland, 2011). To meet the demands of this highway system, HMA producers often use RAP, also known as reclaimed asphalt pavement, in their HMA mix designs. RAP is generated when asphalt pavement is either milled at the surface or removed at full-depth with crushing and screening (Chesner et al., 1998). After removal and processing, RAP contains valuable aggregates coated by asphalt binder. The material can be used as an aggregate substitute material in HMA mixes, as well as additional asphaltic binder (Copeland, 2011). Typically, about 5\% of RAP will contribute to binder replacement in an HMA mix. In Wisconsin, an average HMA mix design will contain about 16\% RAP (B. Stran, WAPA, personal communication, November 2015). Although there are many benefits of RAP in HMA, WisDOT limits RAP replacement to $40 \%$ to maintain pavement performance (WisDOT, 2016d). Procedures for selecting the appropriate quantity of RAP for a mix design are specified by ASTM standards as well as DOT specifications. In this study, RAP is included in all HMA mix designs at various percentages. RAP is added to HMA mixtures by the producers from supplies at the plant, i.e. the existing pavement at the case study site is not recycled into the HMA pavement. Rather, RAP gathered from other road rehabilitation projects and brought to the HMA producer is used in the mixes.

In addition to HMA pavement, RAP can also be used as a granular base or subbase material (Chesner et al., 1998). After the road is milled, rather than transporting the RAP to an HMA producer, RAP is graded for use in base course. RAP can be stockpiled offsite, but is frequently reused immediate after processing at the site (Edil et al., 2012; FHWA, 2008; Guthrie 
et al., 2007). RAP gradation is similar to crushed natural aggregate, but often with a higher content of fines. Properly processed RAP has demonstrated satisfactory behavior as granular road base for many years, and if the material properties meet WisDOT specifications, there is no limit to the amount of RAP substitution for conventional base aggregate (WisDOT, 2016c). For this study, RAP was recovered from the existing roadway recycled onsite into the base course.

\subsubsection{RAS}

RAS, also known as roofing shingle scrap, can be incorporated into HMA pavement mixtures. Roofing shingles are produced by interweaving fibers with a hot saturant asphalt, coating with more asphalt, and surfacing with mineral granules (Chesner et al., 1998). After removal from rooftops, the shingle scrap is typically shredded into pieces and screened to a specific gradation. Similar to RAP, RAS consists of aggregates coated by asphalt cement. However, the asphalt content is usually higher than RAP (approximately $20 \%$ ), thus can be of greater economic value (K. Hansen, NAPA, personal communication, November 2015). RAS is reused in roadways to a far lesser extent than RAP, largely due to a lack of knowledge regarding recycling and re-processing protocol (Warner \& Edil, 2012). However, relatively recent studies have investigated the properties of RAS for the purpose of reuse in road construction (A. Soleimanbeigi \& Edil, 2013; Soleimanbeigi et al., 2013; Warner \& Edil, 2012). In this Wisconsin case study, RAS used in some of the HMA mix designs.

\subsubsection{RCA}

RCA, also known as reclaimed concrete material, consists of high-quality, well-graded aggregates bonded by hardened cementitious paste (Chesner et al., 1998). RCA is generated from the demolition of PCC in not only roads, but other concrete structures. After demolition and excavation, the RCA is typically either hauled to a stockpiling facility (i.e., aggregate supplier), landfilled, or reused on-site. At the stockpiling facility or at the site, the RCA is crushed to the desired gradation and reinforcing steel is removed such that it can serve as high-quality base or 
subbase material (Edil et al., 2012; FHWA, 2008). However, some mesh reinforcements can be difficult or impossible to remove, decreasing the quality of the RCA. Lower-quality RCA can be used as subgrade or fill material. The presence of cementitious paste contribute to a rougher surface texture, lower specific gravity, and higher water absorption than typical aggregates (FHWA, 2008). RCA that has been properly processed and tested per WisDOT specifications can replace conventional virgin aggregate with similar performance expectations (WisDOT, 2016c). In the thesis's main case study, RCA recycled from the existing road was used in the base course onsite. Because the quantity of existing pavement did not meet the requirements of the reconstruction, aggregate suppliers provided additional RCA imported from other projects for the base and subbase courses.

\subsubsection{Coal Bottom Ash}

Coal bottom ash is a course, granular by-product collected from the bottom of coal-fired furnaces used for electricity generation (Chesner et al., 1998). The material is porous with a grain size similar to sand or gravel and is collected from the bottom of the coal combustion chamber. While similar to natural fine aggregate, bottom ash is generally lighter and more brittle (RMRC, 2010), and thus is not traditionally substituted for higher quality base or subbase material. The predominant application for bottom ash is as a light fill material (Rogbeck \& Knutz, 1996). However, bottom ash is less commonly used in road applications as it is not readily available in most locations. Rather than trucking the bottom ash from distant generation facility locations, a more local, cost effective fill source is often used instead. In the case study discussed in Appendix A, a nearby power plant supplied bottom ash to the reconstruction for the purpose of embankment and fill.

\subsubsection{Foundry Sand}

Foundry sand consists of mostly clean, uniformly-sized, high-quality sands bonded to form molds for iron and non-iron castings (Chesner et al., 1998). During the molding process, the sands 
usually pick up components of metals and residual binder material, making them waste material. When recycled, the spent foundry sand requires crushing to reduce or separate oversized materials. Once properly graded, it can be used as a substituted for fine aggregate in paving mixes or as a fine aggregate in fill applications. In the Appendix A case study, foundry sand is used for a small portion of the embankment and fill material.

\subsection{Life Cycle Analyses}

\subsubsection{Life Cycle Assessment}

LCAs were conducted to quantify the environmental benefits gained from using recycled materials in reconstruction. According to the International Organization for Standardization (ISO), LCAs quantify environmental impacts over the lifetime of a product by using a meticulous evaluation methodology (ISO, 2006a). LCA addresses the environmental aspects and potential environmental impacts throughout a product's life cycle from raw material acquisition through production, use, end-of-life treatment, recycling, and final disposal (i.e. cradle-to-grave). The traditional four-step LCA method as described by ISO standards 14040 and 14044 (ISO, 2006a, 2006b) includes:

1) Goal and scope definition, including system boundary and level of detail

2) Life cycle inventory $(\mathrm{LCl})$ analysis, including an inventory of input/output data with regard to the system being studied

3) Life cycle impact assessment (LCIA), with the purpose of providing additional information to assess a product's $\mathrm{LCl}$ results, thus calculating the environmental significance

4) Interpretation, in which the results of an LCI or LCIA are summarized and discussed

According to the Federal Highway Administration (FHWA) (2014), LCAs provide a 
comprehensive approach to evaluating the total environmental burden of a particular product or a more complex system of produces and processes. They examine all inputs and outputs over the service life, from raw material production to end of life. In the case of pavements, LCAs often evaluate the impacts from the materials and processes used to construct the highway, the transportation of those material, and any rehabilitation processes. Rehabilitation and maintenance can be considered the end-of-life practices for roads (FHWA, 2014b). Impacts during the use phase are often not considered, as those impacts are produced by the vehicles on the road rather than the road itself. In this thesis, material production, transportation, and construction processes for both the initial road construction and future rehabilitation processes are within LCA boundaries, while impacts resulting from the use of the roadway are not.

The use of LCA to evaluate road construction impacts is not a novel idea. Researchers from many countries have been studying roads using LCAs for decades. For example a 1996 study at the Technical Research Centre of Finland assed the environmental impact of concrete and asphalt pavement (Hakkinen \& Makela, 1996). They found that the environmental burden of concrete pavement depended mostly on its cement content, while asphalt pavement depended on the bitumen, or binder, content. Similar findings are concluded in this thesis. The research included in this thesis focuses on a specific highway reconstruction project, similar to a study conducted on the Tohoku Expressway construction in Japan (Piantanakulchai et al., 1999). Piantanakulchai et al. agreed that LCA should be applied to study construction projects because of the accumulation of carbon emissions that contribute to global warming over time. Unlike this thesis, Piantanakulchai et al. focuses on calculating the $\mathrm{CO}_{2}$ emissions only. Another case study performed in UK was conducted in 2014, which focused on the impacts not only from the construction materials, but also from delaying traffic during maintenance (Huang et al., 2014).

Other studies used LCAs to evaluate specific material, rather than road construction projects. Mroueh et al. (Mroueh et al., 2001) studied life cycle impacts of industrial by-products and found that the use of by-products decreased the environmental impact of roads compared to 
reference construction materials. An LCI and LCA model was developed specifically for the aggregate industries by researchers at the Imperial College London (Korre \& Durucan, 2009). Similar to Hakkinen \& Makela (1996), another study looked at the energy consumption of pavement materials, both asphalt and concrete (Zapata \& Gambatese, 2005). They also agreed that the majority of energy is consumed during material production, particularly of cement in concrete and asphalt mixing in HMA. One study used an LCA tool in common with the analysis presented in this thesis to specifically evaluate life cycle impacts of pavement rehabilitation options, mainly asphaltic in-place recycling and overlays (Cross et al., 2011). Cross et al. suggests a potential benefit of using LCA models is to assist transportation officials in developing updated transportation policy.

The research and questions posed in this thesis differ from past case studies and LCAs. The focus of the thesis is to compare data collection methodologies for the purpose of LCA and LCCA. To date, the process of collecting the necessary data from DOTs and road construction contractors is not well defined. This thesis seeks to compare two collection methods and recommend a data collection procedure for future projects where LCA impacts are an issue. Additionally, two LCA tools are used to assess and validate the impacts. While it is not uncommon to compare LCA results across tools, there has been few studies specific to recycled materials in road construction that analyze the results across two LCA tools. Overall, the answers to the research questions posed in this thesis should contribute valuable road LCA knowledge for academia as well as the transportation industry.

\subsubsection{Life Cycle Cost Assessments}

LCCA is an analysis technique that builds on traditional economic analysis to evaluate the long-term, life cycle economic efficiency between competing alternatives (FHWA, 1998). Unlike LCAs, there is no independent ISO standard for LCCAs. Instead, guidelines for performing LCCAs of building and constructed assets and their parts are included in the larger standard ISO 15686 
(ISO, 2008). Other guidelines specifically for road LCCAs are provided by the FHWA (FHWA, 1998). The FHWA recommends that LCCAs should be conducted as early in project development as possible, such as in the design stage. In this way, the most economical alternative is chosen for the actual construction. LCCAs are of particular value to DOTs as they can improve the agencies' investment decisions in terms of when and where to reconstruct. One of the major challenges DOTs face today is determining an appropriate rehabilitation schedules that meet the demands of traffic while staying within DOT budget. To make these decisions, WisDOT uses WisPave, a pavement design and LCCA software program for pavement selection (WisDOT, 2014a).

A simple cost savings analysis is used to conduct the LCCAs included in this thesis. The analysis focuses on agency costs, such as the cost of materials and processes, rather than user costs, i.e. the cost to those who would have used the highway during construction (FHWA, 1998). Construction quantities and costs are directly related to the initial design and subsequent rehabilitation strategy. However, it should be noted that significant assumptions must be made to include rehabilitation costs. According to WisDOT personnel, the variability in material availability, use specifications, and costs are too great to allow for an accurate prediction of cost savings from future rehabilitation. While maintenance savings are presented in this report, they initial construction cost savings likely reflect a more accurate analysis than those estimated for future road maintenance procedures. 


\section{Chapter 3: Methods and Analysis Tools}

\subsection{Beltline Reconstruction Case Study}

To answer the research questions posed in this thesis, a typical Wisconsin highway reconstruction project was studied. The use of recycled materials in the reconstruction and expansion of a 2.4-km (1.5-mi) stretch of the eastbound Beltline Highway (US 12/14 west of the Verona Rd. interchange, US 12/14/18/151 east of the Verona Rd. interchange) from Whitney Way to Seminole Highway in Madison, Wisconsin (Figure 1) was quantitatively analyzed. Recycled materials used in this reconstruction include: fly ash, blast furnace slag, RAS, RAP, and RCA. Fly ash and blast furnace slag were used as a partial replacement of Portland cement in the readymix, or PCC. RAP was used in both HMA pavement as well as a base course material. Properly processed RAP consists of high-quality, well-graded aggregates coated by asphalt cement (RMRC, 2010). The aggregated RAP often undergoes a specific gradation process such that it becomes fractionated recycled asphalt pavement (FRAP). In HMA, the asphalt content of RAP can be used as binder, while the aggregate portion can replace virgin aggregates (Reyes-Ortiz et al., 2012). Similarly, RAS was substituted for binder and aggregate material in some HMA mix designs. In the Beltline project, approximately $20 \%$ of RAS and $4 \%$ of RAP contributed to binder replacement. RAP was also used with RCA as base aggregate and fill material. 


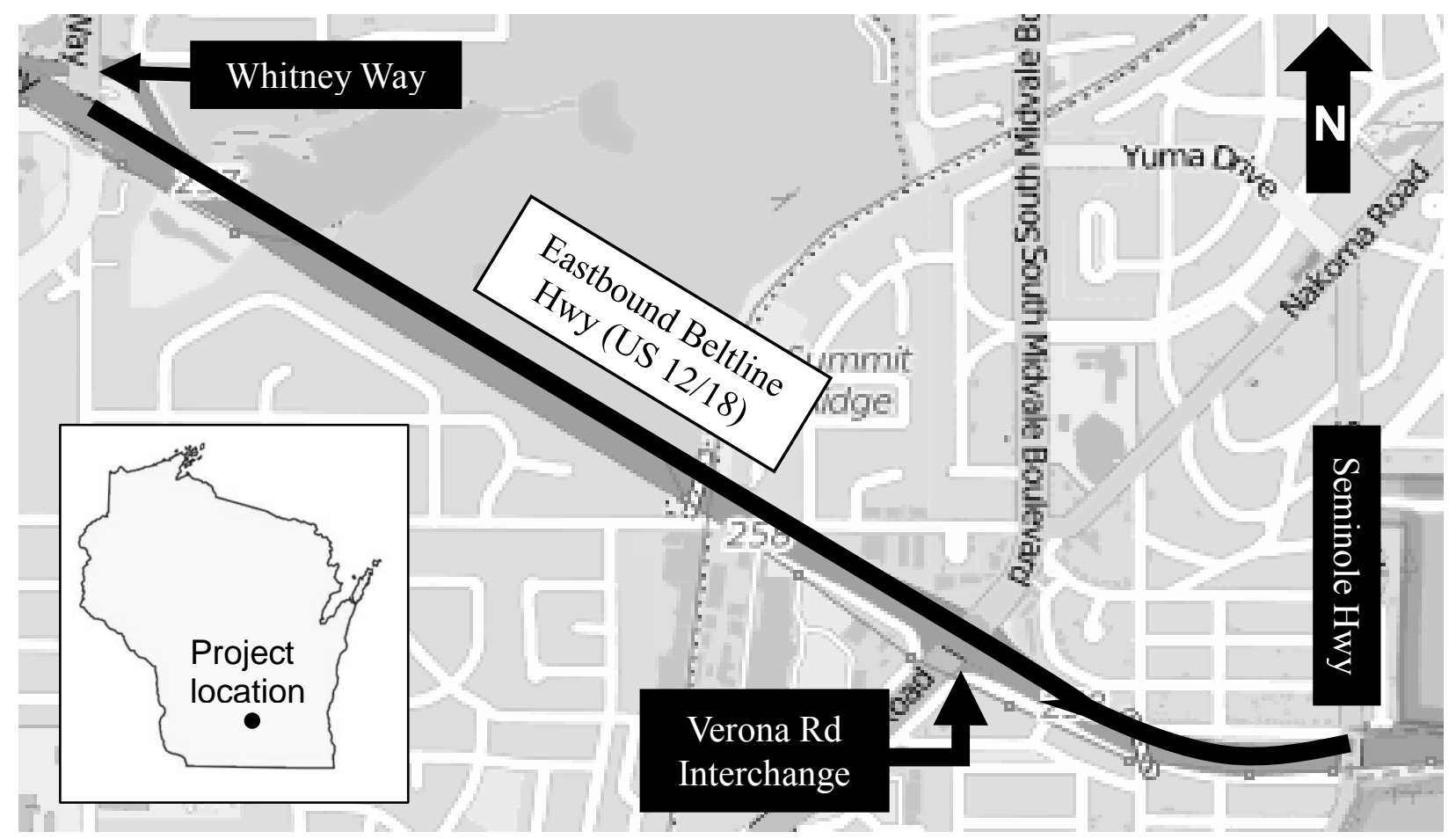

Figure 1. Beltline project location

\subsubsection{Reconstruction Specifications}

The Beltline Highway is a multi-lane, urban, and major arterial highway used by a substantial number of local and regional travelers in the Madison area. Fed by numerous local roads, county roads, and other major routes in southwest Wisconsin, the Beltline is a crucial route for both trucks and passenger vehicles (WisDOT, 2015). Key reasons for the Beltline's expansion are safety and population growth. According to WisDOT, numerous sections of the Beltline have crash rates higher than the state-wide average for similar highways. The population of Dane County is estimated to increase by approximately 150,000 residents by 2035 , with vehicle traffic at the Verona Road interchange increasing to between 52,900 and 68,800 vehicles per day by the year 2030. Increased mobility is vital to the efficiency of Beltline travelers. 
This RMRC analysis focuses on the first part of stage one of this project: eastbound Beltline Highway reconstruction from Whitney Way to Seminole Highway. The reconstruction involves expanding from two to three lanes in each direction, at times with an auxiliary lane (Strand Associates, 2014). The existing pavement was replaced with 28-cm (11-in) PCC pavement, in certain locations over an asphaltic base. Six ramps were updated and four were added. Construction began in spring of 2014 on Verona Road and in fall of 2014 on the Beltline. Construction ended in late 2015 for eastbound lanes and is expected to end in fall 2016 for westbound lanes (WisDOT, 2015).

The typical existing pavement structure varies for the 2.4-km (1.5-mi) stretch of this study, but was generally comprised of the layers shown in Figure 2.

\section{8-15 cm (3-6 in) HMA pavement}

$23 \mathrm{~cm}$ (9 in) reinforced PCC pavement

$8 \mathrm{~cm}$ (3 in) asphaltic stabilized base course (varies)

$15-30 \mathrm{~cm}$ (6-12 in) crushed aggregate base course

Figure 2. Schematic of existing pavement structure, not to scale (Strand Associates, 2014) 
The reconstruction design is generally comprised of the layers shown in Figure 3.

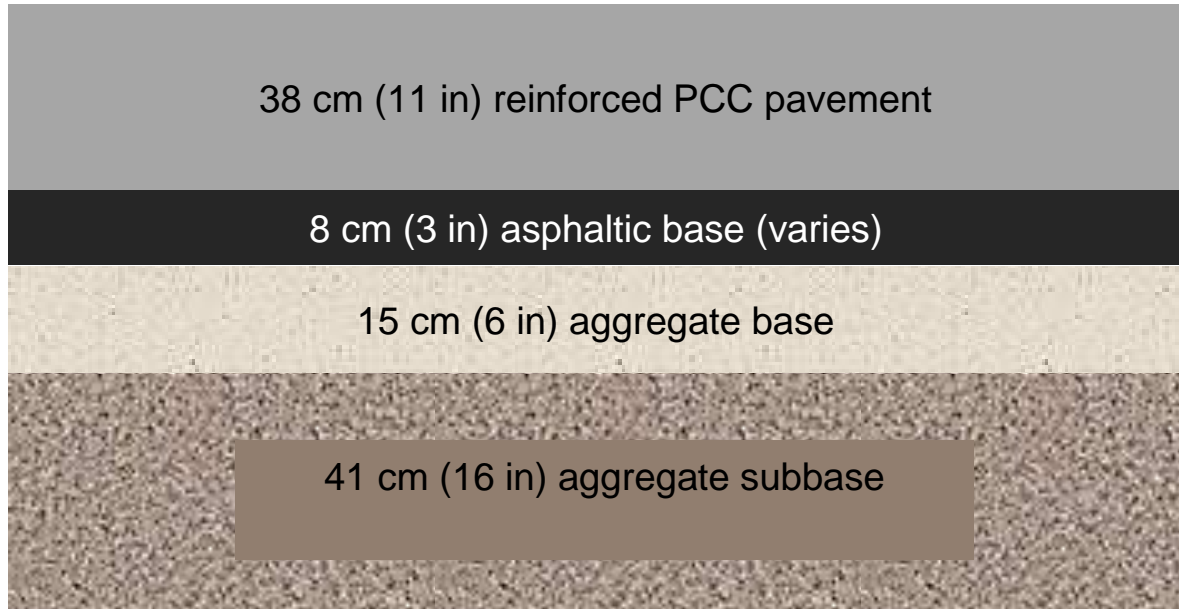

Figure 3. Schematic of reconstruction pavement structure (Strand Associates, 2014)

Time constraints were enacted by the City of Madison so that major construction did not occur during peak travel times. Thus, fast curing concrete mixes, which exclude fly ash, were required in some areas. Mixes omitting fly ash included high early strength (HES) and super high early strength (SHES) concrete. Space constraints were a critical element of the project, decreasing available storage areas flanking the highway for stockpiles of RAP and RCA. Recycled material from the existing road had to be either trucked offsite or immediately placed for embankment/fill or base course. Once removed from the site, the contractor had the option to store, sell, or landfill the material. According to the prime contractor, all RAP and RCA from the existing pavement were recycled onsite directly into the base course or as fill material in the new Beltline Highway.

\subsection{Data Collection}

Two data collection methodologies were employed to gather the necessary inputs for LCA of the reconstruction: 1) material quantities estimated from designs and specifications as planned 
prior to construction (referred as Planned), and 2) material quantities explicitly tracked and collected while construction was on-going (referred as Constructed).

\subsubsection{Collecting Planned Data}

Plans for the Beltline reconstruction project were analyzed to estimate LCA input material quantities. These plans consisted of designs for the highway's mainline, ramps, and concrete bridges and structures. For the mainline and ramp plans, volumes were calculated from crosssectional drawings using the provided length, width, and depth dimensions. For the purpose of this study, only designs for eastbound sections were included in the estimated data. In the highway cross section, thicknesses were provided for layers including concrete pavement, base aggregate, and subbase SCM. An asphaltic base layer was present along certain lengths of the highway. Averages were used to determine some dimensions, as ranges were occasionally provided for lane widths and thicknesses. The volumes in cubic yards were calculated for each layer, then divided into component materials based on average mix designs and estimated ratios. In previous projects, mix designs for concrete and HMA, as well as estimated recycled-to-virgin aggregate ratios in the base and subbase, were provided by WisDOT and the project contractors. Because explicit material use was determined prior to estimating quantities from plans in this study, some recycled material percentages were back calculated based on the known replacement ratios. The average concrete mix designs were based on a weighted average of the various mixes actually used on the project. Because the plans only included an asphaltic base, only the HMA mix design for the asphaltic base was considered. Also included in the design plans were total material volumes for the concrete bridges. Similar to pavement concrete, the weighted average of various structural concrete mixes was applied to determine the components of the concrete bridges.

In previous projects, contractors have provided estimates of the percent RAP and RCA in the base and subbase courses. In this case, ratios of virgin to recycled aggregates were 
calculated based on contractor estimates. In order to assess material production and transportation impacts, the amount of onsite and imported material was required. For this project, all RAP and some RCA in the base was recycled on-site from existing pavements, while some RCA was imported from a near-by aggregate supplier. The ratio of virgin to RAP and RCA in the base course was first calculated from known quantities, then applied to the estimated quantities. Based on the contractor-estimated proportions of base materials, the base course would be $24 \%$ RAP and $24 \%$ RCA recycled onsite, $41 \%$ imported $\mathrm{RCA}$, and $11 \%$ imported virgin aggregate. In the subbase, $66 \%$ of aggregates would be imported RCA and $34 \%$ virgin SCM. The on-site pavement was not allowed to be recycled into the subbase material, but was instead used in fill and embankment

To perform a full life cycle analysis, materials for future rehabilitation and maintenance were required. WisDOT provided a maintenance schedule over the 50-year lifetime of the road, including material quantities for the rehabilitation processes (Table 1). Anticipated maintenance activities, as determined by the WisDOT Pavement Type Selection Report, includes repair and grind in years 25 and 33, and repair and overlay in year 41 (WisDOT, 2015). Minor concrete repair and patches are estimated for each repair and grind rehabilitations. A 10-cm (4-in) HMA overlay would be added in year 41 of the road's service life. The mix designs and sourcing for the maintenance materials are estimated based on initial pavement specifications. All future maintenance costs have been brought to present value.

Table 1. Rehabilitation schedule for Beltline Highway

\begin{tabular}{cccc}
\hline Year & Type of Work & Activity & Service Life \\
\hline 0 & Initial Construction & -- & 25 \\
25 & $1^{\text {st }}$ Rehabilitation & Repair \& Grind & 8 \\
33 & $2^{\text {nd }}$ Rehabilitation & Repair \& Grind & 8 \\
41 & $3^{\text {rd }}$ Rehabilitation & Repair \& Overlay & 15 \\
\hline
\end{tabular}




\subsubsection{Collecting Constructed Data}

WisDOT facilitated much of the collection process while the construction was on-going. The WisDOT project manager helped define the scope of work and provided key assumptions for the project. As research progressed, RMRC researchers contacted contractor and sub-contractor representatives who clarified quantities and procedures. Key, site-specific WisDOT and subcontractor files, including Item Record Account (IRA) spreadsheets, Quality Management Plan (QMP) specifications, concrete and HMA pavement mix designs, site plans, and bid item lists, were accessed for information on materials. Such files aided in tracking materials, specifically material type, volume, tonnage, unit cost, equipment/processes for installation, and transportation distance.

QMP plans kept particularly detailed records of the type and amount of material being used, as well as their sources. WisDOT uses a QMP specification to verify product acceptance based on contractor's quality control testing (WisDOT, 2015). Quality testing must be verified per a certain amount of product used in the road construction. Therefore, QMP plans tracked the quantity of materials, supplier, and date of placement in great detail. Weigh tickets were also critical in data collection because they specified the material, its origin, and its quantity. Weigh tickets were used to track the quantity and supplying quarries for subbase SCM, as SCM was not tracked by WisDOT's QMP reports.

Omitted from weigh tickets were pavements recycled in situ, such as RAP and RCA used as base course or embankment/fill. To account for these un-weighed materials, the site plans were used to calculate the tonnage of RAP and RCA recycled from the existing road. After calculating the volume of the existing asphalt and concrete pavement, density conversions were used to determine the approximate tonnage of RAP and RCA. Some of this material was used as base aggregate and tracked for QMP purposes. However, a portion of the recycled pavement was used as fill material and not explicitly tracked. The quantity designated for embankment/fill was estimated as the difference between the total RAP and RCA, and the RAP and RCA used 
for base course as specified by QMP reports. This estimate was deemed valid because the contractor stated a) in the Beltline construction, almost all RAP and RCA was immediately used for the new highway and b) rebar was the majority of the reinforcement in existing concrete, while significantly smaller amounts of mesh reinforcement were found. Mesh causes concrete separation difficulties, and thus was not recycled in the new highway base.

As the rehabilitation construction will not begin for a number of years, the material information for these processes could not be collected. Therefore, maintenance material data was estimated based upon the anticipated strategies.

\subsubsection{Data Inputs Assumptions}

The assumptions made while performing the LCAs are summarized as follows:

- In calculating the quantity of planned material from design dimensions, rangers were provided for some road widths. In this case the average of the range was used to calculate the volume. Similarly, existing road dimensions from plans were used to calculate the volume of RAP and RCA. Again, average widths were used when rangers were provided in the plans.

- Any maintenance material quantities provided by WisDOT were assumed to be for the entire road. Therefore, these quantities were divided in half to estimate materials for eastbound work alone.

- Supplier locations were obtained via weigh tickets and QMP reports. Transportation distances were determined from the material origin to either the plant locations or the Beltline/Verona Rd. intersection.

- Unless otherwise stated, the assumed transportation vehicles were dump trucks, with the exception of cement trucks for cement/fly ash. Cement was also shipped across Lake Michigan via a barge. 
- Virgin material was substituted ton-for-ton for recycled material. In reality, different dimensions or quantities of virgin material may be required to construct the Virgin design road to meet the structural support requirement. Table 2 includes the recycled materials and their assumed virgin counterparts.

- Some material quantities required conversions from volumes to weights. The unit weights listed in Table 3 were used to perform these calculations. The unit weights were found from the PaLATE LCA software (see Section 3.3.1), and the explicit sources for each unit weight are listed within the software.

Table 2. Recycled materials and virgin material counterparts

\begin{tabular}{cc}
\hline Recycled Material & Virgin Material Counterpart \\
\hline RAP in base course or embankment/fill & Crushed aggregate \\
RCA in base course or embankment/fill & Crushed aggregate \\
Fly Ash & Portland cement \\
Blast Furnace Slag & Portland cement \\
RAP in HMA (binder) & Asphalt cement \\
FRAP in HMA (aggregate) & Virgin aggregate in HMA \\
RAS in HMA (binder) & Asphalt cement \\
RAS in HMA (aggregate) & Virgin aggregate in HMA \\
\hline
\end{tabular}

Table 3. Typical unit weights for road construction materials

\begin{tabular}{cc}
\hline Material & Unit weight (ton/CY) \\
\hline Asphalt mix (HMA) & 1.23 \\
Ready-mix concrete (PCC) & 2.03 \\
Virgin aggregate & 2.23 \\
Bitumen & 0.84 \\
Cement & 1.27 \\
RAP/FRAP & 1.85 \\
RAS & 1.12 \\
RCA & 1.88 \\
Coal fly ash & 2.20 \\
Blast furnace slag & 1.72 \\
Water & 0.84 \\
Gravel & 1.35 \\
Sand & 1.25 \\
\hline
\end{tabular}




\subsection{LCA Methods and Tools}

Two prominent tools were used to conduct the LCA with the objective of validating LCA results. Both tools provide individual impact assessment parameters, as well mutual impact categories that could be used for a comparison.

\subsubsection{PaLATE}

The Pavement Life-cycle Assessment Tool for Environmental and Economic Effects (PaLATE) is an open-source LCA and LCCA program commissioned by the RMRC and designed by the Consortium on Green Design and Manufacturing from the University of California, Berkeley (Horvath, 2007). It is an LCA/LCCA tool specifically developed for highway construction and available in the public domain. Users input the initial design, initial construction materials and transportation, maintenance materials and transportation, equipment use, and cost of a road. PaLATE calculates environmental impacts in three stages of the roads construction: material processing, materials transportation, and installation processes/equipment. Environmental outputs include:

- Energy consumption (GJ)

- Water consumption (kg)

- Carbon dioxide $\left(\mathrm{CO}_{2}\right)$ emissions $(\mathrm{Mg})$

- Nitrous oxide $\left(\mathrm{NO}_{\mathrm{x}}\right)$ emissions $(\mathrm{kg})$

- Particulate matter $10\left(\mathrm{PM}_{10}\right)$ emissions $(\mathrm{kg})$

- Sulfur dioxide $\left(\mathrm{SO}_{2}\right)$ emissions $(\mathrm{kg})$

- Carbon monoxide (CO) emissions (kg)

- Mercury (g)

- Lead $(\mathrm{g})$ 
- Resource Conservation and Recovery Act (RCRA) hazardous waste generated $(\mathrm{kg})$

When comparing the LCAs of two or more products, a relative ranking of alternatives can be analyzed as well as the absolute impacts. For this study, the design of the actual roadway that incorporated recycled material (referred to as Recycled) was compared to a hypothetical design comprised of no recycled material (referred to as Virgin). In the Virgin design, recycled material quantities were replaced with equivalent virgin materials, i.e. the Virgin design is $100 \%$ virgin materials. This method demonstrates the savings from the use of recycled material. A Recycled and Virgin design was analyzed for both the Planned and Constructed data (Planned Recycled, Planned Virgin, Constructed Recycled, and Constructed Virgin). The full lists of PaLATE inputs for all designs are included in Appendix C.

One challenge of LCAs is comparing results from different environmental impacts as each impact category differs in units. Normalization was used to compare the impacts of different road designs (i.e. Recycled versus Virgin, Planned versus Constructed) across impact categories (ISO, 2006a; Tsang et al., 2014). Raw LCA scores are normalized per category, per product as:

$$
L C A_{n}^{x}=\frac{L C A_{r a w}^{x}}{L C A_{\max }^{x}}
$$

where $L C A_{n}^{x}$ is the normalized impact per category x per design, $L C A_{\text {raw }}^{x}$ is the raw impact per category $\mathrm{x}$ per product, and $L C A_{\max }^{x}$ is the maximum value across the designs for category $\mathrm{x}$. The results of normalization provide impacts on a scale of 0 to 1 , with 1 being the maximum impact across the designs.

\subsubsection{SimaPro}

SimaPro is one of the leading software programs for LCA studies and is commonly employed worldwide (Herrmann \& Moltesen, 2015; PRe Sustainability, 2016). It is a professional LCA software used to collect, analyze, and monitor the sustainability performance data of products and services. For this study, the PhD license of SimaPro version 8.1.1.16 was used. 
Unlike PaLATE, SimaPro LCAs are not specific to road construction projects. SimaPro procedure includes include: (1) goal and scope definition, (2) inventory analysis, (3) impact assessment, and (4) interpretation. The goal and scope definition is mainly for the benefit of the user. Users can input their project's goal, reason, commissioner, functional unit, reference flows, and more. However, these inputs are not explicitly used in any of the software's calculations.

The inventory analysis includes a compilation, tabulation, and preliminary analysis of all environmental exchanges of the materials and processes of the final product (Rebitzer et al., 2004). Perhaps the most useful aspect of SimaPro is its built-in inventory of many products and processes from a collection of life cycle inventory databases. The inputs (raw material, energy, etc.) and outputs (waste, emissions, etc.) for some common road construction processes such as concrete material production, asphaltic material production, rock crushing, stone quarrying, and transportation are readily available in SimaPro. However, for a few of the recycled materials specific to roads are not included (e.g. RAP and RAS), SimaPro allows user to create new processes for these materials. To simulate the environmental impact for the grinding, milling, and crushing of (F)RAP and RAS material, the impact was found for the hypothetical amount of diesel fuel used in these processes. This is the same assessment methodology used in some other LCAs, namely PaLATE (Horvath, 2007). Concrete recycling was present in SimaPro's inventory and included the impact from concrete demolition. An additional process of crushing was added to the RCA inventory to simulate crushing the demolished concrete into desired aggregate sizes. Also included in SimaPro's inventory was cement with fly ash and slag replacement.

Certain road construction processes were also not included in SimaPro's built-in inventory. These includes processes for paving the road, compacting and placing base course, combining PCC mix materials, and combining HMA mix materials. However, based on previous LCAs conducted by the RMRC, it was concluded that construction processes had a relatively low environmental impact (less than 10\%) as compared to the construction materials production and transportation (Bloom et al., In press). Therefore, the impacts from these processes were ignored 
in the SimaPro analysis. With these parameters, a complete SimaPro inventory of both Planned and Constructed road construction material inputs was created for impact assessment. This inventory is included in Appendix C.

To evaluate the environmental impact of the highway project, a life cycle impact assessment method was chosen. SimaPro's Tool for the Reduction and Assessment of Chemical and other environmental Impacts (TRACl) was selected to analyze the Beltline because it was developed by the U.S. EPA specifically for North America using input parameters consistent with U.S. locations (EarthShift, 2016). For this study, TRACI 1 version 3.02 was used. TRACl's impact categories were researched to construct methodologies for representing potential effects in the U.S. Impact categories in TRACI include:

- Ozone depletion (kg chloroflurocarbon (CFC) ${ }^{-11}$ equivalents (eq))

- Global warming ( $\mathrm{kg} \mathrm{CO}_{2}$ eq)

- Smog (kg ozone $\left(\mathrm{O}_{3}\right)$ eq)

- Acidification ( $\mathrm{kg} \mathrm{SO}_{2}$ eq)

- Eutrophication (kg nitrogen $(\mathrm{N})$ eq)

- Carcinogenics (CTUh $\left.{ }^{1}\right)$

- Non-carcinogenics (CTUh)

- Respiratory effects (kg in particulate matter $2.5\left(\mathrm{PM}_{2.5}\right)$ eq)

- Ecotoxicity $\left(\mathrm{CTUe}^{2}\right)$

- Fossil fuel depletion (MJ surplus)

To validate the LCA results, impacts predicted by PaLATE versus SimaPro were compared. Unfortunately, none of the TRACI impacts can be directly compared to PaLATE's.

\footnotetext{
1 CTUh: comparative toxic unit for human toxicity impacts. The characterization factor for human toxicity impacts has units of disease cases per $\mathrm{kg}$ emissions (USEtox®, 2016).

2 CTUe: comparative toxic unit for aquatic ecotoxicity impacts. The characterization factor for aquatic ecotoxicity impacts has units of the potential affected fraction of species in cubic meter-days per $\mathrm{kg}$ emissions (USEtox®, 2016).
} 
However, additional SimaPro analyses can be conducted for single LCA issues, which includes a broad range of categories such as specific gas emissions, toxicity emissions, environmental footprints, energy demands, and more. There are some single-issue impact categories similar to PaLATE's, including energy, $\mathrm{CO}_{2}, \mathrm{NO}_{x}, \mathrm{SO}_{2}, \mathrm{CO}$, and lead. For the emissions such as $\mathrm{CO}_{2}$, these single issue impacts evaluate the emission of that gas alone, as opposed to $\mathrm{CO}_{2}$ equivalencies such as is provided by the TRACI global warming impact category. The energy impact includes the cumulative energy demand, based on the method published by the LCI Ecoinvent version 2.0 (Moreno Ruez et al, 2014). The other emissions are calculated using selected LCI single issue impact assessment, also based on methods from Ecoinvent 2.0. The selected LCI indicators are the summation of selected substances emitted by the inventories products and processes. Because construction processes were ignored in the SimaPro analysis, they are removed from the PaLATE results when comparing the two LCA tools' impact predictions.

\subsection{LCCA Methods}

The LCCA was conducted using a simple cost-savings based on unit prices for each material or process. Unit prices used in the cost analysis came from a variety of sources. To calculate the savings, the cost for a recycled material was compared to the cost for an equivalent virgin material (e.g. fly ash vs. cement). A summary of the unit costs and their sources are listed in Table 4. The average savings for fly ash substitution for cement is $\$ 30 /$ ton are based on historical Wisconsin averages. The savings for RCA, both from existing pavement onsite and hauled in from offsite, were found by comparing the reduced prices of RCA to WisDOT's average bid item price for base aggregate (WisDOT, 2015). This led to savings of $\$ 4.50 /$ ton and $\$ 1.00 /$ ton for RCA from onsite and offsite, respectively.

The cost for RAP recycled onsite into base aggregate was also found from the WisDOT average bid item price list. The average cost for salvaged asphaltic pavement milling led to 
savings compared to conventional base aggregate of $\$ 4.00 /$ ton. Cost savings for RAP in HMA pavement were provided by WAPA at $\$ 5.72 /$ ton of mix that uses RAP as asphalt cement or aggregate. For the Beltline, RAS was also used as an asphalt supplement in some HMA mixes. According to NAPA, RAS for pavement construction purposes can be acquired for essentially no cost. Therefore, all savings by not using conventional aggregate or asphalt binder are realized. Using the WisDOT average bid item cost for aggregate, as well as recommendations from WisDOT personnel, this equates to saving $\$ 10 /$ ton and $\$ 450 /$ ton of RAS as HMA aggregate and binder, respectively.

Table 4. Materials and unit costs for 2.4-km of highway construction

\begin{tabular}{l|ccc}
\hline Category & Material & Unit Cost & Source \\
\hline \multirow{2}{*}{ Concrete } & Fly Ash & $\$ 75.00$ & WCPA \\
& Cement & $\$ 105.00$ & WCPA \\
\hline \multirow{3}{*}{ Base Aggregate } & RAP onsite & $\$ 6.00$ & WisDOT \\
(including SCM) & RCA onsite & $\$ 5.50$ & WCPA \\
& RCA offsite & $\$ 9.00$ & WCPA \\
& Virgin Base Aggregate & $\$ 10.00$ & WisDOT \\
\hline \multirow{4}{*}{ HMA } & Mix with RAP & $\$ 49.47$ & WAPA \\
& Mix without RAP & $\$ 42.75$ & WAPA \\
& RAS & $\$ 0$ & NAPA \\
& Aggregate & $\$ 10.00$ & WisDOT \\
& Asphalt binder & $\$ 450.00$ & WisDOT \\
\hline
\end{tabular}




\section{Chapter 4: Results}

\subsection{Planned vs. Constructed Material Quantities}

A summary of the resulting Beltline reconstruction material quantities for each Planned and Constructed data collection methodologies are shown in Table 5. The material quantities obtained from the two data collection methods are within one order of magnitude for all categories, demonstrating general agreement regardless of Constructed or Planned data. Generally, the Constructed data predicts slightly greater (1.2x to $2.2 x)$ material use as compared to the Planned data. When explicitly tracking the material during construction, a more thorough collection of all of the materials and constructed features were identified. For example, the designs specified the dimensions of concrete for the road surface. However, the Constructed data also include ancillary concrete quantities, which is any concrete item not explicitly part of the pavement such as curbs, gutters, dividers, and more. These concrete quantities were not included in the design plans.

Similarly, only the HMA used in the asphaltic base pavement was included in the design specifications. More HMA of varying mix designs was used in the actual construction as driveways, temporary pavements, shoulders, and tie-ins to existing pavement on the ends and sides of the construction. It also appears that a lesser amount of base and subbase materials were specified in the designs as were actually purchased. Some of the recycled pavements were used in embankment and fill as well as base courses.

One benefit of using recycled materials is the reduction of virgin resource consumption. WisDOT has specific initiatives to conserve resources, minimize waste, and keep materials out of landfills (WisDOT, 2016a). Of the estimated $62,900 \mathrm{~m}^{3}\left(82,800 \mathrm{yd}^{3}\right)$ of material specified by the design plans, $40 \%$ of the material was recycled. The majority of the recycled volumes were from the use of RCA and RAP in base and subbase, both recycled on site and imported from material suppliers. Of all the recycled material, approximately $20 \%$ of the material was recycled from the 
existing pavement. According to the Constructed quantities, $43 \%$ of the total $87,200 \mathrm{~m}^{3}(114,000$ $\mathrm{yd}^{3}$ ) were recycled, with $41 \%$ of those recycled materials supplied by the existing pavement. These quantities indicate a significant amount of recycled material replacement for the Beltline Highway. Sections 4.2 and 4.3 will discuss how this recycled material replacement affected the project's environmental and economic impacts, respectively.

Table 5. Summary of initial construction material quantities found from Planned and Constructed data collection methodologies

\begin{tabular}{|c|c|c|}
\hline Material & $\begin{array}{l}\text { Planned Volumes } \\
\text { in } \mathrm{m}^{3}\left(\mathrm{yd}^{3}\right)\end{array}$ & $\begin{array}{l}\text { Constructed Volumes } \\
\text { in } \mathrm{m}^{3}\left(\mathrm{yd}^{3}\right)\end{array}$ \\
\hline Cement & $1,880(2,450)$ & $2,380(3,110)$ \\
\hline Fly ash & $715(936)$ & $567(742)$ \\
\hline Slag & 0.00 & $17.2(22.5)$ \\
\hline PCC aggregate & $15,800(20,700)$ & $20,100(26,300)$ \\
\hline PCC mix water & $7,270(3,560)$ & $3,500(4,580)$ \\
\hline Bridge concrete total & $2,900(3,790)$ & $3,040(3,980)$ \\
\hline Pavement concrete total & $18,200(23,900)$ & $23,900(31,200)$ \\
\hline RAP binder & $3.15(4.12)$ & $10.6(13.8)$ \\
\hline RAS binder & $15.4(20.1)$ & $30.7(40.1)$ \\
\hline Asphalt binder & $55.6(72.7)$ & $227(296)$ \\
\hline FRAP & $206(269)$ & $395(516)$ \\
\hline RAS aggregate & $44.1(57.7)$ & $86.9(114)$ \\
\hline HMA aggregate & $1,210(1,590)$ & $1,690(2,220)$ \\
\hline HMA total & $1,550(2,020)$ & $2,440(3,180)$ \\
\hline On-site RAP & $2,510(3,280)$ & $7,630(9,970)$ \\
\hline On-site RCA & $2,480(3,250)$ & $7,550(9,870)$ \\
\hline Imported RCA & $4,230(5,530)$ & $7,100(9,280)$ \\
\hline Imported virgin aggregate & $1,220(1,600)$ & $3,010(3,930)$ \\
\hline SCM subbase & $6,980(9,130)$ & $9,040(11,800)$ \\
\hline RCA subbase & $13,700(17,900)$ & $12,700(16,600)$ \\
\hline
\end{tabular}

\subsection{LCA Results}

\subsubsection{PaLATE Environmental Impacts}

The LCA results for the Beltline reconstruction completed by the end of 2015 as determined by PaLATE are listed in Table 6 and Table 7. Table 6 contains the results using the 
Planned LCA input data, and Table 7 contains the results using the Constructed LCA input data. Results are reported in terms of percent reduction, which equates to the reduction in impact using recycled materials relative to the Virgin design and is calculated by the difference in impact between the Recycled and Virgin divided by the Virgin impact. A graph of Planned versus Constructed percent reduction is shown in Figure 4. Reductions were seen in most PaLATE categories from the use of recycled materials, regardless of data collection methodology. However, most categories predicted greater impact reductions for the Planned data as compared to the Constructed data.

Although the absolute value of the reductions differs, the trends between the Constructed and Planned data are similar. The greatest reductions are seen in $\mathrm{PM}_{10}$ at $21 \%$ (Planned) and 24\% (Constructed). Because more recycled material was used with a smaller transportation distance, less vehicles and equipment were used on and off site, resulting in fewer particulate emissions. WisDOT has focused reducing their impacts of energy, water, and $\mathrm{CO}_{2}$ emissions in particular. The reductions in energy, water, and $\mathrm{CO}_{2}$ emissions for the Planned data are $17 \%$, $15 \%$, and $17 \%$, respectively, and the Constructed data reductions are $13 \%, 12 \%$, and $12 \%$, respectively. These impacts largely stem from resources needed for virgin materials production. Mining and grading virgin aggregate is a more resource intensive process than milling and grinding existing pavement. Similarly, milling asphalt pavement and grinding recycled shingles to use in HMA is a far less intensive process than producing virgin asphalt cement or aggregates for the mix. Because fly ash is a by-product, any energy, water or emissions associated with its production are not included. Compared to the production of concrete, using fly ash allows for significant impact reductions. 
Table 6. PaLATE results of the Planned Beltline material

\begin{tabular}{|c|c|c|c|c|c|c|}
\hline & Energy (GJ) & \multicolumn{2}{|c|}{ Water (kg) } & $\mathrm{CO}_{2}(\mathrm{Mg})$ & $\mathrm{NO}_{\mathrm{x}}(\mathrm{kg})$ & $\mathrm{PM}_{10}(\mathrm{~kg})$ \\
\hline Recycled & 111,000 & \multicolumn{2}{|c|}{32,900} & 7,610 & 76,300 & 27,200 \\
\hline Virgin & 134,000 & \multicolumn{2}{|c|}{38,600} & 9,210 & 80,600 & 34,500 \\
\hline Difference & 23,000 & \multicolumn{2}{|c|}{5,700} & 1,600 & 4,300 & 7,300 \\
\hline \multirow[t]{2}{*}{ Reduction } & $17 \%$ & \multicolumn{2}{|c|}{$15 \%$} & $17 \%$ & $5 \%$ & $21 \%$ \\
\hline & $\mathrm{SO}_{2}(\mathrm{~kg})$ & $\mathrm{CO}(\mathrm{g})$ & $\mathrm{Hg}(\mathrm{g})$ & $\mathrm{Pb}(\mathrm{g})$ & \multicolumn{2}{|c|}{$\begin{array}{c}\text { RCRA Hazardous } \\
\text { Waste Generated (kg) }\end{array}$} \\
\hline Recycled & 316,000 & 30,000 & 129 & 7,200 & \multicolumn{2}{|c|}{624,000} \\
\hline Virgin & 320,000 & 31,200 & 142 & 8,110 & \multicolumn{2}{|c|}{719,000} \\
\hline Difference & 4,000 & 1,200 & 13 & 910 & \multicolumn{2}{|c|}{95,000} \\
\hline Reduction & $1 \%$ & $4 \%$ & $9 \%$ & $11 \%$ & \multicolumn{2}{|c|}{$13 \%$} \\
\hline
\end{tabular}

Table 7. PaLATE results of the Constructed Beltline material

\begin{tabular}{|c|c|c|c|c|c|c|}
\hline & Energy (GJ) & \multicolumn{2}{|c|}{ Water (kg) } & $\mathrm{CO}_{2}(\mathrm{Mg})$ & $\mathrm{NO}_{\mathrm{x}}(\mathrm{kg})$ & $\mathrm{PM}_{10}(\mathrm{~kg})$ \\
\hline Recycled & 141,000 & & 300 & 9,730 & 96,600 & 34,200 \\
\hline Virgin & 162,000 & & 600 & 11,100 & 98,700 & 45,000 \\
\hline Difference & 21,000 & & 300 & 1,370 & 2,100 & 10,800 \\
\hline \multirow[t]{2}{*}{$\%$ Redux } & $13 \%$ & & $2 \%$ & $12 \%$ & $2 \%$ & $24 \%$ \\
\hline & $\mathrm{SO}_{2}(\mathrm{~kg})$ & CO (g) & $\mathrm{Hg}(\mathrm{g})$ & $\mathrm{Pb}(\mathrm{g})$ & \multicolumn{2}{|c|}{$\begin{array}{c}\text { RCRA Hazardous } \\
\text { Waste Generated (kg) }\end{array}$} \\
\hline Recycled & 390,000 & 37,900 & 162 & 9,030 & \multicolumn{2}{|c|}{787,000} \\
\hline Virgin & 394,000 & 38,700 & 171 & 9,830 & \multicolumn{2}{|c|}{858,000} \\
\hline Difference & 4,000 & 800 & 9 & 800 & \multicolumn{2}{|c|}{71,000} \\
\hline Reduction & $1 \%$ & $2 \%$ & $5 \%$ & $8 \%$ & \multicolumn{2}{|c|}{$8 \%$} \\
\hline
\end{tabular}




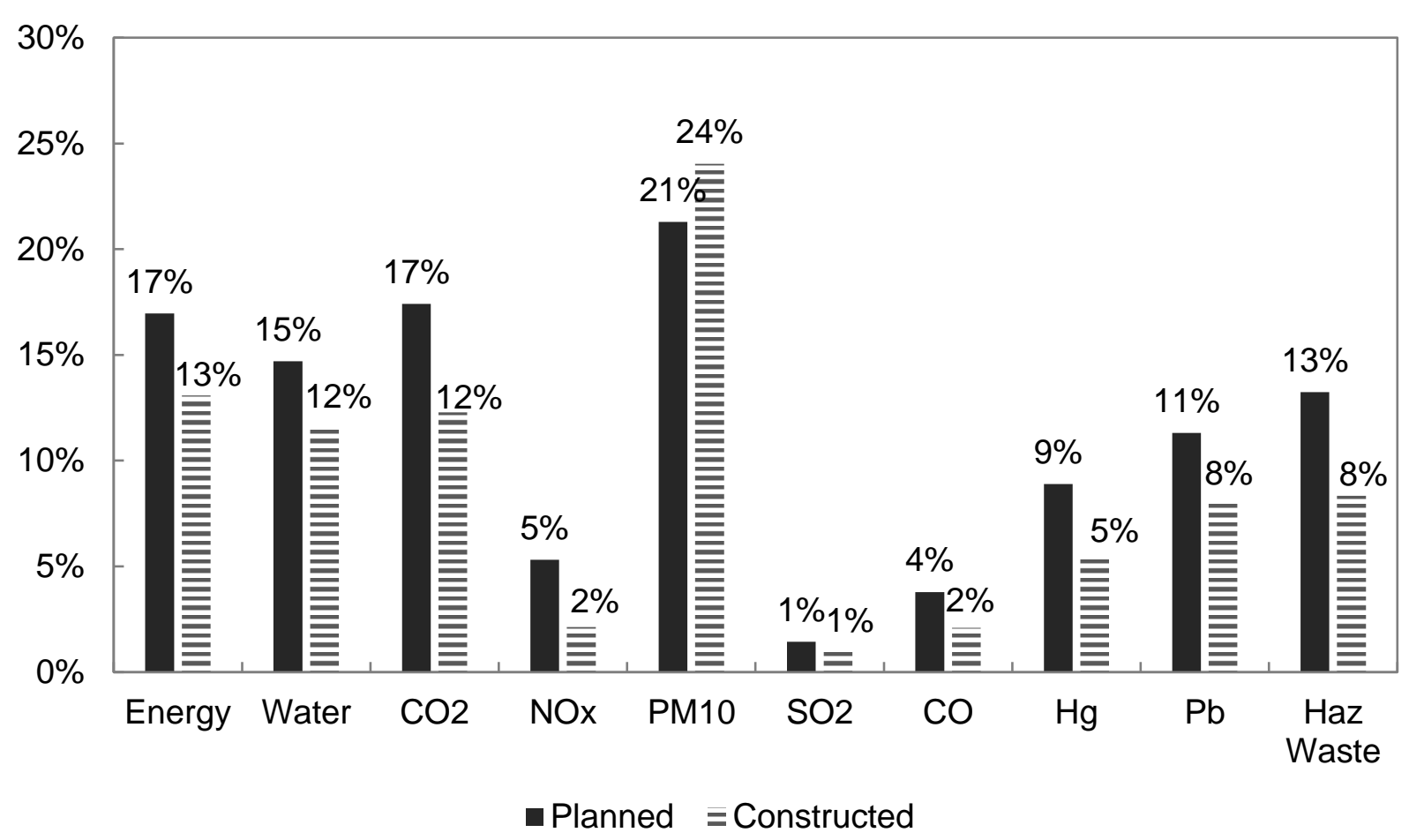

Figure 4. Percent reduction of the Planned and Constructed Beltline material by using recycled versus virgin material; from PaLATE analyses

Four designs were analyzed in PaLATE: (1) Recycled design with Planned data, (2) Virgin design eithPlanned data, (3) Recycled design with Constructed data, and (4) Virgin design with Constructed data. The results of all four designs were also normalized to assist with comparisons of the absolute impact of each design (See Section 3.3). The normalized results are listed in Table 8 and displayed graphically in Figure 5. In Figure 4, the reductions calculated with the Planned data appear greater than the results calculated with the Constructed data. However, the normalized results reveal that the absolute impact predicted using the Planned data is less than the impacts when using the Constructed data. The absolute impact results are most sensitive to the total quantity of material inputs. The material quantity data estimated using design plans and specifications resulted in smaller quantities of materials than those actually used during construction (see Table 5). These discrepancies are further discussed in Section 5.1. 
Table 8. Normalized PaLATE results for the four analyzed designs, including the Recycled and Virgin designs using both the Planned and Constructed data

\begin{tabular}{|c|c|c|c|c|c|c|}
\hline & Energy & \multicolumn{2}{|c|}{ Water } & $\mathrm{CO}_{2}$ & $\mathrm{NO}_{\mathrm{x}}$ & $\mathrm{PM}_{10}$ \\
\hline Planned, Recycled & 0.69 & \multicolumn{2}{|c|}{0.71} & 0.69 & 0.77 & 0.60 \\
\hline Constructed, Recycled & 0.87 & \multicolumn{2}{|c|}{0.88} & 0.88 & 0.98 & 0.76 \\
\hline Planned, Virgin & 0.83 & \multicolumn{2}{|c|}{0.83} & 0.83 & 0.82 & 0.77 \\
\hline Constructed, Virgin & 1.00 & \multicolumn{2}{|c|}{1.00} & 1.00 & 1.00 & 1.00 \\
\hline & $\mathrm{SO}_{2}$ & CO & $\mathrm{Hg}$ & $\mathrm{Pb}$ & \multicolumn{2}{|c|}{$\begin{array}{l}\text { RCRA Hazardous } \\
\text { Waste Generatec }\end{array}$} \\
\hline Planned, Recycled & 0.80 & 0.78 & 0.75 & 0.73 & \multicolumn{2}{|c|}{0.73} \\
\hline Constructed, Recycled & 0.99 & 0.98 & 0.95 & 0.92 & \multicolumn{2}{|c|}{0.92} \\
\hline Planned, Virgin & 0.81 & 0.81 & 0.83 & 0.83 & \multicolumn{2}{|c|}{0.84} \\
\hline Constructed, Virgin & 1.00 & 1.00 & 1.00 & 1.00 & \multicolumn{2}{|c|}{1.00} \\
\hline
\end{tabular}

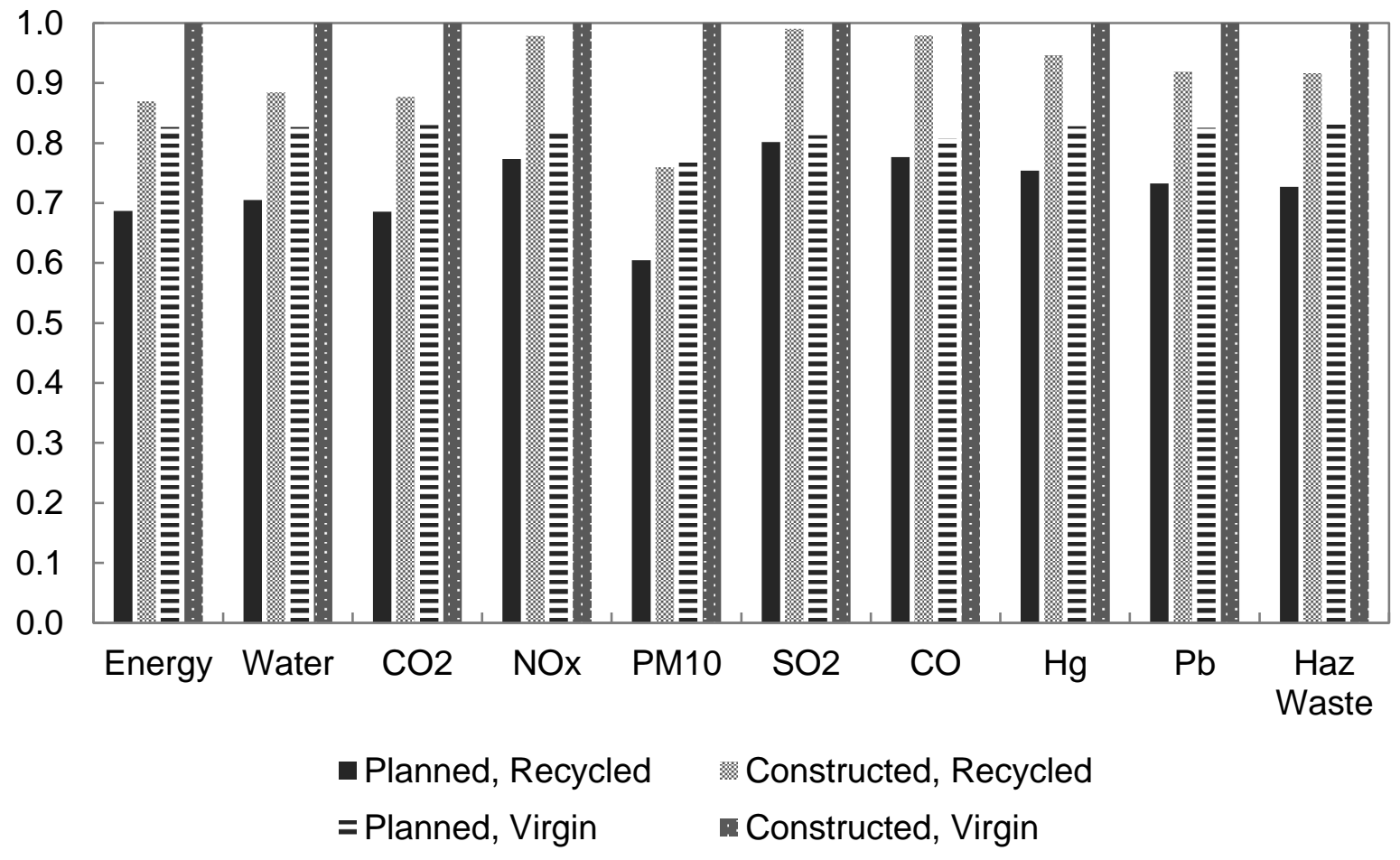

Figure 5. Graphical representation of normalized PaLATE results across all impact categories for four design scenarios 


\subsubsection{SimaPro Environmental Impacts}

The SimaPro TRACI analysis results using the Planned and Constructed data are listed in Table 9 and Table 10, respectively. These results include the impacts from all road material production and transportation, but excludes impacts due to construction processes as discussed in Sec 3.3.2. In general, there are significant reductions in most TRACI impact categories using both data sets. The greatest reductions in the TRACI results are for carcinogens, eutrophication, ecotoxicity, and non-carcinogens, all of which reduce the impacts by about a third compared to the Virgin design.. In the recycled design, impacts in these four categories are dominated by cement production, followed by gravel crushing, and all material transportation. The majority of gravel crushing impacts are from the production of aggregate within the concrete mix, as well as virgin granular base aggregate. In the virgin design, the four impact categories are dominated by gravel crushing, then followed by cement production. While the virgin design uses the same amount of aggregate in the pavement mixes, there is a significant increase in virgin aggregates in the base and subbase. This increase is contributing much of the reductions in carcinogens, eutrophication, ecotoxicity, and non-carcinogens.

Although most categories see reductions, SimaPro does predict an increase in respiratory effects with the Recycled design. The increase is due to a greater prediction of particulate matter from recycling concrete as compared to production equivalent amounts of virgin crushed gravel. In SimaPro, the crushed gravel processes includes an aggregated inventory of manufacturing process (i.e. mining, crushing), internal processes (i.e. transport, etc.) and infrastructure. The SimaPro aggregated inventory for waste concrete gravel recycling includes the energy from and the particulate matter emissions from demolition and handling. According to the Ecoinvent LCI details, both inventories are based on current technology up to 2014 (Moreno Ruiz et al., 2014). Unfortunately, because SimaPro is a commercial LCA tool, not all aspects of the LCIA calculations are visible to the user. While it is apparent from the TRACI results that, based on the Ecoinvent LCls for virgin crushed gravel and concrete recycling, there are greater respiratory effects 
predicted for the recycling process, no further detail is revealed in SimaPro on how the $\mathrm{PM}_{2.5}$ eq quantities for each process are calculated. This lack of transparency is a disadvantage of SimaPro discussed further in Section 5.2.

Table 9. SimaPro TRACI results of Planned data LCA

\begin{tabular}{|c|c|c|c|c|}
\hline Impact Category & Recycled & Virgin & Difference & $\%$ Redux \\
\hline Ozone depletion (kg CFC-11 eq) & 0.809 & 0.901 & 0.092 & $10 \%$ \\
\hline Global warming ( $\mathrm{Mg} \mathrm{CO}_{2}$ eq) & 4,620 & 6,060 & 1,440 & $24 \%$ \\
\hline $\operatorname{Smog}\left(\mathrm{kg} \mathrm{O} \mathrm{O}_{3} \mathrm{eq}\right)$ & 354,000 & 419,000 & 65,000 & $15 \%$ \\
\hline Acidification ( $\left.\mathrm{kg} \mathrm{SO}_{2} \mathrm{eq}\right)$ & 19,500 & 24,800 & 5,300 & $21 \%$ \\
\hline Eutrophication (kg N eq) & 7,590 & 11,500 & 3,910 & $34 \%$ \\
\hline Carcinogenics (CTUh) & 0.106 & 0.162 & 0.056 & $35 \%$ \\
\hline Non carcinogenics (CTUh) & 0.507 & 0.745 & 0.238 & $32 \%$ \\
\hline Respiratory effects (kg $\left.\mathrm{PM}_{2.5} \mathrm{eq}\right)$ & 3,130 & 2,280 & -850 & $-37 \%$ \\
\hline Ecotoxicity $\left(10^{3}\right.$ CTUe $)$ & 12,100 & 18,800 & 6,700 & $36 \%$ \\
\hline Fossil fuel depletion (GJ surplus) & 8,520 & 9,620 & 1,100 & $11 \%$ \\
\hline
\end{tabular}

Table 10. SimaPro TRACI results of Constructed data LCA

\begin{tabular}{|c|c|c|c|c|}
\hline Impact Category & Recycled & Virgin & Difference & $\%$ Redux \\
\hline Ozone depletion (kg CFC-11 eq) & 1.00 & 1.17 & 0.17 & $14 \%$ \\
\hline Global warming $\left(\mathrm{Mg} \mathrm{CO}_{2} \mathrm{eq}\right)$ & 5,480 & 7,840 & 2,360 & $30 \%$ \\
\hline $\operatorname{Smog}\left(\mathrm{kg} \mathrm{O} \mathrm{O}_{3} \mathrm{eq}\right)$ & 431,000 & 563,000 & 132,000 & $23 \%$ \\
\hline Acidification ( $\left.\mathrm{kg} \mathrm{SO} \mathrm{SO}_{2} \mathrm{eq}\right)$ & 23,900 & 35,000 & 11,100 & $32 \%$ \\
\hline Eutrophication (kg N eq) & 9,470 & 18,600 & 9,130 & $49 \%$ \\
\hline Carcinogenics (CTUh) & 0.132 & 0.264 & 0.132 & $50 \%$ \\
\hline Non carcinogenics (CTUh) & 0.617 & 1.090 & 0.473 & $43 \%$ \\
\hline Respiratory effects (kg $\left.\mathrm{PM}_{2.5} \mathrm{eq}\right)$ & 4,060 & 3,540 & -520 & $-15 \%$ \\
\hline Ecotoxicity $\left(10^{3}\right.$ CTUe) & 15,000 & 29,100 & 14,100 & $48 \%$ \\
\hline Fossil fuel depletion (GJ surplus) & 10,500 & 12,500 & 2,000 & $16 \%$ \\
\hline
\end{tabular}

GHG emissions and energy consumption are often analyzed when considering the environmental impact of roads. The TRACI categories that best capture these impacts are global warming and fossil fuel depletion. In both categories, there are reductions from using recycled materials. The global warming reduction (24\% Planned, 30\% Constructed) largely stems from the use of RCA and RAP in the base and subbase layers, followed by the substitution of fly ash for 
cement in the concrete pavement. This is very similar to the trends seen in carcinogens, eutrophication, ecotoxicity, and non-carcinogens. In both the Recycled and Virgin design, the majority of fossil fuel-generated energy is consumed during asphalt binder production at the refinery. Although a relatively small quantity of binder was used in the road, the energy to produce and store binder or other petroleum products is so intensive that it dominates impacts. The substitution of RAP for asphalt binder contributes to the $11 \%$ Planned data and $16 \%$ Constructed data impact reduction. Other energy reductions are seen mainly from the substitution of fly ash for cement and recycled pavements for base aggregate.

The TRACI assessment reductions for the two data sets are portrayed in Figure 6. For most TRACI categories, SimaPro predicted greater reductions for the Constructed data as compared to the Planned data. However, although the absolute reductions are not the same, both data sets follow similar trends across the categories. For example, both data sets saw the greatest reductions in carcinogens, followed by eutrophication and ecotoxicity. Both data sets also saw negative impact reductions in respiratory effects.

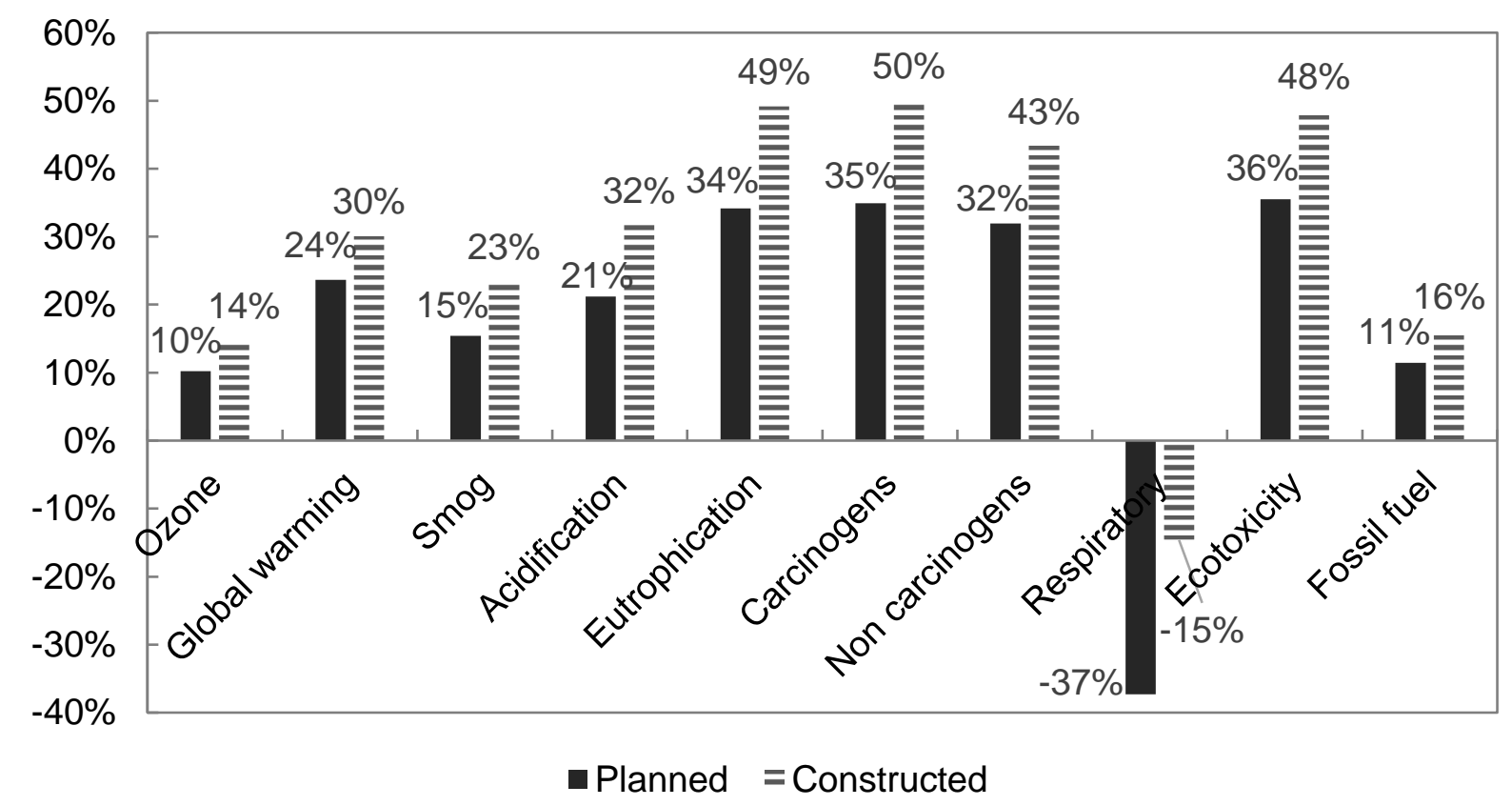

Figure 6. Percent reduction of the collected and estimated Beltline material by using recycled 


\section{versus virgin material; from SimaPro analyses}

As was done with the PaLATE results, the absolute impact of all four designs from the data sets were normalized to compare absolute impact results across TRACI categories. The normalized results are listed in Table 11 and represented visually in Figure 7. Unlike PaLATE, SimaPro predicts greater impacts for the Constructed data set as compared to the Planned data for both the Virgin and Recycled designs. This is consistent with the trends seen in the comparison of the percent reduction in TRACI categories between the two data sets. For the TRACI impact assessment, the Constructed materials considered in the analysis had greater absolute impacts, and resulted in greater impact reduction.

In all impact categories except respiratory effects, the Virgin design from Constructed data predicted the largest impacts. In the case of respiratory effects, the largest impacts were found in the Constructed data's Recycled design. As aforementioned, SimaPro predicted a negative reduction in respiratory effects. Therefore, it is expected that the Recycled designs from both the Planned and Constructed data would have greater respiratory impacts as compared to the Virgin.

Table 11. Normalized SimaPro results for the four analyzed designs, including the Recycled and Virgin designs of both the collected and estimated data

\begin{tabular}{lcccc}
\hline Impact Category & $\begin{array}{c}\text { Planned, } \\
\text { Recycled }\end{array}$ & $\begin{array}{c}\text { Constructed, } \\
\text { Recycled }\end{array}$ & $\begin{array}{c}\text { Planned, } \\
\text { Virgin }\end{array}$ & $\begin{array}{c}\text { Constructed, } \\
\text { Virgin }\end{array}$ \\
\hline Ozone depletion & 0.69 & 0.86 & 0.77 & 1.00 \\
Global Warming & 0.59 & 0.70 & 0.77 & 1.00 \\
Smog & 0.63 & 0.77 & 0.74 & 1.00 \\
Acidification & 0.56 & 0.68 & 0.71 & 1.00 \\
Eutrophication & 0.41 & 0.51 & 0.62 & 1.00 \\
Carcinogens & 0.40 & 0.50 & 0.62 & 1.00 \\
Non carcinogens & 0.47 & 0.57 & 0.68 & 1.00 \\
Respiratory effects & 0.77 & 1.00 & 0.56 & 0.87 \\
Ecotoxicity & 0.42 & 0.52 & 0.65 & 1.00 \\
Fossil fuel depletion & 0.68 & 0.84 & 0.77 & 1.00 \\
\hline
\end{tabular}




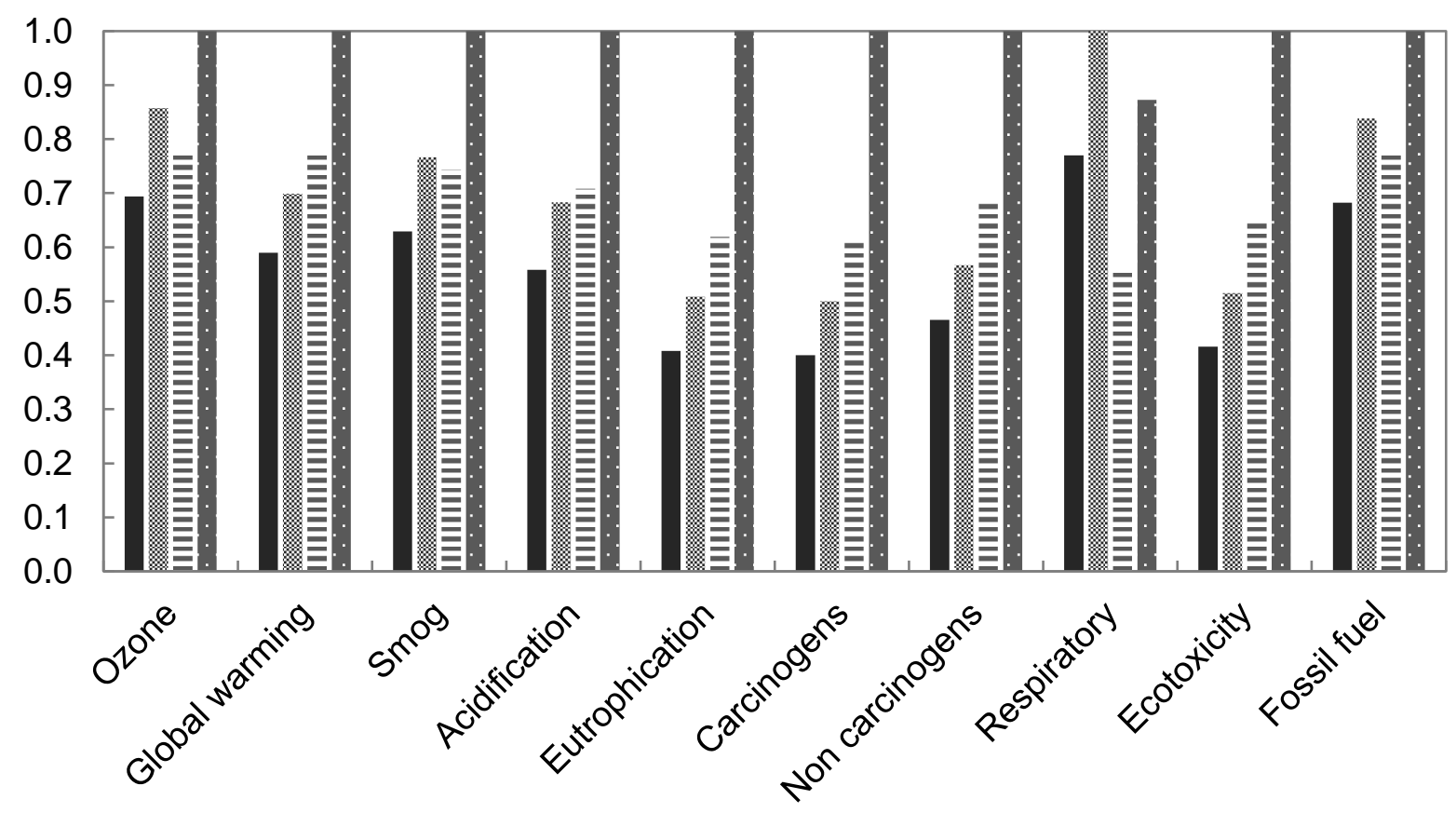

- Designed, Recycled $\approx$ Constructed, Recycled $=$ Designed, Virgin $\approx$ Constructed, Virgin

Figure 7. Graphical representation of normalized SimaPro results across all impact categories for four design scenarios

In addition, those SimaPro categories comparable to PaLATE impacts were included in the impact assessment. The Planned results from both tools are shown in Table 12. A detailed discussion of these results is included in Section 5.2 
Table 12. Comparison of Constructed data results for PaLATE and SimaPro

\begin{tabular}{|c|c|c|c|c|c|c|c|}
\hline & & Energy (GJ) & $\mathrm{CO}_{2}(\mathrm{Mg})$ & $\mathrm{NO}_{\mathrm{x}}(\mathrm{kg})$ & $\mathrm{SO}_{2}(\mathrm{~kg})$ & $\mathrm{CO}(\mathrm{kg})$ & Lead $(g)$ \\
\hline \multicolumn{8}{|c|}{ Planned Data } \\
\hline \multirow{4}{*}{$\frac{w}{\frac{\omega}{\sigma}}$} & Recycled & 76,700 & 5,380 & 41,300 & 16,400 & 10,300 & 3,780 \\
\hline & Virgin & 99,200 & 6,980 & 44,600 & 20,600 & 11,500 & 4,700 \\
\hline & Savings & 22,500 & 1,600 & 3,300 & 4,200 & 1,200 & 920 \\
\hline & Reduction & $23 \%$ & $23 \%$ & $7 \%$ & $20 \%$ & $10 \%$ & $20 \%$ \\
\hline \multirow{4}{*}{$\frac{\stackrel{\circ}{\frac{0}{0}}}{\frac{5}{\infty}}$} & Recycled & 72,000 & 4,470 & 14,200 & 8,370 & 8,800 & 1,190 \\
\hline & Virgin & 85,700 & 5,840 & 16,800 & 11,300 & 12,400 & 1,890 \\
\hline & Savings & 13,700 & 1,370 & 2,600 & 2,930 & 3,600 & 700 \\
\hline & Reduction & $16 \%$ & $23 \%$ & $15 \%$ & $26 \%$ & $29 \%$ & $37 \%$ \\
\hline \multicolumn{8}{|c|}{ Constructed Data } \\
\hline \multirow{4}{*}{$\frac{\omega}{\overleftarrow{\sigma}}$} & Recycled & 97,100 & 6,930 & 51,400 & 20,500 & 13,100 & 4,760 \\
\hline & Virgin & 118,000 & 8,300 & 53,700 & 24,300 & 14,000 & 5,560 \\
\hline & Savings & 20,900 & 1,370 & 2,300 & 3,800 & 900 & 800 \\
\hline & Reduction & $18 \%$ & $17 \%$ & $4 \%$ & $16 \%$ & $6 \%$ & $14 \%$ \\
\hline \multirow{4}{*}{$\begin{array}{l}\frac{0}{0} \\
\frac{0}{\sigma} \\
\frac{\xi}{5}\end{array}$} & Recycled & 98,500 & 6,000 & 22,620 & 10,600 & 14,600 & 1,480 \\
\hline & Virgin & 115,000 & 7,510 & 22,600 & 16,800 & 19,000 & 2,760 \\
\hline & Savings & 16,500 & 1,510 & -20 & 6,200 & 4,400 & 1,280 \\
\hline & Reduction & $14 \%$ & $20 \%$ & $0.1 \%$ & $37 \%$ & $23 \%$ & $46 \%$ \\
\hline
\end{tabular}

\subsection{LCCA Cost Savings}

LCCA cost savings results estimated from the unit prices listed in Table 4 (Section 3.4) are shown in Table 13. For this analysis, it was assumed that both the Recycled and Virgin designs would have the same service life. Therefore, material costs are estimated over the 50year service life, including rehabilitation material costs. From the Planned data, savings due to the use of recycled materials are predicted to be about $\$ 182,600$ during initial construction, 
reducing the costs by approximate $20 \%$. The majority of the savings are seen from the substitution of RAP and RCA for base and subbase material. Savings were also estimated for future maintenance materials and brought to present value. The maintenance reduced costs by an estimated $\$ 27,200$ at present value through the anticipated substitution of fly ash for cement and use of RAP and RAS in HMA mixes. Grand total Planned savings for the lifetime of the project were estimated to be approximately $\$ 209,800$, or $19 \%$ reduction in costs due to the use of recycled material.

LCCA savings for the Constructed data initial construction are estimated to be $\$ 239,800$, reducing the cost by $20 \%$. Since future construction costs must be estimated for the collected data as well, the total maintenance savings is the same for both data sets at $\$ 27,200$. This equates to a Constructed data grand total saved over the lifetime of the project of $\$ 267,000$ for the collected data, a 19\% reduction in cost compared to the Virgin design costs. The differences in the two data sets' savings is discussed in Section 5.3.

Table 13. Summary of cost savings from Planned and Constructed data sets

\begin{tabular}{lcc}
\hline Savings Origination & Planned & Constructed \\
\hline Initial Construction & & \\
Fly ash in concrete & $\$ 61,800$ & $\$ 49,000$ \\
RAP/RCA in (sub)base & $\$ 95,800$ & $\$ 133,000$ \\
RAP/RAS in HMA & $\$ 25,000$ & $\$ 57,800$ \\
Initial Construction Total & $\mathbf{\$ 1 8 2 , 6 0 0}$ & $\mathbf{\$ 2 3 9 , 8 0 0}$ \\
\hline Maintenance (at present value) & $\mathbf{\$ 2 7 , 2 0 0}$ & $\mathbf{\$ 2 7 , 2 0 0}$ \\
\hline GRAND TOTAL & $\mathbf{\$ 2 0 9 , 8 0 0}$ & $\mathbf{\$ 2 6 7 , 0 0 0}$ \\
\hline
\end{tabular}




\section{Chapter 5: Discussion}

\subsection{Planned vs. Constructed data}

One goal of the thesis was to evaluate the two data collection methodologies and their LCA results. For the PaLATE LCA, this comparison is best made in Figure 4 and Figure 5. Figure 4 shows greater impact reductions from the Planned data as compared to the Constructed data. The quantities input into PaLATE for the Planned data were calculated from design plans and contractor mix specifications. Materials comprising the pavement concrete, bridge concrete, and asphalt pavement were calculated from average mix material percentages. In this way, the Planned materials often over-generalize the actual materials used in construction. For example, the average concrete pavement mix contained $3 \%$ fly ash. However, the Constructed data revealed that some sections of the road were paved with concrete containing no fly ash i.e. HES and SHES mixes, for curing purposes. These mixes were specifically designed to harden as quickly as possible due to time constraints on blocking traffic. Because cement in concrete has a large impact in the PaLATE analysis, the ratio of fly ash to cement is significantly influential in recognizing impact reductions. The Planned data predicts a larger ratio of fly ash to cement than the Constructed data, thus it predicts larger reductions.

For the HMA surfaces, only the asphaltic base was included in the design plans. However, from the Construction data it was found that HMA was also used elsewhere such as the median, shoulder, temporary pavement, and connecting pavement sections. Although these other HMA mixes were used in relatively small amounts as compared to the asphaltic base, the additional HMA use does differentiate the quantities in the Constructed data. Although greater amounts of FRAP and RAS were calculated in the Constructed data, there was a larger ratio of RAP and RAS substitution in the binder for the Planned data as compared to the Constructed data. In PaLATE's analysis, the impacts from asphalt binder production are greater than those of aggregate 
production. Therefore, the Planned data's higher RAP to virgin binder ratio leads to greater reductions. There are relatively similar ratios of virgin to recycled materials in the base and subbase for both the Recycled and Virgin designs. Therefore, the base materials have little contribution to the difference in the percent reductions from the two data sets.

Although the PaLATE analysis saw greater reductions from the Planned data, the normalized impacts shown in Figure 5 predict greater absolute environmental impacts for the Recycled and Virgin designs from the Constructed data. The greater impacts are due in large to the greater quantity of materials collected during construction as compared to the quantities estimated from the designs. As previously mentioned, calculating Planned materials excluded some details found from the Constructed data. When collecting data during construction, it was found that more concrete, HMA, and base aggregate were used than depicted in the design plans. For the HMA pavement, the plans only specify the asphaltic base and no other smaller HMA pavement work. For concrete, the difference in material use is likely caused from changes from the plans during the actual construction. For example, width ranges are provided for certain lanes in the plans (e.g. lane is $0-12$ feet wide), and average widths were used in the design quantities calculation (e.g. lane average is 6 feet wide).

The largest difference in material quantities is in the base course. There is almost a $60 \%$ decrease from the Constructed to the Planned base course material predictions. While the ratios of RCA and RAP to virgin aggregate are relatively uniform, the total volume of base calculated from the plans differs significantly from the quantity collected during construction. The Constructed base quantities were gathered mainly from two sources: (1) calculated volumes from existing pavement plans and (2) QMP testing of imported material and recycled pavement used in base. All base material, both imported and recycled on site, were tested for their quality and therefore explicitly tracked by WisDOT personnel. However, a certain amount of recycled pavement was used for embankment and fill, mostly on the ramps. This material was not tested 
or tracked for QMP purposes. This discrepancy is the likely cause for the greater quantity of base material in the Constructed data set, and thus greater overall environmental impact.

Similar percent reductions and normalize impacts graphs are shown for the SimaPro analysis in Figure 6 and Figure 7. Like the PaLATE results, SimaPro showed greater absolute impacts for the Recycled and Virgin Constructed data as compared to the Planned data in most TRACI categories (Figure 7). Again, this is caused by the greater quantity of material in the Constructed data set as compared to the Planned data. However, unlike PaLATE, SimaPro predicted greater reductions from the Constructed data. There are a number of reasons for this inconsistency. One example is the TRACI impact categories are different than PaLATE's. The same trends we see in PaLATE's impacts may not be the same in a TRACl analysis. The perceived results when viewing percent reductions may be skewed because the reductions are calculated relative to the absolute impact of the Virgin design. The quantitative reduction, rather than the percent difference, may reveal different information and trends. This is why it is important to analyze the absolute impacts as shown in the normalized figures as well as percent reduction. Additionally, SimaPro's material inventory differs from that included in PaLATE. While the boundaries on the user input material remained the same for both the Constructed and Planned data, SimaPro's built-in inventory may have included other processes or used different calculations and conversions than PaLATE. A more detailed comparison of PaLATE and SimaPro is included later in the discussion (Section 5.2).

Overall, the Planned and Constructed data produced relatively similar results. The reductions between the two data sets ranged from a difference of $3 \%\left(\mathrm{NO}_{x}, \mathrm{CO}\right)$ to $24 \%\left(\mathrm{PM}_{10}\right)$ in the PaLATE analysis. In the particularly relevant categories of energy and $\mathrm{CO}_{2}$ emissions, the two data sets' results had a difference of only $7-8 \%$. In the SimaPro analysis with TRACI impacts, reductions ranged from differences of $4 \%$ (ozone depletion) to $22 \%$ (respiratory effects). In TRACl's global warming and fossil fuel depletion categories, the Constructed data predicted a 5$6 \%$ difference from the Planned data impacts reductions. Although the normalized results did 
show greater impacts from the Constructed data, both data sets' results are relatively similar, with no difference between like-design results greater than 0.29 from PaLATE and 0.38 from SimaPro. The largest discrepancy in material quantities is in the base course, mostly from the recycled pavement. Because not all pavement recycled on site was tracked, there can only be an estimate of how much material was actually used in the project. The Planned data only considered the predicted quantities of base course. However, this method ignores any pavement recycled into fill, and therefore, the Planned results underestimate the overall environmental impact.

It may be concluded that to gain the most accurate understanding of environmental and economic benefits from road construction, detailed recycled material tracking is necessary. However, should the DOT be unable to explicitly track recycled material use and application, an evaluation of quantities based on design plans and typical mix designs would provide a reasonable estimate of the benefits.

\subsection{SimaPro vs. PaLATE}

Comparing results across multiple LCA tools can be a challenging task. There has not yet been an internationally accepted data format developed for LCAs (Goedkoop et al., 2016). Different data format leads to different boundaries within material inventories, i.e. the inputs and outputs of the same material in different inventories might not be consistent. Most material inventories are an aggregation or average of the inputs and outputs of processes and products. For example, because PaLATE was specifically designed for roadways, rock crushing impacts would be calculated for processes included in crushing rock for the purpose of aggregate in roads. Because SimaPro is a more general LCA tool, its rock crushing processes includes an average impact of rock crushing for multiple purposes. Additionally, the location and temporal range of the data within the software can vary. PaLATE was created in 2004, so most of its inventory was created from data in the years preceding 2004. The version of SimaPro used in this analysis was 
updated in January 2016. However, SimaPro's database pulls from multiple LCA inventories including Agri-footprint 2.0 (Agri-footprint, 2015), ecoinvent v3.1 (Moreno Ruiz et al., 2014), and the USA Input Output, or CEDA (Suh, 2010). Most of the SimaPro inventory is more recent than PaLATE's. SimaPro is an internationally applicable software, therefore has inventory data from multiple nations. Some of the materials, process, and assessment methods are specifically for the US. However, some inventories are aggregated from global or developing world averages. PaLATE was created in the US and designed to be used by state DOTs.

To further evaluate the differences between PaLATE and SimaPro's LCAs, a course sensitivity analysis was conducted. For the Recycled designs based on both the Constructed and Planned data quantities, SimaPro and PaLATE analyses were conducted while varying broad material quantities. The inputs were varied by: 1) no change in inputs (True impact), 2) doubling base and subbase quantities (2xBase), 3) doubling surface pavement quantities, i.e., concrete and HMA materials (2xSurface), and 4) doubling binder quantities, i.e., cement, fly ash, asphalt, etc. (2xBinder). For simplification purposes, only energy consumption impacts were included in the analysis. Figure 8 shows the increase in energy consumption due to the various adjustments of input material. Doubling the base led to only small increases (8-9\%) in overall impacts for both PaLATE and SimaPro. However, doubling the surface material, particularly the binder, led to much greater increases in energy, particularly for PaLATE. Doubling the surface material led to a 74\% (Planned) and 75\% (Constructed) increase in energy consumption in the PaLATE analysis. From the SimaPro results, the energy impact only increased 34\% (Planned) and 54\% (Constructed) due to doubling the surface material. Similar increases are felt when doubling the binder material alone. This trend indicates that both analysis tools are most sensitive to changes in binder material inputs, but PaLATE may be more sensitive to the ratio of recycled to virgin binder material as compared to SimaPro. 


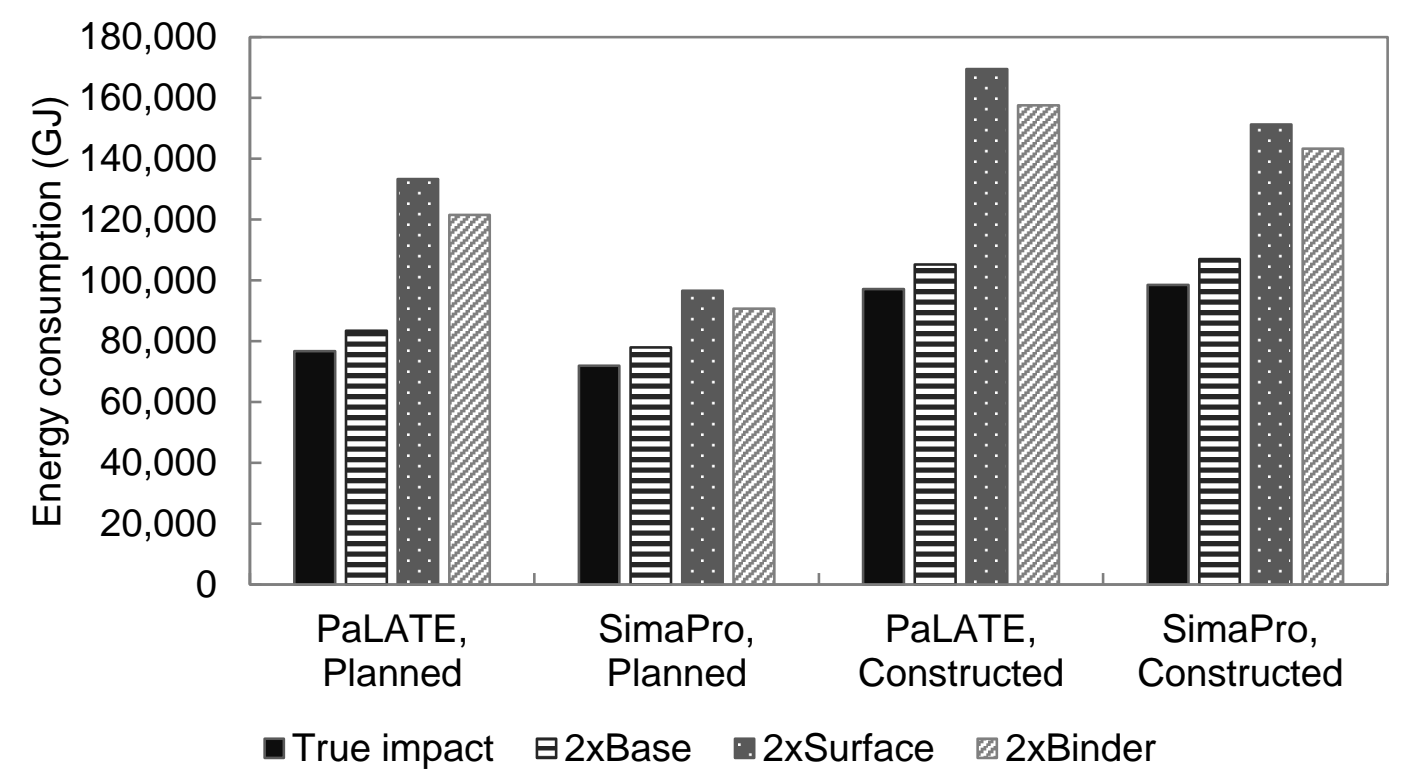

Figure 8. Results of sensitivity analysis for change in energy consumption impacts when certain inputs (base, surface, and binder material quantities) are doubled (2x)

With these differences in mind, the paper evaluates six common environmental impacts between the two software as listed in Table 12. Figure 9 and Figure 10 help to visualize this comparison. Figure 9 shows the percent reductions predicted for both the Constructed and Planned data by PaLATE and SimaPro. The reductions in the energy and $\mathrm{CO}_{2}$ impact categories for all analyses are relatively similar, within $10 \%$ of each other. There is more variability in the predictions for nitrous oxides, sulfur dioxide, carbon monoxide, and lead. This largely stems from differences in the inventory and assessment methods. PaLATE predicts that most savings in $\mathrm{NO}_{\mathrm{x}}$, $\mathrm{SO}_{2}, \mathrm{CO}$, and lead will occur from the replacement of fly ash for cement. SimaPro predicts more savings in these categories from the substitution of recycled pavement in the base. These calculations are related to each software's estimation of impact reduction per unit of material production. In PaLATE, these are based on EPA emissions standards among other references. Because SimaPro is a proprietary software, the calculation methods and inventory are not readily visible. Therefore it is not clear how the software allocates its impacts differently than PaLATE. 


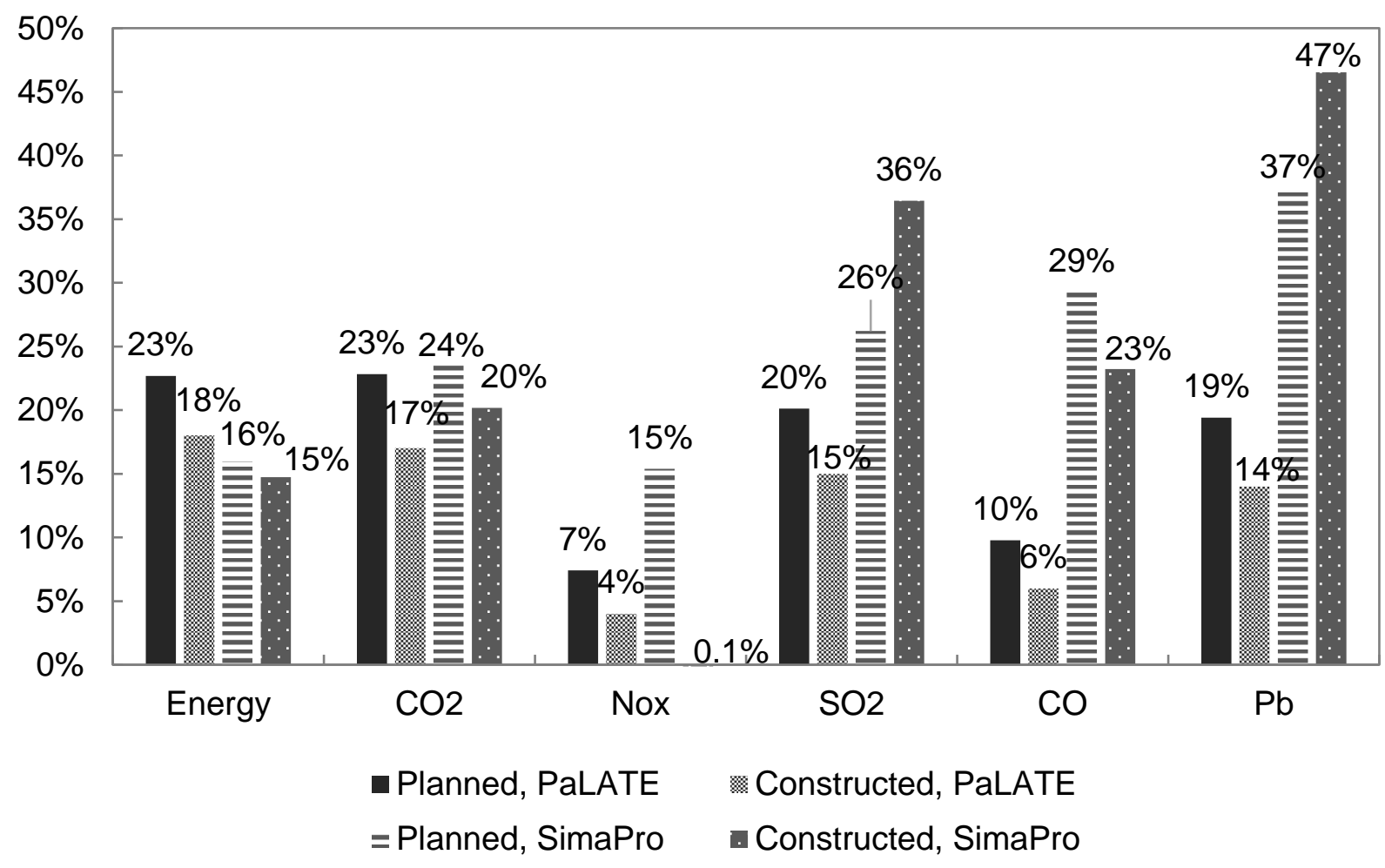

Figure 9. Percent reductions from PaLATE and SimaPro analyses of Planned and Constructed data sets

Figure 10 shows the normalized impacts from the Recycled and Virgin designs from both data sets analyzed by the two LCA tools. As mentioned previously, percent reductions can be misleading representations of results as they are dependent not only on the reduction in impact, but also the reference environmental impact. Therefore, the normalized visualization of the absolute impacts shown in Figure 10 should also be analyzed. Again, the predictions from both tools for energy and $\mathrm{CO}_{2}$ emissions appear to have less variability than the other categories. For both analysis tools, the Constructed data consistently predicts greater impacts than the Planned data. However, for the same design (Recycled or Virgin) from the same data set (Constructed or Planned), SimaPro and PaLATE predict relatively similar results, particularly in energy, $\mathrm{CO}_{2}$ emissions, and carbon monoxide. For example, looking at only the energy impacts for the Recycled design results (the first four bars in Figure 10), the absolute impacts from the same data set (e.g. Planned) are within 0.05 across the two analysis tools. For both the SimaPro and 
PaLATE energy results, greater energy impacts for the Constructed data as compared to the Planned data. Overall, these trends indicate that the data collection methods and resulting LCA inputs have a greater influence in environmental impact predictions as compared to analysis tools, particularly for the relevant categories of energy and $\mathrm{CO}_{2}$ emissions.

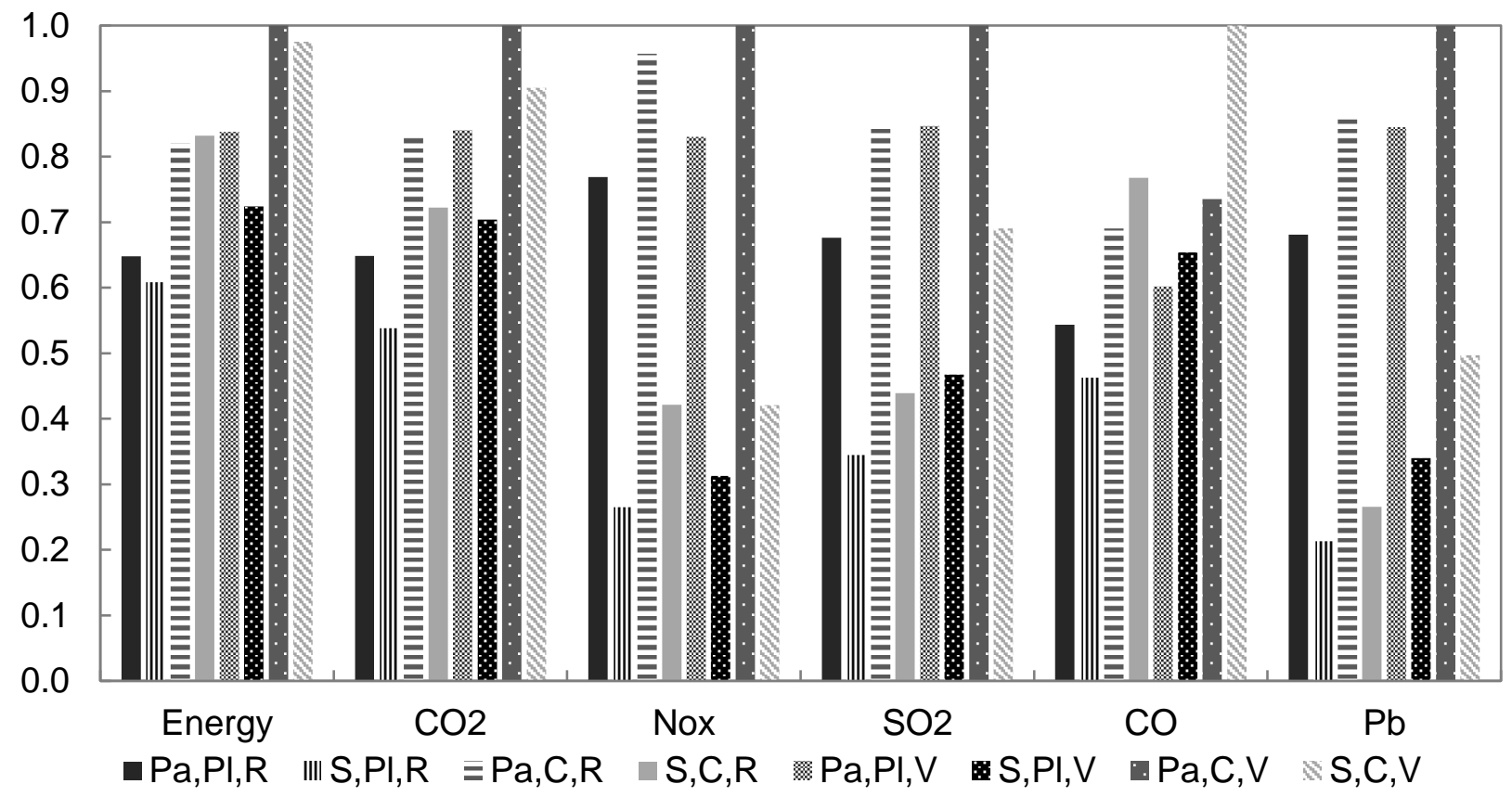

Figure 10. Absolute impacts from PaLATE (Pa) and SimaPro (S) analyses of Recycled (R) and Virgin (V) designs from Planned (PI) and Constructed (C) data sets. In the legend, the labels should be read as the initials for: LCA tool (Pa vs. S), Data set (PI vs. C), Design (R vs. V)

\subsection{Discussion of Cost Savings}

For most recycled materials, the Constructed data set showed greater cost savings than the Planned data. In the base course, greater recycled pavements were determined from the Constructed as compared to the Planned data. Therefore, more cost savings are recognized from using the Constructed volume of RCA and RAP as substitution for virgin base aggregate. Additionally, more HMA was predicted by the Constructed data, most of which contained at least RAP in their pavement mixes. More overall HMA pavement with RAP led to greater savings from 
all HMA pavements. The Planned data did predict greater savings from the substitution of fly ash. This is likely because the Constructed concrete quantities used some mix designs with no fly ash, while the Planned average mix did include fly ash. The grand total savings different by approximately $\$ 57,000$. While this may seem like a small number compared to the total cost for the project, it becomes significant when considering it is the savings for only 3 lane-miles. This stresses why explicit tracking may be important to accurately determine cost reductions from recycled material use. 


\section{Chapter 6: Conclusions and Recommendations}

This paper discusses the methods of data collection for the purpose of both economic and environmental life cycle analyses. To evaluate data collection methods, as well as LCA tools, a case study was performed on a $2.4 \mathrm{~km}(1.5-\mathrm{mi})$ stretch of Wisconsin highway. Data estimates were made from design plans and mix specifications arbitrary to the timing of the construction. A separate data set was collected from constructed materials while the work was on-going. Based on the LCAs and LCCA, the two data sets provided similar impacts and reductions. However, both analysis tools saw greater absolute impacts from the Constructed data. This is directly related to the quantity of materials predicted by the data collection. The Constructed data was able to capture more applications of material, as well as a greater variety of material types and mix designs. Although this in-depth tracking of material may have resulted in more accurate life cycle impact predictions, the Planned data provided similar enough results to suggest that it could be an acceptable method for estimating impacts in the future.

In addition to the data collection analyses, two LCA tools were used to calculate impacts and compared. PaLATE was specifically designed for the RMRC to perform LCAs of road construction. Therefore, it included most if not all typical recycled and virgin road material as well as construction processes. Contrarily, SimaPro is designed to be used for an LCA of any material or process. Most road construction materials were included in the software's inventory, but some recycled material impacts were estimated. Based on comparable impact assessment parameters, the two software tools provided similar results in terms of energy use and $\mathrm{CO}_{2}$ emissions. While the other comparable impact categories had greater variability in results, there was a more significant difference between the impacts of the two data sets, rather than the impacts predicted by the different tools. Therefore, DOTs should attempt to focus future efforts on material tracking for the purpose of LCAs and LCCAs when these issues are critical. 


\subsection{Future Research Opportunities}

This thesis found that explicitly tracking material during construction improved LCA impact prediction accuracy. However, most DOTs do not and are not required to track their recycled material use. The RMRC is currently working to provide state DOTs with a holistic, user-friendly tracking tool (RMRC, 2016) that will aid in quantifying state-wide recycled material usage. The program uses pavement mix design and recycled material ratios to calculate the tons or volume of recycled materials used on a project-by-project basis. Additionally, the tool tabulates the quantities from each project to provide data for an entire state s recycled material use. While the tool currently does not provide LCCA or LCA results, these analysis could be integrated into the program. Thus, states could automatically calculate not only recycled material use, but the corresponding economic and environmental benefits. Future construction on the Beltline Highway, as well as other upcoming WisDOT reconstructions could serve as pilot projects for the tracking tool and subsequent LCA case studies.

This thesis also looked at the analysis methods and results of two LCA tools. Although the goal of the study was not to prove one tool superior, areas of improvement were noted for both LCA software. PaLATE was created in 2004 and may contain outdated inventory data. Thus, it is recommended that the PaLATE inventories and calculations be evaluated for possible updates and improvements. This will increase the accuracy of results if the RMRC chooses to use PaLATE in future LCAs. Alternatively, the RMRC could conduct future studies using SimaPro rather than or in addition to PaLATE. However, SimaPro is non-specific to roads and does not contain inventories for certain road materials and construction processes. To improve SimaPro LCAs, inventories should be created for the materials and processes that it lacks. The results of this thesis demonstrated that in common LCA categories such as energy and $\mathrm{CO}_{2}$ emissions, PaLATE and SimaPro predicted similar environmental impacts. Therefore, later studies may not need to 
conduct LCAs using both tools unless data verification is critical. Instead, the RMRC may choose to focus on improving one LCA tool for future studies. 


\section{Appendix A: Life Cycle Assessment of Interstate 94 A Case Study Report on the Successful Use of Recycled Materials in Highways}

\section{A.1. Introduction}

The goal of this report is to quantitatively and accurately determine the environmental and economic benefits of using recycled material through the reconstruction of a Wisconsin roadway project, thereby further demonstrating the viability of life cycle analyses in evaluating the advantages of sustainable road construction. The Recycled Materials Resource Center (RMRC) analyzed the benefits of incorporating recycled materials in the reconstruction of I-94 in Kenosha County, WI, using the analysis tool Building Environmentally and Economically Sustainable Transportation-Infrastructure-Highway (BE²ST-In-Highways) (Lee et al., 2013). BE$^{2}$ ST-In-Highways integrates various supporting databases and uses LCA and life cycle cost analysis (LCCA) techniques to evaluate the overall impact of highway construction projects. The $\mathrm{BE}^{2} \mathrm{ST}$-In-Highways support program is the Pavement Life-cycle Assessment Tool for Environmental and Economic Effects (PaLATE) which calculates the environmental impacts of reconstruction. A second LCA tool, SimaPro, was also used to calculate environmental impacts, which were compared to the $\mathrm{BE}^{2} \mathrm{ST}$-In-Highways results. Additional analyses from the Wisconsin Department of Transportation (WisDOT) were used to determine lifetime and maintenance parameters of the project. The RMRC targeted a $1.6 \mathrm{~km}(1-\mathrm{mi})$ stretch of the Kenosha County portion of the I-94 North-South Freeway Project because of its unique use of recycled materials in its reconstruction. The goal of this report is to quantitatively determine the environmental and economic benefits of using recycled material in the reconstruction of I-94, thereby further demonstrating the viability of $\mathrm{BE}^{2} \mathrm{ST}$-In-Highways in assessing the advantages of sustainable road construction. As a part of this goal, the results of the $\mathrm{BE}^{2} \mathrm{ST}$-In-Highways were compared the results of the SimaPro analysis to validate the predicted impacts. 


\section{A.2. Background}

Sustainable roadway construction has become an increasingly popular topic because of the contributions to global climate change and rising costs of virgin materials in road construction. Buildings and infrastructure utilize $40 \%$ of all materials extracted in the U.S. (Kibert, 2002), and the construction industry emits approximately $6 \%$ of total U.S. industry-related greenhouse gasses (GHGs) (Truitt, 2009). To be sustainable, environmental impacts of highways must be reduced through thoughtful planning, design and construction. This includes reducing the use of virgin materials (Gambatese \& Rajendran, 2005). Materials commonly used in road construction, such as virgin aggregate or cement, often incur high transportation costs, consume natural materials and energy, generate GHG emissions, and are increasingly limited in supply (AASHTO, 2008; Lee et al., 2010). After demolition, previously used concrete or asphalt pavement is either recycled or sent to a specifically designed landfill, usually at a cost, and remains unused (Edil, 2013; FHWA, 2008; Guthrie et al., 2007). However, sustainable road construction incorporates as much existing material on site as possible. Recycled coal by-products such as fly ash and bottom ash may also be used instead of virgin material. The RMRC has studied, and continues to study, the viability of fly ash as an alternative binder both in the surface concrete mix and as stabilization in the base course (RMRC, 2010). The larger-grained coal by-product, bottom ash, can act as a fill or aggregate in the embankment layer (RMRC, 2010).

\section{A.2.1 The I-94 North-South Freeway Project}

The I-94 North-South corridor spans 56 km (35 mi) from Milwaukee to Kenosha County and is one of Wisconsin's most frequently used highways (WisDOT, 2007). In the early 2000s, WisDOT investigated the viability of reconstructing a section of I-94 in southeast Wisconsin. In response to the findings of the investigation, WisDOT initiated the I-94 North-South Freeway Project (Freeway Project). Issues that stemmed from the corridor's initial construction would require full reconstruction and redesign of the roadway. The Freeway Project stipulates not only 
rebuilding the freeway, but incorporating safer frontage roads, improved interchanges and entrance/exit ramps, and better overall road design. Projected increases in traffic congestion necessitate the widening of the freeway to eight lanes from the Wisconsin/llinois border to Milwaukee. The entire Freeway Project is projected to be completed in 2021.

\section{A.2.2 Design of Reconstruction}

The construction plan for Freeway Project was separated into two sections: Milwaukee and Racine Counties, and Kenosha County. The RMRC analysis focuses on the Kenosha County design. In Kenosha County, construction plans outline a multi-year reconstruction, modernization, and expansion of I-94 mainline and ramps, as well as State Highway (STH) 142, between STH 158 and County Highway E. The divided 6-lane freeway is being converted to a divided 8-lane freeway with full pavement reconstruction (N. Schlegel and B. Blum, personal communication, Aug.-Jan. 2013-2014). A private consulting firm developed the design of the reconstruction. The RMRC targeted a $1.6 \mathrm{~km}(1-\mathrm{mi})$ stretch of the Kenosha County portion of the Freeway Project for a case study (Figure A1). Recycled materials used in the project include fly ash, bottom ash, foundry sand, recycled concrete aggregate (RCA), and recycled asphalt pavement (RAP). Fly ash was used as part of the concrete pavement mix. RAP and RCA were used in the base course and subbase, respectively. It was assumed that RAP would also be used in future HMA overlays for rehabilitation purposes. Foundry sand and bottom ash comprised a significant portion of the embankment and fill. 

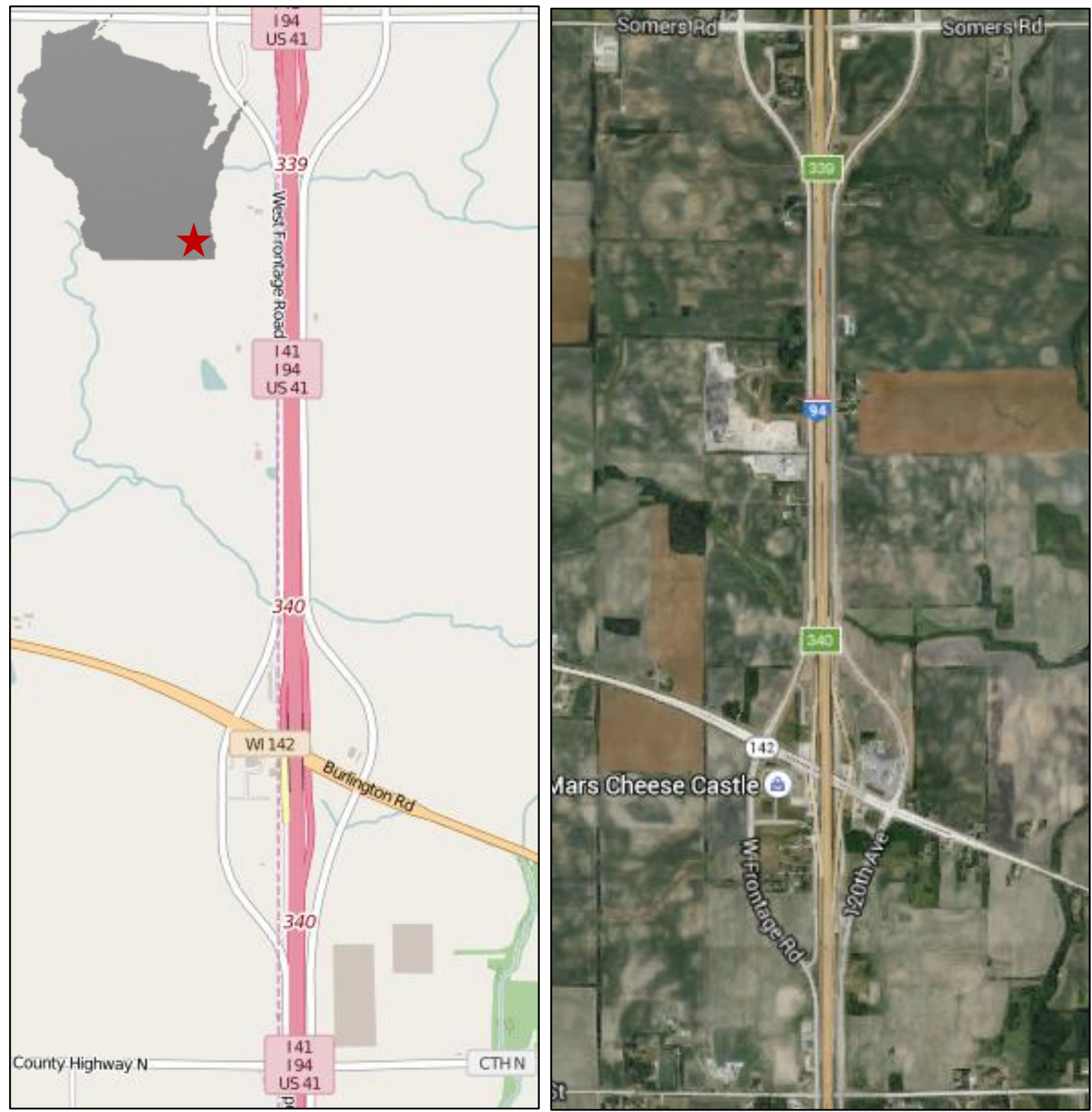

Figure A1. 1.6 km (1 mi) l-94 reconstruction location in Kenosha County. The red star on the state of Wisconsin (upper left) shows the location within the state.

A series of designs were considered to improve the initial conditions of I-94. The selected design was a modernization of the roadway and an expansion to an eight-lane highway. This plan improves safety while significantly reducing freeway congestion. Under the eight-lane modernization option, construction improvements would include: one lane added in each 
direction, a consistent shoulder width, a paved median with a concrete barrier, and relocated frontage roads. In Kenosha County, there was full pavement reconstruction (WisDOT, 2007).

\section{A.2.1.1 Initial Conditions}

The I-94 North-South corridor was built in the late 1950s and early 1960s, consisting of six primary traffic lanes (three in each direction) for most the route. The northbound lanes split into east and west directions near Milwaukee at the Mitchell Interchange. Seventeen service interchanges were constructed in addition to the Mitchell Interchange on I-94.

A study was conducted from 2000 to 2003 by the Southwest Wisconsin Regional Planning Commission to evaluate the current state of I-94. The study determined that safety issues, pavement and design deficiencies, and traffic congestion would require a full reconstruction and redesign of the corridor. During the time of this study, an average of 2.2 crashes occurred in the corridor each day (WisDOT, 2007), further evidence of the need for improved safety measures in the reconstruction design. The existing pavement structure was comprised of the following layers (Figure A2):

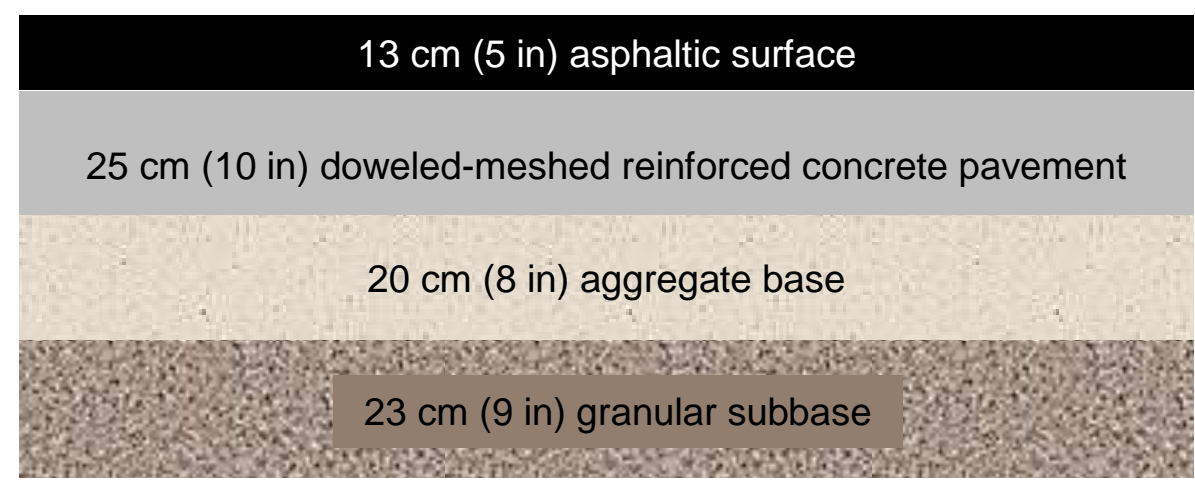

Figure A2. Schematic of existing pavement structure, not to scale (N. Schlegal and Brad B. Blum, personal communication, August-January 2013-2014)

\section{A.2.1.2 Alternatives}

WisDOT studied three options for the reconstruction before choosing the preferred alternative (WisDOT, 2007). The three options were as follows: 
- Replace-in-kind (six lanes)

- Modernizations (six lanes)

- Modernization with capacity expansion (eight lanes)

Replace-in-kind - In the construction plans for this option, existing pavement is removed and replaced in its current location. This plan does not address safety and crashes, correct outdated designs, or relieve congestion.

Modernization - The modernization (six lanes) option would maintain the existing three northbound and three southbound lanes between Racine and Kenosha counties. It would provide a consistent width for inside and outside shoulders. A paved median with concrete barriers would be added. The frontage roads on either side of the freeway would be pushed out to create wider ditches, thus improving the quality of storm water runoff. This model would improve safety, but would do little to relieve congestion.

Modernization with Expansion-This alternative design included constructing an additional lane in each direction, for a total of 8 lanes, and replacing deteriorating pavement and structures with new designs. Ultimately, the modernization with capacity expansion was chosen for the reconstruction.

\section{A.2.1.3 Road Specifications}

There are three components within the $1.6 \mathrm{~km}(1-\mathrm{mi})$ study project: mainline, ramps, and STH 142. The materials for all three portions, as well as the embankment and fill, are listed in Table A1 through Table A4. Due to Wisconsin's cooler climate, WisDOT typically uses portland cement concrete (PCC) surface pavement (Johanneck \& Khazanovich, 2010; WisDOT, 2016b). The typical structure for rigid pavement includes a layer of concrete over base aggregate over the subgrade (Huang, 2003). This design also includes an asphalt base layer below the surface concrete, which provides a waterproof barrier over the bases as well as additional support strength (Pavement Interactive Consortium, 2009). The amount of recycled pavements, such as 
RAP and RCA, depended on the availability of material from existing conditions. The percentage of fly ash in the concrete mix was left to the discretion of the pavement contractors. The ramps and STH 142 are comprised of layers similar to the mainline, but with different thicknesses. STH 142 underwent resurfacing, rather than full reconstruction. Embankment was used in various locations with varying thicknesses in order to replace removed material and elevate roads to the design elevations. A total volume of approximately 235,000 cubic yards of embankment was used for this portion of the I-94 construction.

Table A1. Mainline materials by layers with dimensions and sources

\begin{tabular}{l|cccc}
\hline \multicolumn{1}{c|}{ Layer } & $\begin{array}{l}\text { Thickness } \\
\text { in cm (in) }\end{array}$ & Material & Source & $\begin{array}{c}\text { Distance } \\
\text { in } \mathbf{~ k m ~ ( m i ) ~}\end{array}$ \\
\hline Concrete Surface & $30(12)$ & $\begin{array}{c}\text { Fly Ash } \\
\text { Cement } \\
\text { Aggregate+Water }\end{array}$ & $\begin{array}{c}\text { We Energies } \\
\text { LaFarge } \\
\text { Michels Paving }\end{array}$ & $\begin{array}{c}16(10) \\
88(55) \\
1.6(1)\end{array}$ \\
\hline Asphalt Base & $8(3)$ & $\begin{array}{c}\text { Binder } \\
\text { Aggregates }\end{array}$ & Payne \& Dolan & $2.4(1.5)$ \\
\hline Base & $15(6)$ & $\begin{array}{c}\text { Virgin Aggregate } \\
\text { RAP (55\%) }\end{array}$ & $\begin{array}{c}\text { Bartel Aggregate } \\
\text { Recycled On-Site }\end{array}$ & $\begin{array}{c}38(17.5) \\
0\end{array}$ \\
\hline Subbase & $33(13)$ & $\begin{array}{c}\text { Virgin Aggregate } \\
\text { RCA (37.5\%) }\end{array}$ & $\begin{array}{c}\text { Franklin Aggregates } \\
\text { Recycled On-Site }\end{array}$ & $\begin{array}{c}43(30) \\
0\end{array}$ \\
\hline
\end{tabular}

Table A2. Ramp materials by layers with dimensions and sources

\begin{tabular}{|c|c|c|c|c|}
\hline Layer & $\begin{array}{l}\text { Thickness } \\
\text { in } \mathrm{cm} \text { (in) }\end{array}$ & Material & Source & $\begin{array}{l}\text { Distance } \\
\text { in } \mathrm{km}(\mathrm{mi})\end{array}$ \\
\hline \multirow{3}{*}{ Concrete Surface } & \multirow{3}{*}{$30(12)$} & Fly Ash & We Energies & $16(10)$ \\
\hline & & Cement & LaFarge & $88(55)$ \\
\hline & & Aggregate+Water & Michels Paving & $1.6(1)$ \\
\hline \multirow{2}{*}{ Base } & \multirow{2}{*}{$15(6)$} & Virgin & Bartel Aggregate & $38(17.5)$ \\
\hline & & $\operatorname{RAP}(55 \%)$ & Recycled On-Site & 0 \\
\hline \multirow{2}{*}{ Subbase } & \multirow{2}{*}{$41(16)$} & Virgin & Franklin Aggregates & $43(30)$ \\
\hline & & $\mathrm{RCA}(37.5 \%)$ & Recycled On-Site & 0 \\
\hline
\end{tabular}


Table A3. STH 142 materials by layers with dimensions and sources

\begin{tabular}{l|cccc}
\hline \multicolumn{1}{c|}{ Layer } & $\begin{array}{l}\text { Thickness } \\
\text { in cm (in) }\end{array}$ & Material & Source & $\begin{array}{c}\text { Distance } \\
\text { in km (mi) }\end{array}$ \\
\hline \multirow{3}{*}{ Concrete Surface } & $30(12)$ & $\begin{array}{c}\text { Fly Ash } \\
\text { Aggregate+Water }\end{array}$ & $\begin{array}{c}\text { We Energies } \\
\text { LaFarge }\end{array}$ & $\begin{array}{c}\text { Michels Paving } \\
88(10)\end{array}$ \\
& & Virgin & Bartel Aggregate & $38(17.6)$ \\
\hline \multirow{2}{*}{ Base } & $15(6)$ & RAP $(55 \%)$ & Recycled On-Site & 0 \\
\hline
\end{tabular}

Table A4. Embankment materials with approximate proportions and sources

\begin{tabular}{c|ccc}
\hline Layer & Material & Source & $\begin{array}{c}\text { Distance } \\
\text { in } \mathbf{~ k m ~ ( m i ) ~}\end{array}$ \\
\hline \multirow{3}{*}{ Embankment } & Foundry Sand (5\%) & Rexnord Sand \& Gravel & $89(35)$ \\
& Native clays (25\%) & Onsite & 0 \\
& Bottom ash (70\%) & We Energies & $16(10)$ \\
\hline
\end{tabular}

\section{A.3. Materials and Methods}

\section{A.3.1 BE'2ST-In-Highways}

$\mathrm{BE}^{2} \mathrm{ST}$-In-Highways was created at the University of Wisconsin-Madison as a tool for determining the environmental impacts of highway construction projects (Lee et al., 2013). Using recycled materials in roadway construction has the potential to reduce environmental impacts by over $20 \%$ (Lee et al., 2010). BE²ST-In-Highways is a means to quantify how adequately a highway reduces its environmental impact by incorporating recycled materials in its design. A construction project that contains recycled materials (Recycled) is typically analyzed in comparison to a project that contains virgin materials (Virgin). The criteria considered in the BE 2 ST-In-Highways analysis are important parameters in determining the sustainability of a roadway. These criteria, which were determined by RMRC stakeholders, for improvement in performance include:

- Energy use (MJ)

- Global warming potential (GWP) (Mg)

- Water consumption $(\mathrm{kg})$ 
- Social carbon cost (SCC) (\$)

- Hazardous waste $(\mathrm{kg})$

- In Situ Recycling (CY)

- Total Recycling (CY)

$\mathrm{BE}^{2} \mathrm{ST}$-In-Highways incorporates a number of support programs to conduct its analysis, including the Mechanistic-Empirical Pavement Design Guide (MEPDG), PaLATE, and RealCost. PaLATE was used for the LCA portion of the I-94 mainline analysis. MEPDG is used to determine the lifetime of the roadway. However, the expected lifetime and maintenance schedule for this portion of I-94 were previously determined by WisDOT. The WisDOT analysis results were used for the RMRC's LCA and LCCA. BE'ST-In-Highways uses RealCost to conduct its LCCA. RealCost calculates life cycle costs for both agency and user costs associated with reconstruction and rehabilitation (FHWA, 2004). Because the chosen portion of I-94 was analyzed at a date significantly past construction completion, the parameters required for RealCost's LCCA required too many assumptions to be considered accurate, and were therefore omitted. Instead, the LCCA tool built into the PaLATE program was used to evaluate the economic value of recycled material. PaLATE's LCCA focuses on the cost of processes and materials rather than user costs. Therefore, the analysis can be conducted post construction if the prices of the processes and materials are known.

\section{A.3.2 PaLATE LCA and LCCA}

PaLATE is a spreadsheet LCA and LCCA program designed for the RMRC by the Consortium on Green Design and Manufacturing from the University of California, Berkeley (Horvath, 2007; Nathman, 2008). PaLATE assesses the environmental and economic effects of pavement and road construction. Users input the initial design, initial construction, maintenance, equipment use, and cost for a roadway. PaLATE then determines the environmental impacts based on material production, material transportation, and processes (equipment). Environmental 
outputs include:

- Energy consumption (GJ)

- Water consumption $(\mathrm{kg})$

- Carbon dioxide $\left(\mathrm{CO}_{2}\right)$ emissions $(\mathrm{Mg})$

- Nitrous oxide $\left(\mathrm{NO}_{\mathrm{x}}\right)$ emissions $(\mathrm{kg})$

- Particulate matter $10\left(\mathrm{PM}_{10}\right)$ emissions $(\mathrm{kg})$

- Sulfur dioxide $\left(\mathrm{SO}_{2}\right)$ emissions $(\mathrm{kg})$

- Carbon monoxide (CO) emissions (kg)

- Leachate information, including an analysis of mercury, lead, and Resource Conservation and Recovery Act (RCRA) hazardous waste generated

The LCCA portion of PaLATE allows the user to input the cost of processes and materials for the initial construction and maintenance over the roadway's lifetime. It then calculates the net present value and annualized cost of the initial construction, maintenance, and total cost. Similar to $\mathrm{BE}^{2} \mathrm{ST}$-In-Highways, PaLATE allows the user to conduct a cost comparison of a base (Virgin) and alternative (Recycled) design scenario. LCCA outlines cost comparisons among design alternatives, denoting economic benefits (FHWA, 1998). These are of particular value to DOTs as they can improve the agencies' investment decisions in terms of when and where to reconstruct. This LCCA focuses on agency costs, such as the cost of materials and processes. Construction quantities and costs are directly related to the initial design and subsequent rehabilitation strategy (FHWA, 1998). Unit prices used in the cost analysis and the sourcing information is provided in Table A5. Costs were provided by material supplies (We Energies), state agencies, and WisDOT. State agencies include the Wisconsin Concrete Pavement Association (WAPA) and the Wisconsin Asphalt Pavement Association (WAPA). WisDOT provided an state-wide average unit price list for all bid items (WisDOT, 2015), as well as prices for specific materials used for this project, mainly virgin material. 
Table A5. Material unit costs for I-94 LCCA analysis

\begin{tabular}{l|ccc}
\hline Category & Material & Unit Cost & Source \\
\hline \multirow{2}{*}{ Concrete } & Fly ash & $\$ 55.00 /$ ton & We Energies \\
& Cement & $\$ 105.00 /$ ton & WCPA \\
\hline \multirow{3}{*}{ Base Aggregate } & RAP onsite & $\$ 6.00 /$ ton & WisDOT \\
& RCA onsite & $\$ 5.50 /$ ton & WCPA \\
& Virgin base aggregate & $\$ 10.00 /$ ton & WisDOT \\
\hline \multirow{2}{*}{ HMA } & Mix with RAP & $\$ 49.47 /$ ton & WAPA \\
& Mix without RAP & $\$ 42.75 /$ ton & WAPA \\
\hline \multirow{2}{*}{ Embankment/Fill } & Bottom ash & $\$ 4 / \mathrm{CY}$ & WisDOT \\
& Foundry sand & $\$ 4 / \mathrm{CY}$ & WisDOT \\
& Virgin granular fill & $\$ 6.50 / \mathrm{CY}$ & WisDOT \\
\hline
\end{tabular}

Based on the estimated cement and fly ash costs in Table A5, savings of $\$ 50$ per ton of fly ash replacement are expected. Prices for bottom ash and virgin fill led to savings of $\$ 2.50$ per CY of bottom ash replacement. It was assumed that the replacement of foundry sand for virgin sand fill would yield similar savings as bottom ash. For base aggregates, the estimated savings are $\$ 4.00$ per ton of RAP and $\$ 4.50$ per ton of RCA replacement. While no RAP was used in the initial construction HMA layer, it was assumed that RAP would be included in an HMA overlay during rehabilitation. WAPA estimates $\$ 5.72$ per ton of mix that uses RAP as asphalt cement or aggregate.

\section{A.3.3 SimaPro}

SimaPro is one of the leading software program for LCA studies and is commonly employed worldwide (Herrmann \& Moltesen, 2015; PRe Sustainability, 2016). It is a professional LCA software used to collect, analyze, and monitor the sustainability performance data of products and services. SimaPro follows the traditional four-step LCA method as described by ISO standard 14040 (ISO, 2008). These steps include: (1) goal and scope definition, (2) inventory analysis, (3) impact assessment, and (4) interpretation. The goal and scope definition is mainly for the benefit of the user. Users can input their project's goal, reason, commissioner, functional unit, reference flows, and more. However, these inputs are not explicitly used in any of the 
software's calculations.

The inventory analysis includes a compilation, tabulation, and preliminary analysis of all environmental exchanges of the materials and processes of the final product, in this case the final product is I-94 Highway (Rebitzer et al., 2004). Perhaps the most useful aspect of SimaPro is its built-in inventory of many products and processes from a collection of life cycle inventory databases. The inputs (raw material, energy, etc.) and outputs (waste, emissions, etc.) for some common road construction processes such as concrete material production, asphaltic material production, rock crushing, stone quarrying, and transportation are readily available in SimaPro. However, for a few of the recycled materials specific to roads are not included (e.g. RAP and bottom ash), SimaPro allows user to create new processes for these materials. To simulate the environmental impact for the milling and crushing of RAP material, the impact from the hypothetical amount of diesel fuel used in these processes was determined. This is the same assessment methodology used in some other LCAs, namely PaLATE (Horvath, 2007). Since bottom ash is a by-product, it was assumed no environmental impact for its production, but impact due to the materials' transportation was evaluated. Concrete recycling was present in SimaPro's inventory and also included data for the the impact from concrete demolition. An additional process of crushing was added to the RCA inventory to simulate crushing the demolished concrete into desired aggregate sizes. Also included in SimaPro's inventory was cement with fly ash replacement.

Certain road construction processes were also not included in SimaPro's built in inventory. These included processes for paving the road, compacting and placing base course, combining PCC mix materials, and combining HMA mix materials. However, based on previous LCAs conducted by the RMRC, it was concluded that construction processes had a relatively low relative environmental impact between recycled materials and virgin materials as compared to the construction materials production and transportation. Therefore, the impacts from these processes were ignored in the SimaPro analysis. With these parameters, a complete SimaPro 
inventory was created for impact assessment. This inventory is included in Appendix C.

To evaluate the environmental impact of the highway project, a life cycle impact assessment method was chosen. The Tool for the Reduction and Assessment of Chemical and other environmental Impacts (TRACI) was selected to analyze I-94 because it was developed by the U.S. EPA specifically for North America using input parameters consistent with U.S. locations (EarthShift, 2016). TRACl's impact categories constructed to represent potential effects in the U.S. Impact categories in TRACI include:

- Ozone depletion (kg chloroflurocarbon (CFC) ${ }^{-11}$ equivalents (eq))

- Global warming $\left(\mathrm{kg} \mathrm{CO}_{2}\right.$ eq)

- $\quad$ Smog (kg ozone $\left(\mathrm{O}_{3}\right)$ eq)

- Acidification ( $\mathrm{kg} \mathrm{SO}_{2}$ eq)

- Eutrophication (kg nitrogen $(\mathrm{N})$ eq)

- Carcinogenics $\left(\mathrm{CTUh}{ }^{3}\right)$

- Non-carcinogenics (CTUh)

- Respiratory effects (kg in particulate matter $2.5\left(\mathrm{PM}_{2.5}\right)$ eq)

- Ecotoxicity $\left(\mathrm{CTUe}{ }^{4}\right)$

- Fossil fuel depletion (MJ surplus)

One objective of this study was to compare the difference in impacts predicted by PaLATE versus SimaPro. Unfortunately, none of the TRACI impacts can be directly compared to PaLATE's impacts. However, additional SimaPro analyses can be conducted for single LCA issues, which includes a broad range of categories such as specific gas emissions, toxicity emissions, environmental footprints, energy demands, and more. There are some single-issue

\footnotetext{
${ }^{3}$ CTUh: comparative toxic unit for human toxicity impacts. The characterization factor for human toxicity impacts has units of disease cases per $\mathrm{kg}$ emissions (USEtox®, 2016).

${ }^{4}$ CTUe: comparative toxic unit for aquatic ecotoxicity impacts. The characterization factor for aquatic ecotoxicity impacts has units of the potential affected fraction of species in cubic meter-days per $\mathrm{kg}$ emissions (USEtox®, 2016).
} 
impact categories similar to PaLATE's, including energy (GJ), $\mathrm{CO}_{2}(\mathrm{~kg}), \mathrm{NO}_{x}(\mathrm{~kg}), \mathrm{SO}_{2}(\mathrm{~kg}), \mathrm{CO}$ $(\mathrm{kg})$ and lead $(\mathrm{kg})$. In addition, because construction processes were ignored in the SimaPro analysis, they are also removed from the PaLATE analysis when comparing the two LCA tools' impact predictions.

\section{A.3.4 WisDOT Analysis for Service Life and Rehabilitation}

Although $\mathrm{BE}^{2} \mathrm{ST}$-In-Highways incorporates the MEPDG program for an evaluation of a highway's lifetime, WisDOT provided its own recommendations for the lifetime and maintenance schedule of the reconstructed I-94 corridor based upon historical pavement performance. WisDOT used the WisPAVE design program to predict the cost of the roadway prior to construction (WisDOT, 2014b). WisPAVE is WisDOT's pavement design and LCCA software program for pavement type selection. Policies and procedures for pavement structural design and pavement selection type for WisPAVE are provided by Chapter 14 of WisDOT's Facilities Development manual. For the I-94 analysis, WisDOT compared six alternative designs and the resulting maintenance requirement. The chosen PCC pavement, with stabilizing asphalt base alternative, was evaluated for a lifetime of fifty years.

The I-94 reconstruction maintenance schedule is shown in Table A6. The initial construction design has an expected lifetime of 25 years, over which maintenance of the PCC pavement will be evaluated at year 10 and 15, with repairs as needed. In year 25, a more significant rehabilitation of the PCC pavement will be conducted via repair and grind. Diamond grinding is a concrete pavement restoration technique that corrects irregularities such as faulting and roughness on concrete pavements (FHWA, 2014a). It can be used in conjunction with other rehabilitation techniques such as joint sealing, slab stabilization, partial-depth repairs, full-depth repairs, and load transfer restoration as needed. This rehabilitation has a service life of eight years. In year 33, I-94 will undergo another rehabilitation, including repairs as needed. After PCC repairs are complete, the roadway will be overlain with four inches of hot mix asphalt (HMA), 
providing a service life of 15 years. In year 48, I-94 will undergo its last rehabilitation before the end of the analysis period. For this rehabilitation, the year-33 HMA overlay will be milled away, the PCC repaired, and the road will be covered by another four inches of HMA. This should provide 15 more years of service life for the roadway.

In this analysis, the Recycled and Virgin designs were conservatively assumed to have the same lifetime, with a 1-to-1 replacement of recycled with virgin material for the Virgin design. In reality, a roadway may be designed differently or may have varying lifetimes depending on the use of recycled materials. Rehabilitation materials were considered for the LCA because of the anticipated use of recycled materials in future repairs and overlays. The materials and process required for I-94's rehabilitations were considered in the LCA using the PaLATE software. However, maintenance was not included in the LCCA cost savings. According to WisDOT personnel, the variability in material availability, use specifications, and costs are too great to allow for an accurate prediction of cost savings from future rehabilitation. Instead, cost savings for the initial construction alone are analyzed.

Table A6. Maintenance schedule for I-94 design

\begin{tabular}{cccc}
\hline Year & Type of Work & Activity & Service Life \\
\hline 0 & Initial Construction & -- & 25 \\
25 & $1^{\text {st }}$ Rehabilitation & Repair \& Grind & 8 \\
33 & $2^{\text {nd }}$ Rehabilitation & Repair \& Overlay & 15 \\
48 & $3^{\text {rd }}$ Rehabilitation & Mill, Repair \& Overlay & 15 \\
\hline
\end{tabular}

\section{A.3.5 Data Input Assumptions}

Significant assumptions were required to perform the LCA and LCCA of the Recycled and Virgin designs. The assumptions are as follows:

- The Virgin design dimensions were assumed exactly the same as the Recycled design's dimensions. Virgin aggregate or other traditional material was substituted in place of recycled material in the Virgin design. In reality, different dimensions or quantities of virgin material may have been required based on the actual properties of the materials involved. 
- The quantities of materials used in each layer were proportional to the volume of the layer as calculated from the design plans. Recycled purchased quantities for the reconstruction could not be obtained.

- Ranges of percentages of recycled material used in the base aggregate and subbase layers were provided. The average of these ranges was used to calculate the volume of material in these layers

- The dimensions of roadway fill and embankment could not be accurately quantified from roadway plans. However, the total volume of embankment material was provided. This quantity was used in the analysis.

- The amount of individual material within the surface PCC pavement was calculated from the proportions in the PCC mix design used by the pavement contractor.

- No recycled materials were included in the HMA mix for the asphaltic base. Therefore, it was assumed there would be no difference in the asphalt base's environmental impact between the Recycled and Virgin designs.

- Although the lifetime of the roadway may differ between the Recycled and Virgin design, the lifetime and maintenance schedule predicted by WisDOT was used for both designs.

- The material required for maintenance procedures was assumed to have the same designs and mixes as the initial reconstruction. The exception is for the HMA overlays, which were assumed to have an average 16\% RAP replacement in HMA mixes for the state of Wisconsin (personal communication, Brandon Strand of WAPA, Oct. 5, 2015).

- If the designer did not provide a transportation method, it was assumed that the material was transported via dump truck.

- The transportation distances were based on project-specific data. Transportation distances were calculated from the material suppliers (quarries, pavement mix plants, etc.) to the I-94 reconstruction site. 
- The impact from RAP production was estimated based on the amount of diesel fuel needed to power the equipment to mill the asphalt pavement as well as the impact of rock crushing, which was present in SimaPro's inventory. It was also assumed that bottom ash would have no production impacts.

- The life cycle costs were estimated from average costs of raw materials provided by suppliers, WisDOT, Wisconsin Concrete Pavement Association (WCPA), and Wisconsin Asphalt Pavement Association (WAPA). Economic transportation costs were not available and, therefore, not used in this analysis.

\section{A.4. Results}

Results of this analysis include environmental and economic impacts of the I-94 reconstruction. The PaLATE analysis evaluated for environmental impacts, $\mathrm{BE}^{2} \mathrm{ST}$-In-Highways presented improvements collectively, and the SimaPro analysis provided comparative impacts. The life expectancies and rehabilitation quantities from WisDOT and the environmental results from PaLATE were input to the $\mathrm{BE}^{2} \mathrm{ST}$-In-Highways to collectively assess and present the results. Also included in $\mathrm{BE}^{2} \mathrm{ST}$-In-Highways assessment is an evaluation of the ratios of recycled material to virgin material use. The TRACI results from SimaPro were used to assess common environmental impacts, and single issue impacts were compared to PaLATE results. The following sections discuss the results from each source.

\section{A.4.2 PaLATE Environmental Impacts}

The PaLATE LCA total results are listed in Table A7. The quantities of these parameters were calculated during two portions of a road's lifetime: its initial construction, and the maintenance performed for the remainder of its life. In Table A7, the impacts are divided into three categories: materials production, materials transportation, and processes (equipment). The sum of these categories for both the initial and maintenance construction equal the total impact for 
both the Recycled and Virgin designs.

Table A7. Environmental results of PaLATE LCA

\begin{tabular}{|c|c|c|c|c|c|c|}
\hline & & Energy (GJ) & Water (kg) & $\mathrm{CO}_{2}(\mathrm{Mg})$ & $\mathrm{NO}_{\mathrm{x}}(\mathbf{k g})$ & $\mathrm{PM}_{10}(\mathbf{k g})$ \\
\hline \multirow{4}{*}{ 㕿 } & Production & 161,000 & 47,300 & 10,500 & 83,800 & 83,400 \\
\hline & Transportation & 31,700 & 5,400 & 2,370 & 43,300 & 7,340 \\
\hline & Processes & 2,370 & 230 & 178 & 3,850 & 294 \\
\hline & Total & 195,000 & 52,900 & 13,100 & 131,000 & 91,100 \\
\hline \multirow{4}{*}{$\begin{array}{l}\mathbf{D} \\
\frac{\mathbb{d}}{0} \\
\mathbb{d} \\
\mathbb{d} \\
\mathbb{x}\end{array}$} & Production & 114,000 & 38,500 & 7,250 & 76,200 & 39,300 \\
\hline & Transportation & 6,090 & 1,040 & 455 & 24,500 & 4,810 \\
\hline & Processes & 2,940 & 285 & 220 & 4,760 & 347 \\
\hline & Total & 124,000 & 39,800 & 7,930 & 105,000 & 44,500 \\
\hline & & $\mathrm{SO}_{2}(\mathrm{~kg})$ & $\mathrm{CO}(\mathrm{kg})$ & $\mathrm{Hg}(\mathrm{g})$ & $\mathrm{Pb}(\mathrm{g})$ & $\begin{array}{l}\text { RCRA Hazardous } \\
\text { Waste }(\mathrm{kg})\end{array}$ \\
\hline \multirow{4}{*}{ 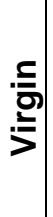 } & Production & 657,000 & 42,300 & 138 & 9,470 & 579,000 \\
\hline & Transportation & 2,210 & 3,070 & 22.9 & 1,070 & 228,000 \\
\hline & Processes & 0.00 & 829 & 1.58 & 0.00 & 15,80 \\
\hline & Total & 659,000 & 46,200 & 163 & 10,500 & 824,000 \\
\hline \multirow{4}{*}{ 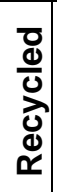 } & Production & 649,000 & 37,400 & 135 & 8,190 & 541,000 \\
\hline & Transportation & 1,470 & 2,040 & 4.40 & 205 & 43,900 \\
\hline & Processes & 315 & 1,030 & 1.00 & 92.6 & 19,900 \\
\hline & Total & 651,000 & 40,400 & 141 & 8,490 & 605,000 \\
\hline
\end{tabular}

\section{A.4.3 BE'2ST-In-Highways Environmental Impacts}

The results of the $\mathrm{BE}^{2} \mathrm{ST}$-In-Highways analysis are summarized in Table A8. The criteria for the Recycled and Virgin from PaLATE include energy use, GWP, water consumption, and hazardous waste. The SCC is based on a unit SCC of $69 \$ / \mathrm{MJ}$ of $\mathrm{CO}_{2}$. The percent improved is calculated by the percent increase or decrease in the results of constructing the Recycled as compared to the Virgin design. For most criteria, a decrease in environmental results is desired for the Recycled. The exceptions are the recycling criteria. For these, an increase in recycled material for the Recycled design is desirable. The recycling improvements are based on the percentage of recycled material used for the reconstruction. The in situ recycling refers to the percent of in situ recycled material only. In the Virgin design, no recycled materials are used. 
Table A8. Results of BE²ST-In-Highways

\begin{tabular}{lcccc}
\hline Environmental Criteria & Virgin & Recycled & Savings & $\%$ Reduction \\
\hline Energy Use (GJ) & 195,000 & 124,000 & 71,000 & $37 \%$ \\
Water Consumption (kg) & 52,900 & 39,800 & 13,100 & $25 \%$ \\
GWP (Mg) & 13,100 & 7,930 & 5,170 & $39 \%$ \\
SCC & $\$ 806,000$ & $\$ 489,000$ & $\$ 317,000$ & $39 \%$ \\
Hazardous Waste (kg) & 824,000 & 604,000 & 220,000 & $27 \%$ \\
\hline Recycling & Virgin & Recycled & $\%$ Material Recycled \\
\hline In Situ Recycling (CY) & 0 & 24,960 & \multicolumn{2}{c}{$7 \%$} \\
Total Recycling (CY) & 0 & 202,200 & \multicolumn{3}{c}{$57 \%$} \\
\hline
\end{tabular}

\section{A.4.4 SimaPro Environmental Impacts}

The TRACI results from SimaPro for I-94 are listed in Table A9. As discussed in Section A.3.3, SimaPro was used to analyze only the material production and transportation. By this analysis method, SimaPro is the most useful for calculating the difference in the two designs' impacts and percent reduction. Based on these results, there are reductions in all TRACI impact categories due to the use of recycled materials.

Table A9. SimaPro TRACI results of I-94 reconstruction

\begin{tabular}{|c|c|c|c|c|}
\hline Impact Category & Recycled & Virgin & Difference & \% Reduction \\
\hline Ozone depletion ( $\mathrm{kg} \mathrm{CFC}^{-11} \mathrm{eq}$ ) & 1.64 & 1.95 & 0.310 & $16 \%$ \\
\hline Global warming $\left(\mathrm{Mg} \mathrm{CO}_{2} \mathrm{eq}\right)$ & 8,310 & 13,700 & 5,390 & $39 \%$ \\
\hline $\operatorname{Smog}\left(\mathrm{kg} \mathrm{O}_{3}\right.$ eq $)$ & 627,000 & $1,125,000$ & 498,000 & $44 \%$ \\
\hline Acidification $\left(\mathrm{kg} \mathrm{SO}_{2}\right.$ eq) & 35,700 & 65,000 & 293,300 & $45 \%$ \\
\hline Eutrophication (kg N eq) & 14,100 & 31,600 & 17,500 & $56 \%$ \\
\hline Carcinogenics (CTUh) & 0.193 & 0.461 & 0.268 & $58 \%$ \\
\hline Non carcinogenics (CTUh) & 0.955 & 1.96 & 1.01 & $51 \%$ \\
\hline Respiratory effects $\left(\mathrm{kg} \mathrm{PM}_{2.5} \mathrm{eq}\right)$ & 3,680 & 6,080 & 2,400 & $39 \%$ \\
\hline Ecotoxicity $\left(10^{3} \mathrm{CTUe}\right)$ & 22,900 & 51,800 & 28,900 & $56 \%$ \\
\hline Fossil fuel depletion (GJ surplus) & 17,600 & 23,100 & 5,500 & $24 \%$ \\
\hline
\end{tabular}

In addition to the TRACI results, SimaPro was also used to find certain single issue impacts comparable to PaLATE results, including energy, $\mathrm{CO}_{2}$ emissions, nitrous oxides, sulfur dioxide, carbon monoxide, lead. These results are listed in Table A10. Since only the material 
production and transportation were considered in the SimaPro assessment, only material production and transportation impacts were compared to the PaLATE results. Both tools predict reductions in all common categories, but PaLATE predicts slightly higher reductions in energy consumption and $\mathrm{CO} 2$ emissions. In contrast, SimaPro predicts larger reductions in nitrous oxides, sulpher dioxide, carbon monoxide, and lead. Although the two softwares predict different absolute impacts for I-94, all comparable results are within an order of magnitude of each other. Similarities between the two assessments' results validate the predicted environmental impact reductions for the reconstruction.

Table A10. Comparison of PaLATE and SimaPro results

\begin{tabular}{|c|c|c|c|c|c|c|c|}
\hline & & Energy (GJ) & $\mathrm{CO} 2(\mathrm{Mg})$ & Nox (kg) & SO2 (kg) & $\mathrm{CO}(\mathrm{kg})$ & Lead $(\mathrm{g}$ \\
\hline \multirow{4}{*}{ 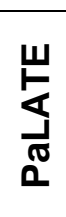 } & Recycled & 78,400 & 5,300 & 59,000 & 29,400 & 17,800 & 4,630 \\
\hline & Virgin & 150,000 & 10,400 & 85,000 & 37,700 & 23,700 & 6,760 \\
\hline & Savings & 71,600 & 5,100 & 26,000 & 8,300 & 5,900 & 2,130 \\
\hline & Reduction & $48 \%$ & $49 \%$ & $31 \%$ & $22 \%$ & $25 \%$ & $32 \%$ \\
\hline \multirow{4}{*}{ 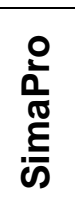 } & Recycled & 146,000 & 8,010 & 25,100 & 15,700 & 17,000 & 2,140 \\
\hline & Virgin & 209,000 & 13,100 & 45,100 & 28,400 & 38,000 & 4,600 \\
\hline & Savings & 63,000 & 5,090 & 20,000 & 12,700 & 21,000 & 2,460 \\
\hline & Reduction & $30 \%$ & $39 \%$ & $44 \%$ & $45 \%$ & $55 \%$ & $53 \%$ \\
\hline
\end{tabular}

\section{A.4.5 LCCA Results}

Cost savings are calculated from the unit price data detailed in Section A.3.2 and summarized in Table A11. Any savings for future rehabilitation procedures were brought to present value using a discount rate of $3 \%$. Savings during the initial construction are estimated to be $\$ 771,000$, approximately a $40 \%$ reduction in cost. The majority of these savings are from the use of bottom ash and foundry sand in the embankment and fill, which resulted in savings of over $\$ 440,000$. The use of recycled materials in base course and concrete pavement saved over $\$ 200,000$ and $\$ 130,000$, respectively. Assuming an average RAP replacement of $16 \%$ in the HMA overlays during rehabilitation, maintenance savings would be approximately $\$ 50,700$ at present 
value. This leads to a total savings over the lifetime of the road of $\$ 820,700$, or a $35 \%$ reduction in overall costs. For the $1.6 \mathrm{~km}$ (1-mi), eight-lane stretch of $\mathrm{I}-94$, this is equivalent to over $\$ 100,000$ per lane-mile.

Table A11. Summary of life cycle cost savings

\begin{tabular}{lc}
\hline Material Category & Savings \\
\hline Initial Construction & -- \\
Fly ash for cement & $\$ 131,000$ \\
RAP/RCA for virgin aggregate & $\$ 200,000$ \\
Bottom ash/foundry sand for virgin embankment & $\$ 440,000$ \\
Total Initial Construction & $\$ 771,000$ \\
\hline Maintenance (at present value) & $\$ 50,700$ \\
\hline Grand Total & $\$ 820,700$ \\
\hline
\end{tabular}

\section{A.5. Discussion}

The I-94 case study provided an opportunity to analyze data collection methodology for highway life cycle analyses. The majority of the data for the I-94 analysis was provided postconstruction. Post-construction data collection for I-94 led to issues including over-generalization of mix designs and sourcing, averaging market prices for materials, and inability for real-time data collection. Because real-time data was not collected, estimates of material quantities were based on road plan dimensions rather than actual amounts of materials used. These case studies also demonstrated recycled material use and tracking in rural construction conditions. Rural construction is advantageous for recycling existing roadways due to adequate storage room for RAP and RCA onsite, eliminating additional offsite transportation.

As aforementioned, the lifetime and maintenance results from the WisDOT analysis were used for both the Virgin and Recycled designs. Previous research has shown that RCA is a stiffer material than typical aggregate (Bozyurt et al., 2012), thus a longer service life can be expected for the Recycled design. Furthermore, longer lifetime is most evident when fly ash is used to stabilize the base course layers. In the Recycled design, recycled asphalt and concrete were used 
in the base course, but the base layers were not stabilized with any cementitious material, such as fly ash. Previous studies have shown that fly ash-stabilized base course can extend the service life of a road, thereby reducing the frequency and intensity of rehabilitation measures (Lee et al., 2013; Wen et al., 2011)

In the PaLATE results, the construction processes for both the Recycled and Virgin scenarios yield approximately the same impacts. However, there are significant differences between the Recycled and Virgin in terms of material productions. Many of the recycled materials are byproducts of industry, such as fly ash. As byproducts, these materials require zero energy and water consumption, and emit no GHGs. Conversely, virgin cementitious material requires extensive energy as well as GHG emissions and water consumption for its production. Milling and grinding to produce RAP and RAS, respectively, from existing roadways produces far less environmental impact than the production of virgin aggregate.

The environmental impacts of the Recycled versus the Virgin are further compared in Figure A3. The percent change in impact due to use of the Recycled rather than Virgin design is calculated by the following equation:

$$
\left(\frac{\text { Impact }_{\text {Virgin }}-\text { Impact }_{\text {Recycled }}}{\text { Impact }_{\text {Virgin }}}\right) \times 100=\text { Change (\%) }
$$

In most categories, the Recycled reduces environmental impacts. The Recycled largely differs from the Virgin in terms of energy, $\mathrm{CO}_{2}, \mathrm{PM}_{10}$, and RCRA hazardous waste generated. It is important for the public to understand that using recycled materials can improve air quality and reduce waste in addition to more commonly referenced environmental issues such as energy and GHG reduction. 


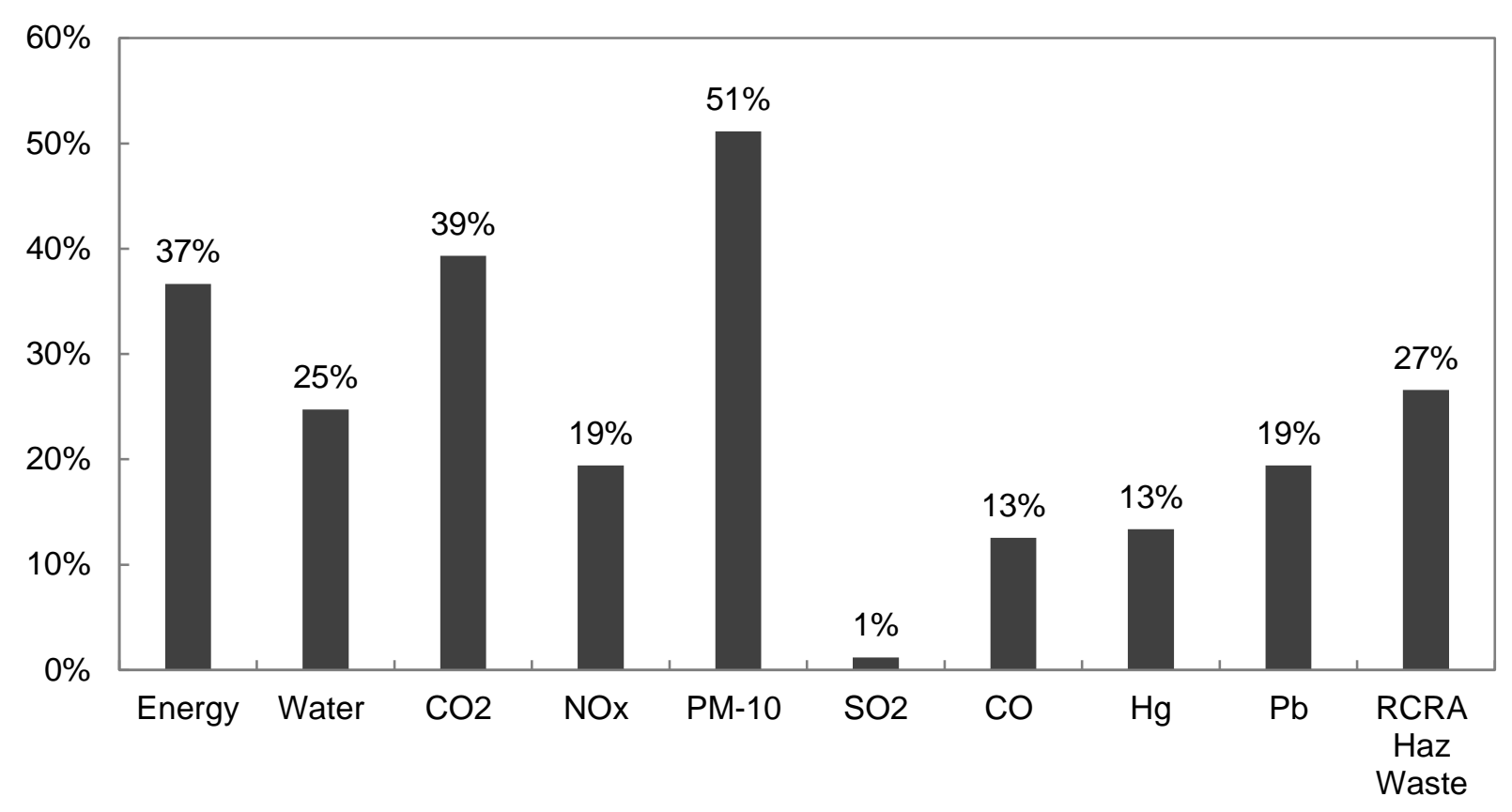

Figure A3. Environmental impact reductions due to the use of recycled materials from PaLATE analysis

$\mathrm{BE}^{2} \mathrm{ST}$-In-Highways is an advantageous tool because it draws from multiple databases and tools to calculate the environmental and economic benefits of recycled materials. Because the tool was created for the RMRC, it addresses the impacts requested by member state departments of transportation and other stakeholders. For all criteria in the $\mathrm{BE}^{2} \mathrm{ST}-\mathrm{In}$-Highways analysis, the Recycled design improves environmental impacts. This conclusion is further demonstrated by Figure A4, where the amoeba graph shows the percent improved in each criterion by using the Recycled as compared to the Virgin. Positive percent change indicates that the Recycled reduces or improves the environmental impact. The greatest percent improved is total recycling. This is, in large, due to the extensive use of bottom ash for embankment and fill material. Approximately $70 \%$ of the embankment was bottom ash. Other contributing recycled materials include foundry sand, fly ash, RAP, and RAS. Only RAP and RAS contributed to the in situ recycled material, and therefore the in situ recycling improved by a smaller percentage than total recycling. Although the bottom ash was not recycled on site, it was transported from a coal 
power plant landfill only $16 \mathrm{~km}(10 \mathrm{mi})$ from the construction site and therefore had low transportation effects.

The second largest improvement is in GWP and SCC, both by 39\%. This means that the Recycled design reduced carbon emissions for the reconstruction project by over one third. Since the SCC is calculated directly from the amount of $\mathrm{CO}_{2}$ emissions, or GWP, they are improved by the same percent. The next largest percent improved is energy use at $37 \%$, followed by hazardous waste at $36 \%$. By using recycled material, WisDOT cut the projects energy use and waste by over a third. The second smallest percent improvement following in situ recycling is water consumption at 25\%. Figure $A 3$ and Figure A4 which summarize the PaLATE and $B E^{2} S T$-In-Highways results support the conclusion that the Recycled is a more sustainable design then the Virgin.

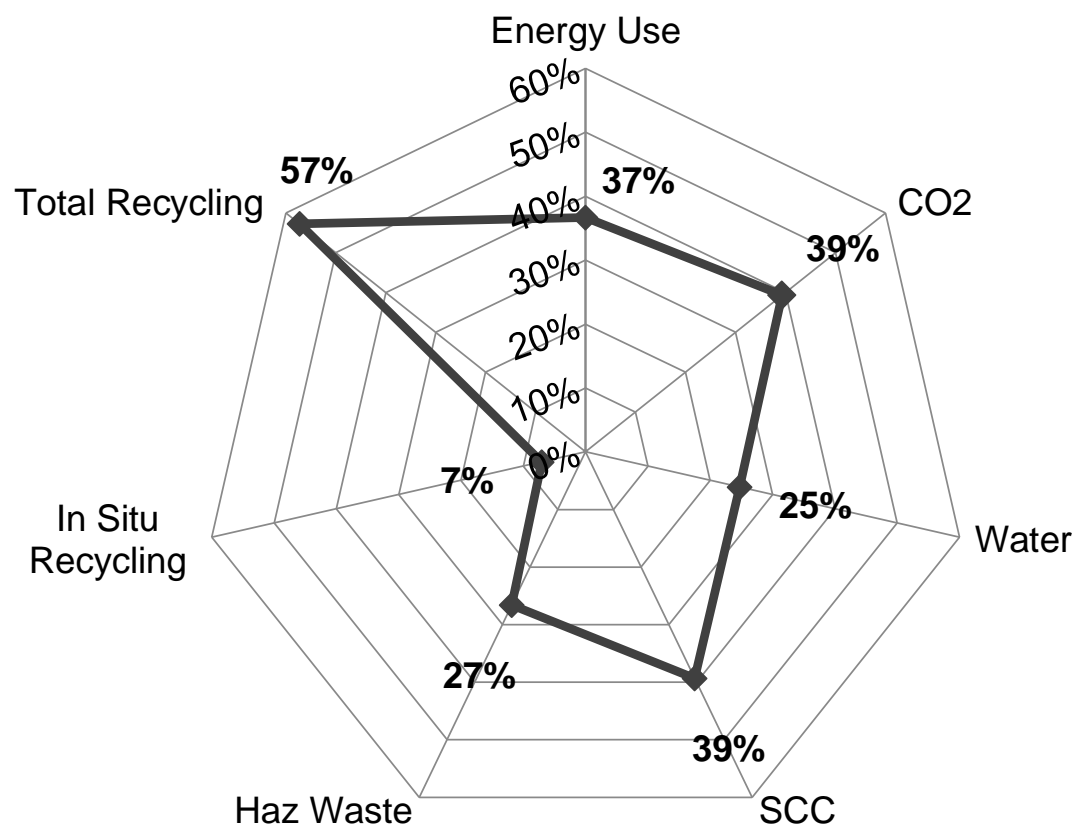

Figure A4. Visualization of improvements in environmental impact and recycling from BE 2 ST-InHighways analysis

SimaPro findings support the PaALTE and BE ${ }^{2}$ ST-In-Highways conclusion that the use of recycled material reduces environmental impact. The greatest reductions are seen in the TRACI 
results for carcinogens, eutrophication, ecotoxicity, and non-carcinogens, all of which reduce impacts by half. In the Recycled design, impacts in these four categories primarily occur during cement production, followed by gravel crushing quarry operations, and all material transportation. The majority of gravel crushing-related impacts stem from the production of aggregate for the concrete mix, as well as virgin granular base aggregate. In the Virgin design, the four impact categories are dominated by gravel crushing, then followed by cement production. While the Virgin design uses the same amount of virgin aggregate in the pavement mixes, there is a significant increase in virgin aggregates in the base and subbase. The substitution of recycled pavement in the Recycled design's subbase is contributing much of the reductions in carcinogens, eutrophication, ecotoxicity, and non-carcinogens.

Since state DOTs often look at GHG emissions and energy consumption when considering the environmental impact of roads, the SimaPro categories for GWP and fossil fuel depletion in the TRACI analysis (Table A9), and cumulative energy demand in the single issue analyses (Table A10) were evaluated. In all three categories, there are reductions from using recycled materials. The GWP reduction (39\%) largely stems from the use of RCA and RAP in the base and subbase layers, followed by the substitution of fly ash for cement in the concrete pavement. These reductions are very similar to the trends seen in carcinogens, eutrophication, ecotoxicity, and non-carcinogens. The TRACI fossil fuel depletion category and single issue energy demand category are closely related because the majority of the project's energy demand stems from the use of fossil fuels. In both the Recycled and Virgin design, the majority of fossil fuel-generated energy use occurs during asphalt cement production. Although a relatively small quantity of this material was used in the road, its production is so energy intensive that it dominates these two impact categories. However, because no recycled materials were substituted for the asphalt binder in the HMA mix as reported by the highway's designers, the impacts for the Virgin and Recycled designs' use of binder are the same. Other energy reductions are seen mainly from the substitution of fly ash for cement and recycled pavements for base 
aggregate.

\section{A.6. Conclusion}

Based on the BE ${ }^{2}$ ST-In-Highways and SimaPro analyses of the I-94 mainline reconstruction, the use of recycled materials reduces the environmental impact of the highway over its lifetime. The results of the $\mathrm{BE}^{2} \mathrm{ST}-\mathrm{In}$-Highways analysis demonstrate that in a comparison of a Virgin highway design using no recycled material and a Recycled design using recycled material, the Recycled improved the environmental impact of the roadway in all categories. The energy usage, GWP, water consumption, social carbon cost, and hazardous waste generated decreased by $43 \%, 35 \%, 22 \%, 35 \%$, and $33 \%$, respectively. The in situ and total recycled material comprised $7 \%$ and $57 \%$, respectively, of all roadway materials over the project's predicted lifetime. SimaPro found that in common impact categories designed by the TRACI assessment method, the use of recycled materials reduced environmental impacts by $16-58 \%$. SimaPro was also used to analyze single issues similar to PaLATE's categories, and demonstrated similar impact reduction predictions in most categories including energy and $\mathrm{CO}_{2}$ emissions. Finally, LCCA techniques were used to predict savings of over $\$ 100,000$ per lane-mile of the project.

In this analysis, the Recycled and Virgin designs were conservatively assumed to have the same lifetime, with a 1-to-1 replacement of recycled with virgin material for the Virgin design. In reality, a roadway may be designed differently or may have varying lifetimes depending on the use of recycled materials. To improve the lifetime and thus environmental impact of I-94, cementitious recycled materials, such as fly ash, could have been used to stabilize the base course. Additionally, the majority of this analysis was conducted after the completion of the I-94 reconstruction. Materials were not tracked during construction. Therefore, many assumptions were made regarding the quantities of materials used, specifically, the assumption that the volume of material brought to and used on the construction site is equal to the volume of the roadway as 
calculated by its dimensions. In future case studies, it is recommended that material usage is tracked and quantified during construction or soon after construction is complete.

This case study further demonstrates the environmental and economic benefits of using recycled materials in road construction. The reduction of the negative environmental impacts during highway construction improves the sustainability of the roadway. State DOTs, including WisDOT, have made it a priority to recycle available materials. This study confirms the practice and justifies the continued use of recycled materials. 


\section{Appendix B: Development of Environmental Impact Tool to Assess the Sustainable Management of Pavements in Poor Condition}

\section{B.1. Introduction}

In 2011, the Minnesota Department of Transportation (MnDOT) began an investigation of developing a comprehensive method for evaluating treatment options for extending the service life of pavements in poor condition until they can be rehabilitated (Adams et. al. 2014). The project was tasked with integrating a selection methodology into a spreadsheet-based decision tool with two components: 1) Identification of available treatments and definition of expected service life based on existing pavement distress levels and operational characteristics, 2) A summary of selection factors. Selection actors considered in the overall analysis include: agency cost, agency benefit, user costs during construction, safety benefits, and environmental impacts. The Recycled Materials Resource Center (RMRC) was tasked with performing the environmental impact analysis of nine treatment strategies for extending the life of pavements in poor condition. This paper explores the methods and results of the environmental analysis and recommends how their impacts can be incorporated in the decision-making tool.

\section{B.1.1 Background}

MnDOT maintains over 12,000 miles of statehighways that serve, on an average day, over 90 million vehicles (MnDOT, 2014). Pavement deterioration is prevalent in the state, and tight budgets and dwindling revenue hinder transportation agencies from fully rehabilitating pavements in poor conditions (Adams et al., 2014). Consequently, MnDOT sought a research project to determine economical and practical "stop-gap" treatment measures to extend the lifetime their roadways until more affordable solutions are feasible. It was stipulated that treatments would be applied to pavement in poor conditions as determined by a ride quality index, which is based on 
measured pavement profiles and calculated international roughness index. A spreadsheet-based tool for selecting and analyzing treatment strategies was required. It was intended that the tool will analyze the options based on effectiveness by providing estimates of project-level equivalent annual agency and user costs and environmental impact. Agency costs include the expenditures to build and maintain roadway facilities (DeCorla-Souza et al., 1997). A user cost is defined as the additional costs borne by motorists and the community at-large because of work zone activity (FHWA, 2011). These costs, combined with environmental impact assessments, lead to considerations of economic and environmental sustainability in maintaining a healthy road system.

The general work plan for the entire project is as follows:

Task 1: Characterize the Pavements in Poor Conditions - Researchers prepared a characterization of MN's roadways in poor conditions. The results of this research was used to define the scope and scale of pavements to be addressed by the treatment methods.

Task 2: Identify and Characterize Treatments for Poor Pavements - A comprehensive list of treatments was developed, including a "do-nothing" scenario and materials (including recycled materials) applicable to pavements in poor conditions.

Task 3: Tool for Recommending Treatments for Pavements in Poor Condition - A spreadsheet tool was created for recommending project-level treatments for pavements in poor condition. This tasks focused on technical feasibility of treatments.

Task 4: Memo Describing Cost Effectiveness Parameters - MnDOT provided domain specific knowledge on the estimated performance, service life, agency cost, and reduced maintenance cost for each treatment. This established the cost effectiveness of alternative treatments. 
Task 5: Environmental Impacts Parameters - The basic set of parameters for evaluating the environmental impacts and the unit values of these parameters for each treatment were determined. A recommendation for incorporating the impacts into the tool was also requested. This task was addressed by RMRC and is discussed in this paper.

Task 6: Spreadsheet Tool for Evaluating Cost-Effectiveness and Environmental Impacts - The user guide from Task 3 will be expanded with cost and environmental data from Tasks 4 and 5 . The resulting tool is to assist pavement maintenance decision makers in selecting and evaluating alternative treatment methods. The final tool was developed by the National Center for Freight \& Infrastructure Research \& Education -CFIRE (Adams et al., 2014).

\section{B.2. Treatment Options}

The treatment options were explored in Task 2 and selected prior to the environmental analysis in Task 3. The considered treatments address initial roadway condition and incorporate both virgin and recycled materials. All volumes of treatment materials were calculated per lanemile and corresponding thicknesses. In practice many of the treatments are specified on an area basis (i.e. square meters). However, the RMRC analysis tool, PaLATE, required volumes to perform environmental impacts analysis (Horvath, 2007). The considered treatments, their component materials, and the assumed thicknesses are listed in Table B1. MnDOT provided the quantities of component materials, and the CFIRE research team assumed thicknesses (Adams et. al. 2014). These treatments represent some of the more common and researched methods used by MnDOT (Janisch \& Gaillard, 1998; Johnson, 2003). In the final evaluation tool, assumed thicknesses can be adjusted in a supplemental worksheet if needed, and the environmental impacts will be automatically scaled accordingly. 
Table B1. List of treatments with their corresponding type and thickness

\begin{tabular}{|c|c|c|c|}
\hline Treatment & Type & Thickness & Components \\
\hline Chip Seal & Areal & $1.3 \mathrm{~cm}$ & $\begin{array}{l}1.1 \mathrm{~L} \text { of chip seal emulsion (CRS-2P) } \\
0.53 \mathrm{~L} \text { of fog seal emulsion (CSS- } 1 \mathrm{~h} \text { ) } \\
0.84 \mathrm{~m}^{2}(1 \mathrm{SY}) \text { of aggregate seal coat material }\end{array}$ \\
\hline Double Chip Seal & Areal & $2.5 \mathrm{~cm}$ & $\begin{array}{l}1.7 \mathrm{~L} \text { of chip seal emulsion (CRS-2P) } \\
0.53 \mathrm{~L} \text { of fog seal emulsion (CSS-1h) } \\
1.7 \mathrm{~m}^{2}(2 \mathrm{SY}) \text { of aggregate seal coat material }\end{array}$ \\
\hline Micro-surfacing & Areal & $2.5 \mathrm{~cm}$ & $\begin{array}{l}1.9 \mathrm{~L} \text { of micro-surfacing emulsion (CSS- } 1 \mathrm{~h} \text { ) } \\
6.8 \mathrm{~kg} \text { of scratch coarse (aggregate) } \\
6.8 \mathrm{~kg} \mathrm{of} \mathrm{micro-surfacing} \mathrm{wearing} \mathrm{course} \\
\text { (aggregate) }\end{array}$ \\
\hline CapeSeal & Areal & $3.8 \mathrm{~cm}$ & $\begin{array}{l}1.1 \mathrm{~L} \text { of chip seal emulsion (CRS-2P) } \\
0.84 \mathrm{~m}^{2}(1 \mathrm{SY}) \text { of aggregate seal coat material } \\
1.9 \mathrm{~L} \text { of micro-surfacing emulsion (CSS- } 1 \mathrm{~h}) \\
6.8 \mathrm{~kg} \text { of scratch coarse (aggregate) } \\
6.8 \mathrm{~kg} \text { of micro-surfacing wearing course } \\
\text { (aggregate) }\end{array}$ \\
\hline $\begin{array}{l}\text { UltraThin Bonded } \\
\text { Wear Course }\end{array}$ & Areal & $2.5 \mathrm{~cm}$ & $\begin{array}{l}0.9 \mathrm{~L} \text { of polymer modified tack coat (CSS-1HP) } \\
3.4 \mathrm{~kg} \text { of HMA, } 5.5 \% \text { PMA and } 94.5 \% \text { crushed } \\
\text { aggregate }\end{array}$ \\
\hline $\begin{array}{l}5-\mathrm{cm} \\
\text { Overlay }\end{array}$ & Areal & $5 \mathrm{~cm}$ & $\begin{array}{l}103 \mathrm{~kg} \text { of } \mathrm{HMA}, 5.5 \% \text { asphalt binder, } 94.5 \% \\
\text { aggregate }(90 \% \text { crushed, } 10 \% \text { natural sand })\end{array}$ \\
\hline $\begin{array}{l}\text { Mill \& } 5-\mathrm{cm} \mathrm{HMA} \\
\text { Overlay }\end{array}$ & Areal & $5 \mathrm{~cm}$ & $\begin{array}{l}0.84 \mathrm{~m}^{2}(1 \mathrm{SY}) \text { of milling } 5 \mathrm{~cm} \text { depth } \\
103 \mathrm{~kg} \text { of HMA, } 5.5 \% \text { asphalt binder, } 94.5 \% \\
\text { aggregate }(90 \% \text { crushed, } 10 \% \text { natural sand) }\end{array}$ \\
\hline $\begin{array}{l}\text { Mastic } \\
\text { Patching }\end{array}$ & Localized & $\begin{array}{l}7.6 \quad \mathrm{~cm} \\
\text { (moderate), } \\
15 \quad \mathrm{~cm} \\
\text { (severe) }\end{array}$ & $\begin{array}{l}42 \mathrm{~kg} \text { of mastic, } 7 \% \text { asphalt binder, } 93 \% \text { fine } \\
\text { aggregate } \\
1.1 \mathrm{~L} \text { of chip seal emulsion (CRS-2P) } \\
0.84 \mathrm{~m}^{2}(1 \mathrm{SY}) \text { of seal coat aggregate }\end{array}$ \\
\hline Crack Sealing & Localized & $15.2 \mathrm{~cm}$ & $\begin{array}{l}0.84 \mathrm{~m}^{2}(1 \mathrm{SY}) \text { of aggregate (filler) } \\
10 \% \text { asphalt by volume }\end{array}$ \\
\hline
\end{tabular}

Additionally, the environmental impact of each treatment is dependent on its lifetime. The estimated service lives of each treatment are listed in Table B2. Each treatment has an estimated minimum and maximum service life that are conditional to the initial state of the pavement, designated as moderate, poor, and very poor. Treatment for pavements in moderate condition have longer lifetimes than those in poor conditions. Some of the treatment options are unsuitable 
if the pavement is in very poor condition.

Table B2. Estimated service lives for treatment options based on pavement condition

\begin{tabular}{|l|l|c|c|c|c|c|c|}
\hline \multirow{2}{*}{ Type } & Treatment & \multicolumn{3}{|c|}{$\begin{array}{c}\text { Minimum Service Life } \\
\text { (Years) }\end{array}$} & \multicolumn{3}{c|}{$\begin{array}{c}\text { Maximum Service Life } \\
\text { (Years) }\end{array}$} \\
\cline { 3 - 8 } & Moderate & Poor & $\begin{array}{l}\text { Very } \\
\text { Poor }\end{array}$ & Moderate & Poor & $\begin{array}{c}\text { Very } \\
\text { Poor }\end{array}$ \\
\hline Areal & Chip Seal & 4 & 1 & n/a & 5 & 2 & n/a \\
\hline Areal & Double Chip Seal & 5 & 3 & 1 & 6 & 4 & 2 \\
\hline Areal & Microsurfacing & 4 & 2 & 1 & 5 & 3 & 2 \\
\hline Areal & Cape Seal & 5 & 3 & 2 & 6 & 4 & 3 \\
\hline Areal & UltraThin HMA & 6 & 4 & 3 & 7 & 5 & 4 \\
\hline Areal & $\begin{array}{l}\text { 5-cm } \\
\text { Overlay }\end{array}$ & 5 & 3 & 3 & 6 & 4 & 4 \\
\hline Areal & $\begin{array}{l}\text { Mill \& 5-cm HMA } \\
\text { Overlay }\end{array}$ & 6 & 4 & 3 & 7 & 5 & 4 \\
\hline Local & Crack Sealing & 5 & 3 & 1 & 6 & 4 & 2 \\
\hline Local & Mastic & 6 & 4 & 3 & 7 & 5 & 4 \\
\hline
\end{tabular}

\section{B.3. Environmental Impact Analysis}

The Pavement Life-cycle Assessment Tool for Environmental and Economic Effects (PaLATE) is a spreadsheet LCA program designed by the Consortium on Green Design and Manufacturing from the University of California, Berkeley for RMRC. PaLATE assesses the environmental and economic effects of pavement and road construction. Users input the initial design, initial construction material, maintenance material, and equipment use for a roadway project. Environmental outputs include (Horvath, 2007): energy consumption (GJ), water consumption $(\mathrm{kg}), \mathrm{CO}_{2}$ emissions $(\mathrm{kg}), \mathrm{NO}_{\mathrm{x}}$ emissions $(\mathrm{kg}), \mathrm{PM}_{10}$ emissions $(\mathrm{kg}), \mathrm{SO}_{2}$ emissions (kg), CO emissions $(\mathrm{kg})$, and Leachate information including mercury, lead, Resource Conservation and Recovery Act (RCRA) hazardous waste generated, and both cancerous and non-cancerous human toxicity potential

Four environmental factors for impacts analysis (energy, water consumption, $\mathrm{CO}_{2}$ emissions, and RCRA hazardous waste) were deemed sufficient for evaluation of MnDOT 
maintenance strategies per the initial MnDOT contract specifications. Although the report does not specify that the analysis is limited to these factors, it was determined that the four categories would provide sufficient representation of a treatment's impact.

The RCRA is a United States law that provides general guidelines for a federal waste management program (U.S. EPA, 2015a). Enacted by Congress in 1976 and carried out by the US Environmental Protection Agency's (EPA) Office of Solid Waste, RCRA aims to protect human health and the environment from a diversity of hazardous and nonhazardous wastes. The consideration of RCRA in PaLATE demonstrates the advantages of including regulated substances in assessments (Horvath, 2007).

\section{B.3.1 Assumptions}

The assumptions made to render the provided treatment information compatible with the PaLATE database are provided below.

1) For uniformity, the environmental results were calculated per lane-mile. The provided 0.84 $\mathrm{m}^{2}$ (1 SY) amount of material was multiplied to represent that quantity of material required for an area of 1.6 kilometers ( 1 mile) by one lane. One lane was assumed to be 3.6 meters wide.

2) Palate required volumes of materials for its analysis. The materials for one lane-mile were multiplied by the treatments' appropriate thickness (Table B1) to calculate the volume of material require for one lane-mile.

3) For localized treatments (mastic patching and crack sealing), the extent of patching or crack sealing required was scaled based on existing pavement condition. These estimates are listed in Table B3. For mastic patching percent total pavement are values that were assumed, the quantity of mastic patching in $\mathrm{m}^{3}$ was then calculated based on a patch depth of $7.6 \mathrm{~cm}$. The quantity of crack sealing was based on the presence of both longitudinal and transverse cracks. The number of $1.8-\mathrm{m}$ cracks per roadway station was 
adjusted based on existing pavement condition as shown. Each crack was considered to be $1.3 \mathrm{~cm}$ wide and $2.5 \mathrm{~cm}$ deep. These dimensions were used to calculate the volume of crack sealant required for PaLATE analysis.

Table B3. Dimensions and frequencies used to calculate the volume of localized treatments in one mile of roadway

\begin{tabular}{|c|c|c|}
\hline \multicolumn{3}{|c|}{ Mastic Patching } \\
\hline Existing Pavement Condition & \multicolumn{2}{c|}{ Percent Total Area } \\
\hline \multicolumn{2}{|c|}{ Moderate } & $5 \%$ \\
\hline Poor & $10 \%$ \\
\hline \multicolumn{2}{|c|}{ Very Poor } & $15 \%$ \\
\hline \multicolumn{3}{|c|}{ Crack Sealing } \\
\hline $\begin{array}{c}\text { Existing Pavement } \\
\text { Condition }\end{array}$ & $\begin{array}{c}\text { Cracks Per Road Station } \\
\text { (30 meters) }\end{array}$ & $\begin{array}{c}\text { Length of Cracks Per } \\
\text { Road Station (m) }\end{array}$ \\
\hline Moderate & 3 & 5.5 \\
\hline Poor & 6 & 11 \\
\hline Very Poor & 10 & 18 \\
\hline
\end{tabular}

4) Environmental impacts from water as a material are not considered in the PaLATE analysis. Only the percent asphalt of the bituminous material in each layer was analyzed. The remainder of the bituminous volume (i.e. the water) was ignored. This allowed for differentiation of the bituminous material used in the treatments. Bituminous material with a higher percentage of asphalt has a greater environmental effect then those with a smaller percentage.

5) Some of the materials were provided as weight as opposed to volume quantities. These materials include asphalt binder (bitumen), virgin aggregate, cement, and sand. PaLATE provides average unit weights. These were used to convert material weights to volumes.

6) The polymer coat solids in the UltraThin Bonded Wearing Course were ignored. PaLATE does not have a parameter for this type of material. Since such small amounts were used, it was determined that the solids could be ignored without affecting the analysis.

\section{B.3.2 Analysis Approach}

Material quantities are input to PaLATE and it generates environmental impacts as 
outputs. In this analysis, only environmental impacts from the material initial processing were considered. Construction methods, maintenance, and transportation effects are not analyzed. The environmental outputs of each individual material in each layer were calculated. Asphalts from different portions of one treatment were analyzed separately. The analysis procedure is as follows:

Step 1. Calculate the percent volume of asphalt in each bituminous layer (in gal)

Step 2. Convert all material quantities given in per area bases $\left(\mathrm{m}^{2}\right)$ to volumes $\left(\mathrm{m}^{3}\right)$ based on the thicknesses in Table B1.

Step 3. Multiply the material volumes to the appropriate volume for one lane-mile

Step 4. Calculate the volume of localized treatment materials per one-lane mile from quantities in Table B3.

Step 5. Enter each material into PaLATE spreadsheet's "Initial Cost" page

Step 6. Gather each material's environmental output from "Environmental Results" page

Step 7. Sum the total environmental outputs from each material in each treatment layer

Step 8. Divide the total environmental outputs by the service life of each treatment as stipulated in Table B2 to calculate annualized impacts.

\section{B.4. Results and Recommendations}

The results were analyzed by different methods. The environmental impacts for each treatment were analyzed separately, then comparatively. To compare environmental outputs of different units, such as MJ of energy versus $\mathrm{kg}$ of water, the results were expressed as a percentage of a base or reference treatment, in this instance chip seal was selected as the reference treatment. Finally, the results were annualized to account for differences in service life between treatments. Based on the selection criteria provided, treatment service lives were dependent on the type of treatment and the overall condition of the existing pavement. These 
annualized outputs are used to quantify environmental impacts in the MnDOT spreadsheet tool.

\section{B.4.1 Overall Results}

The results of the analysis are summarized in Table B4. In general, the extent of environmental impact is proportional to the amount of material required for a given treatment. The localized treatments required far less material, thus had far less environmental impacts. The mill and HMA layers required the most material, thus had the greatest environmental impacts.

Table B4. Total environmental results for each treatment - non-annualized

\begin{tabular}{|l|l|c|c|c|c|}
\hline Type & Treatment & $\begin{array}{c}\text { Energy } \\
(\mathbf{G J})\end{array}$ & $\begin{array}{c}\text { Water } \\
\text { consumption } \\
\mathbf{( k g )}\end{array}$ & $\begin{array}{c}\mathbf{C O}_{\mathbf{2}} \\
\mathbf{( k g )}\end{array}$ & $\begin{array}{c}\text { RCRA Hazardous } \\
\text { Waste Generated } \\
\mathbf{( k g )}\end{array}$ \\
\hline Areal & Chip Seal & 169 & 62 & 10,077 & 2,447 \\
\hline Areal & Double Chip Seal & 326 & 99 & 20,417 & 3,564 \\
\hline Areal & Microsurfacing & 184 & 73 & 10,733 & 2,918 \\
\hline Areal & Cape Seal & 398 & 135 & 24,278 & 5,038 \\
\hline Areal & UltraThin & 415 & 163 & 24,106 & 6,722 \\
\hline Areal & 5-cm HMA Overlay & 1,037 & 406 & 60,343 & 16,674 \\
\hline Areal & $\begin{array}{l}\text { Mill \& 5-cm HMA } \\
\text { Overlay }\end{array}$ & 1,044 & 406 & 62,428 & 16,729 \\
\hline Local & Crack Sealing & 0.2 & 0.1 & 9.4 & 2.4 \\
\hline Local & Mastic - Moderate & 1.2 & 0.4 & 70.8 & 14.7 \\
\hline Local & Mastic - Severe & 2.3 & 0.8 & 142 & 29.5 \\
\hline
\end{tabular}

Because the results are a variety of categories that cannot be added, the treatments were compared to a base treatment, which was defined as chip seal for this analysis. The results of the comparison are shows in Figure B1. Most of the areal treatments have greater environmental output then chip seal, with the micro-surfacing providing the most similar environmental impact. The environmental outputs for the HMA and mill \& HMA are far greater than any other treatment. Crack sealing and both levels of mastic have a significantly lower environmental output then the base case. Both localized treatments also have very similar results. 


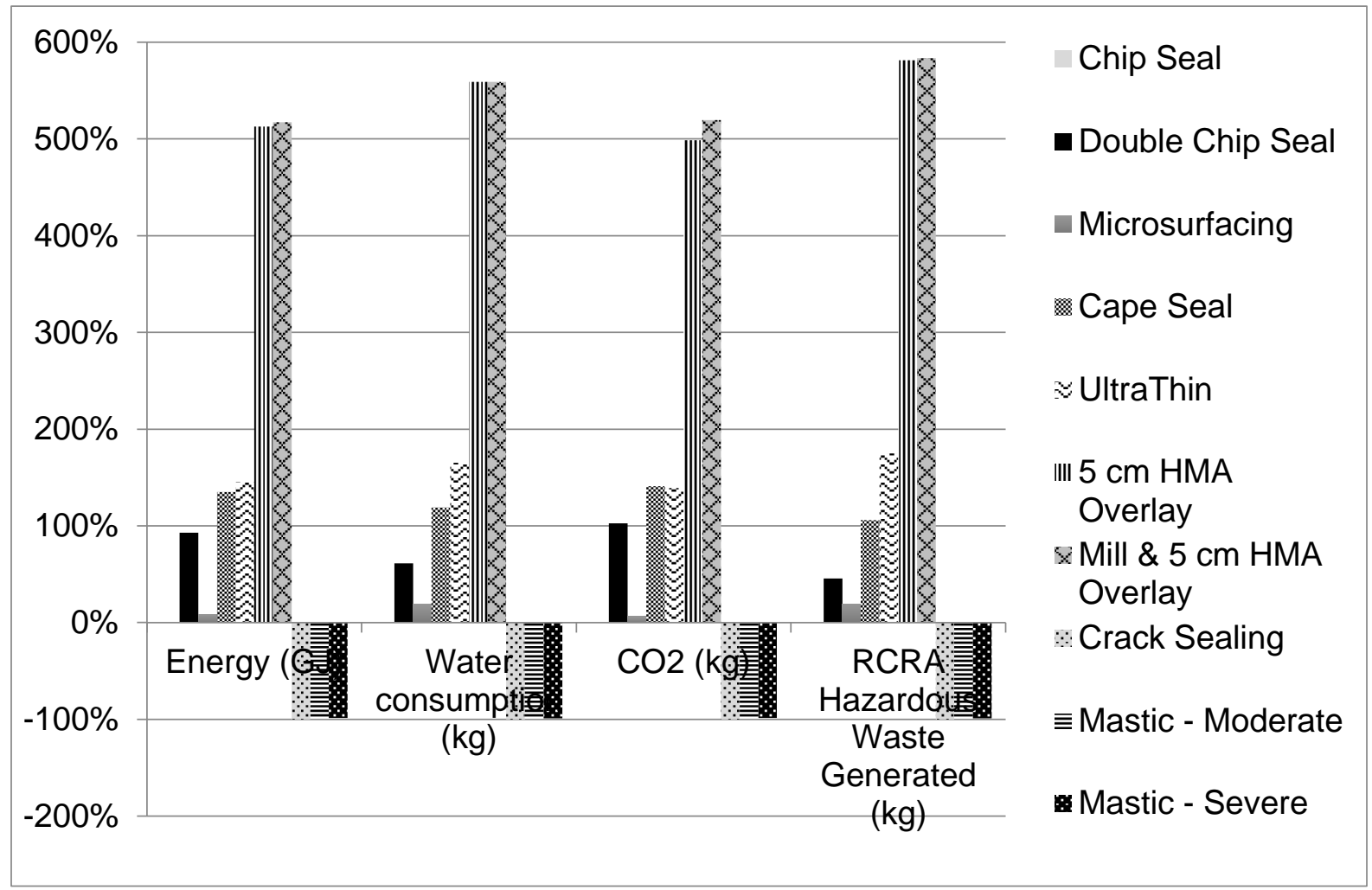

Figure B1. Environmental outputs compared to a base case, chip seal

To more easily discern the least impactful treatment, the treatments were ranked and scored (Table B5). Ranks 1 through 10 were awarded to each treatment for different impact categories, with 10 having the greatest impact and 1 having the least. Impact categories were weighted according to their relevance for impact assessments. Energy and $\mathrm{CO}_{2}$ emission were the two most important categories and were weighted as one times their rank. Water and waste generations considered less critical. These categories were weighted by half of their rank so as to have a smaller influence on the overall score in comparison to energy and emissions. Ranks were multiplied by the appropriate weight to calculate a treatment's score. The treatment with the lowest score would have the smallest environmental effect. The final rank based on the overall score for each treatment is listed in Table B5. 
Table B5. Rank of treatment options based on all four impact categories

\begin{tabular}{|c|c|c|c|c|c|c|}
\hline \multirow{2}{*}{ Treatment } & $\begin{array}{l}\text { Energy } \\
\text { (GJ) }\end{array}$ & $\mathrm{CO}_{2}(\mathrm{~kg})$ & Water (kg) & $\begin{array}{l}\text { RCRA Haz } \\
\text { Waste (kg) }\end{array}$ & \multirow{2}{*}{$\begin{array}{l}\text { Total } \\
\text { Score }\end{array}$} & \multirow{2}{*}{$\begin{array}{l}\text { Fina } \\
\text { Rank }\end{array}$} \\
\hline & Score (x1) & $\begin{array}{c}\text { Score } \\
(\times 1)\end{array}$ & Score $\left(x^{1} 1 / 2\right)$ & Score $\left(\mathbf{X}^{1 / 2}\right)$ & & \\
\hline Chip Seal & 4 & 4 & 2 & 2 & 12 & 4 \\
\hline Double Chip Seal & 6 & 6 & 3 & 3 & 18 & 6 \\
\hline Microsurfacing & 5 & 5 & 2.5 & 2.5 & 15 & 5 \\
\hline Cape Seal & 7 & 8 & 3.5 & 3.5 & 22 & 7 \\
\hline Ultra Thin & 8 & 7 & 4 & 4 & 23 & 8 \\
\hline 5-cm HMA Overlay & 9 & 9 & 4.5 & 4.5 & 27 & 9 \\
\hline $\begin{array}{l}\text { Mill \& 5-cm HMA } \\
\text { Overlay }\end{array}$ & 10 & 10 & 4.5 & 5 & 29.5 & 10 \\
\hline Crack Sealing & 1 & 1 & 0.5 & 0.5 & 3 & 1 \\
\hline Mastic - Moderate & 2 & 2 & 1 & 1 & 6 & 2 \\
\hline Mastic - Severe & 3 & 3 & 1.5 & 1.5 & 9 & 3 \\
\hline
\end{tabular}

The local treatments ranked in the top three positions, with crack sealing with the lowest total score. Of the areal treatments, chip seal ranked the lowest. Both HMA overlay treatments consistently scored highest in all categories, and therefore have the highest total score. This ranking system can be referenced when a user is comparing the absolute environmental impact of multiple treatment options.

\section{B.4.2 Environmental Results by Category}

The individual environmental results are shown in Figure B2 as radar plots. These plots allow for evaluation of the relative severity of the various environmental impacts considered for each treatment. The individual results of each factor are compared for all treatment. The following section discusses comparisons of each individual environmental output. 


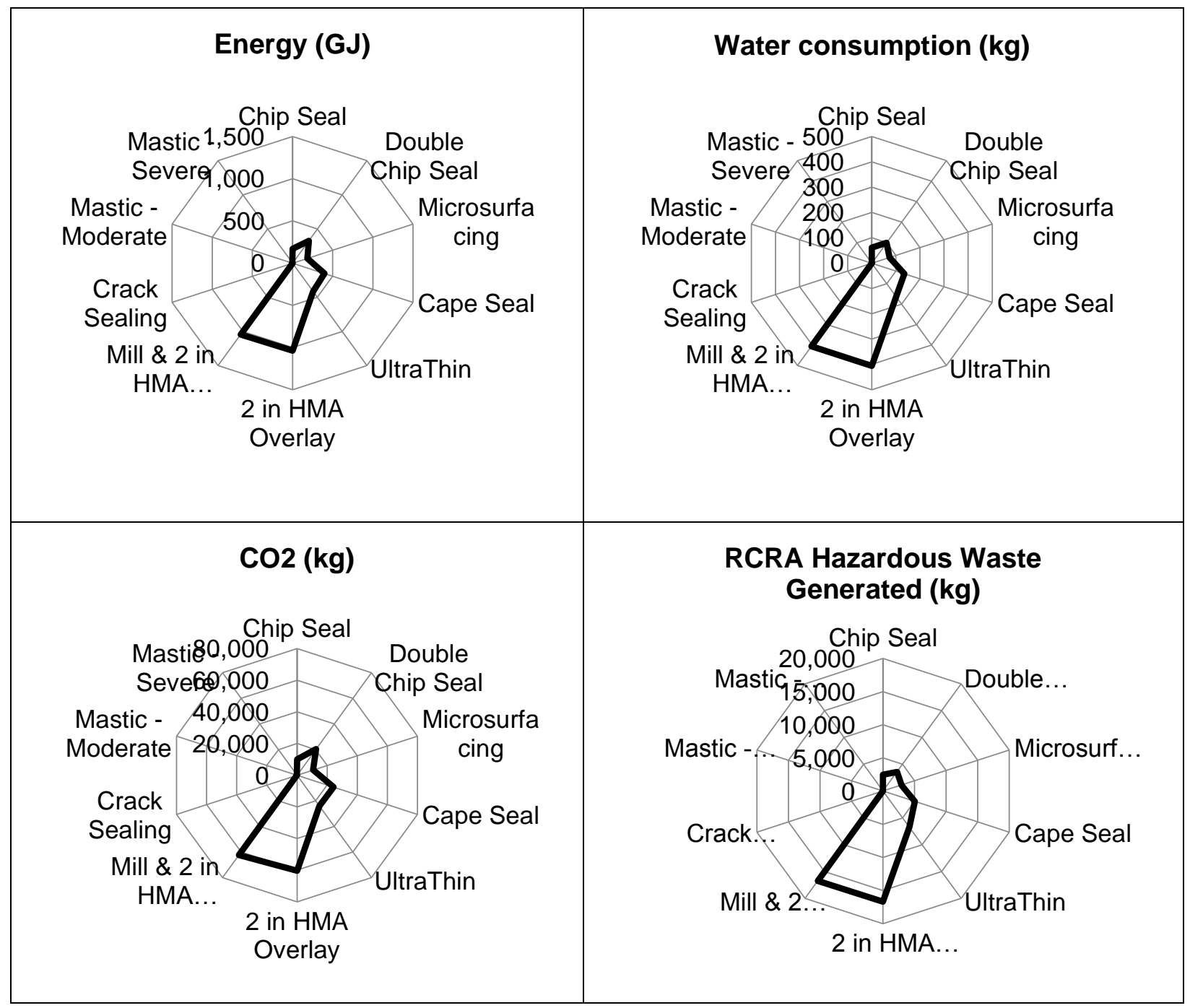

Figure B2. Radar Plot of each treatment results per environmental output.

Energy - The least amount of energy is consumed by the localized treatments, and compared to the other treatments, approaches zero. Of the areal treatments, the chip seal and micro-surfacing have the lowest energy consumption. The mill \& HMA and HMA layers have significantly larger overall energy consumption.

Water consumption - Water requirements follow a similar trend as energy requirements. The localized treatments' water consumption is next to nothing compared to the other treatments. There is less of a gap between the lowest water consumption areal treatments (again chip seal 
and micro-surfacing), and the highest water consumption areal treatments (again mill \& HMA and HMA).

$\mathrm{CO}_{2}$ - Carbon dioxide emissions follow a similar trend as energy and water consumptions, with localized treatments emissions comparatively insignificant, chip seal and micro-surfacing the lowest emitting areal treatment, and mill \& HMA and HMA the highest emitting areal treatment. In these results, there is a greater difference in the double chip seal and the cape seal versus the other low-emitting areal treatments.

RCRA Hazardous Waste - The hazardous waste generation trend is also similar to the above three environmental results. However, unlike $\mathrm{CO}_{2}$ emissions, there is less of a difference between the double chip and cape seal as compared to the low-generating chip and micro-surfacing treatments.

\section{B.4.3 Annualized Environmental Impacts}

Because of the differing lifetimes the treatment options and their dependence on the initial road condition, it is important to compare the impacts for a set amount of time. For this purpose, the results were annualized for each possible initial roadway condition (Table B6). Ultimately, the annualized results are used in the evaluation tool. 
Table B6. Annualized environmental results per treatment per pavement initial condition for the average service life.

\begin{tabular}{|c|c|c|c|c|c|c|}
\hline \multirow[b]{2}{*}{ Treatment } & \multicolumn{3}{|c|}{ Energy (GJ/year) } & \multicolumn{3}{|c|}{ Water Consumption (kg/year) } \\
\hline & Moderate & Poor & $\begin{array}{l}\text { Very } \\
\text { Poor }\end{array}$ & Moderate & Poor & $\begin{array}{l}\text { Very } \\
\text { Poor }\end{array}$ \\
\hline Chip Seal & 38.1 & 127 & $\mathrm{n} / \mathrm{a}$ & 13.9 & 46.2 & $n / a$ \\
\hline Double Chip Seal & 59.8 & 95.2 & 245 & 18.2 & 28.9 & 74.4 \\
\hline Microsurfacing & 41.4 & 76.6 & 138 & 16.5 & 30.6 & 55.1 \\
\hline Cape Seal & 72.9 & 116 & 166 & 24.7 & 39.3 & 56.2 \\
\hline UltraThin & 64.2 & 93.3 & 121 & 25.3 & 36.7 & 47.6 \\
\hline 5-cm HMA Overlay & 190 & 302 & 302 & 74.4 & 118 & 118 \\
\hline $\begin{array}{l}\text { Mill \& 5-cm HMA } \\
\text { Overlay }\end{array}$ & 162 & 235 & 305 & 62.8 & 91.3 & 118 \\
\hline Crack Sealing & 0.0 & 0.0 & 0.1 & 0.0 & 0.0 & 0.0 \\
\hline \multirow[t]{2}{*}{ Mastic } & 0.2 & 0.3 & 0.7 & 0.1 & 0.1 & 0.2 \\
\hline & \multicolumn{3}{|c|}{$\mathrm{CO}_{2}$ (kg/year) } & \multicolumn{3}{|c|}{$\begin{array}{l}\text { RCRA Hazardous Waste } \\
\text { (kg/year) }\end{array}$} \\
\hline Treatment & Moderate & Poor & $\begin{array}{l}\text { Very } \\
\text { Poor }\end{array}$ & Moderate & Poor & $\begin{array}{l}\text { Very } \\
\text { Poor }\end{array}$ \\
\hline Chip Seal & 2,267 & 7,558 & $\mathrm{n} / \mathrm{a}$ & 550 & 1,835 & $\mathrm{n} / \mathrm{a}$ \\
\hline Double Chip Seal & 3,743 & 5,955 & 15,313 & 653 & 1,040 & 2,673 \\
\hline Microsurfacing & 2,415 & 4,472 & 8,050 & 656 & 1,216 & 2,188 \\
\hline Cape Seal & 4,451 & 7,081 & 10,116 & 924 & 1,469 & 2,099 \\
\hline UltraThin & 3,731 & 5,424 & 7,031 & 1,040 & 1,513 & 1,961 \\
\hline 5-cm HMA Overlay & 11,063 & 17,600 & 17,600 & 3,057 & 4,863 & 4,863 \\
\hline $\begin{array}{l}\text { Mill \& 5-cm HMA } \\
\text { Overlay }\end{array}$ & 9,661 & 14,045 & 18,207 & 2,589 & 3,764 & 4,879 \\
\hline Crack Sealing & 1.7 & 2.7 & 7.1 & 0.4 & 0.7 & 1.8 \\
\hline Mastic & 11.0 & 15.9 & 41.3 & 2.3 & 3.3 & 8.6 \\
\hline
\end{tabular}

Users can compare the impacts of multiple treatment options for different pavement conditions. The output of the tool will reveal which option has the lowest annual environmental impact. These results can be combined with an economic analysis to determine the option with the least annual cost and environmental impact. Similar to the overall results, the highest impacts are realized when areal treatments are used, with local treatments impacting the environment significantly less. Even annualized, the HMA overlay options have the highest impacts. 


\section{B.5. Conclusion}

The results of this analysis and the other tasks contributing to the evaluation tool for shortterm treatment of poor pavements are contained in a report by CFIRE (Adams et al., 2014). The deliverables included a spreadsheet tool for evaluating the cost effectiveness and environmental impacts of treatments for pavements in poor condition as well as a user guide for the spreadsheet tool. In the tool, users select the existing pavement distresses, project geometry, traffic characteristics, and daily work zone activity. The tool then determines the pavement's existing condition (moderate, poor, or very poor), treatment area, feasibility and monetary decision factors, qualitative decision factors, and total project costs. Environmental impacts are included in the qualitative decision factors. For the applicable treatments, the tool utilizes the annualized impact results calculated by the RMRC from PaLATE. In practice, most users will find that the localized treatment methods have far lower impacts than the areal treatments, and overlays have the largest impacts of all options.

\section{B.6. Acknowledgements}

Funding for this project was provided by MnDOT through MnDOT Contract No. 89264 Work Order No.5. Prof. Teresa Adams and Dr. Andrew Hanz of CFIRE assisted in providing data for the environmental analysis, as well as incorporating the results into the final evaluation tool. 


\section{Appendix C: Tables and Figures}

\section{C.1 Tables}

\section{C.1.1 PaLATE Input Tables}

Table C1. I-94 Analysis: PaLATE inputs for Recycled design

\begin{tabular}{|c|c|c|c|c|c|}
\hline \multirow{2}{*}{\multicolumn{2}{|c|}{ Material }} & \multirow{3}{*}{$\begin{array}{c}\text { PaLATE Process } \\
\text { Cement }\end{array}$} & \multirow{3}{*}{$\begin{array}{c}\left.\text { Input (yd }{ }^{\mathbf{3}}\right) \\
4,790\end{array}$} & \multicolumn{2}{|c|}{ Transportation } \\
\hline & & & & \multirow{2}{*}{$\begin{array}{c}\text { Distance }(\mathrm{mi}) \\
1\end{array}$} & \multirow{2}{*}{$\begin{array}{c}\text { Vehicle } \\
\text { cement truck }\end{array}$} \\
\hline \multirow{4}{*}{$\begin{array}{l}\frac{0}{0} \\
\frac{0}{0} \\
0 \\
0\end{array}$} & Cement & & & & \\
\hline & Fly Ash & Coal Fly Ash & 1,190 & 10 & dump truck \\
\hline & PCC Agg & Virgin Aggregate & 21,984 & 1 & dump truck \\
\hline & Water in PCC & Water & 3,812 & 0 (onsite) & $n / a$ \\
\hline \multirow{5}{*}{ 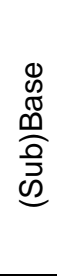 } & \multirow{2}{*}{ RAP onsite } & RAP to recycling plant & 10,512 & 0 (onsite) & $\mathrm{n} / \mathrm{a}$ \\
\hline & & RAP from recycling plant to site & 10,512 & 0 (onsite) & $\mathrm{n} / \mathrm{a}$ \\
\hline & \multirow{2}{*}{ RCA onsite } & RCA to recycling plant & 14,448 & 0 (onsite) & $\mathrm{n} / \mathrm{a}$ \\
\hline & & RCA from recycling plant to site & 14,448 & 0 (onsite) & $\mathrm{n} / \mathrm{a}$ \\
\hline & Base Agg & Gravel & 32,681 & $17.5-30$ & dump truck \\
\hline \multirow{3}{*}{ 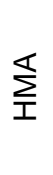 } & Binder & Bitumen & 1,452 & 1 & tanker truck \\
\hline & RAP & RAP & 24,261 & 1 & dump truck \\
\hline & HMA Agg & Virgin Aggregate & 3,320 & 1 & dump truck \\
\hline \multirow{3}{*}{ 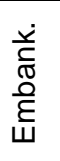 } & Bottom ash & Coal Bottom Ash & 164,284 & 10 & dump truck \\
\hline & Foundry Sand & Foundry Sand & 11,735 & 35 & dump truck \\
\hline & Native Clay & Soil & 58,673 & 0 (onsite) & na/ \\
\hline
\end{tabular}

Table C2. I-94 Analysis: PaLATE inputs for Virgin design

\begin{tabular}{|c|c|c|c|c|c|}
\hline \multirow{2}{*}{\multicolumn{2}{|c|}{ Material }} & \multirow{3}{*}{$\begin{array}{c}\text { PaLATE Process } \\
\text { Cement }\end{array}$} & \multirow{3}{*}{$\begin{array}{c}\text { Input }\left(\mathbf{y d} \mathbf{d}^{\mathbf{3}}\right) \\
5,980\end{array}$} & \multicolumn{2}{|c|}{ Transportation } \\
\hline & & & & \multirow{2}{*}{$\begin{array}{c}\text { Distance }(\mathrm{mi}) \\
1\end{array}$} & \multirow{2}{*}{$\begin{array}{c}\text { Vehicle } \\
\text { cement truck }\end{array}$} \\
\hline$\frac{\pi}{0}$ & Cement & & & & \\
\hline एँ & PCC Agg & Virgin Aggregate & 21,984 & 1 & dump truck \\
\hline U & Water in PCC & Water & 3,812 & 0 (onsite) & $n / a$ \\
\hline \multicolumn{2}{|c|}{ (Sub)Base Agg } & Gravel & 57,641 & $17.5-30$ & dump truck \\
\hline \multirow{2}{*}{ 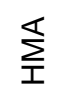 } & Binder & Bitumen & 1,452 & 1 & tanker truck \\
\hline & HMA Agg & Virgin Aggregate & 27,582 & 1 & dump truck \\
\hline \multirow{3}{*}{ 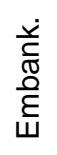 } & Granular fill & Gravel & 164,284 & 25 & dump truck \\
\hline & Sand & Sand & 11,735 & 35 & dump truck \\
\hline & Native Clay & Soil & 58,673 & 0 (onsite) & $\mathrm{n} / \mathrm{a}$ \\
\hline
\end{tabular}


Table C3. Beltline Analysis: PaLATE inputs for Planned data Recycled Design

\begin{tabular}{|c|c|c|c|c|c|}
\hline \multirow{2}{*}{\multicolumn{2}{|c|}{ Material }} & \multirow{2}{*}{ PaLATE Process } & \multirow{2}{*}{ Input $\left(y d^{3}\right)$} & \multicolumn{2}{|c|}{ Transportation } \\
\hline & & & & Distance (mi) & Vehicle \\
\hline \multicolumn{6}{|c|}{ INITIAL CONSTRUCTION } \\
\hline \multirow{6}{*}{ 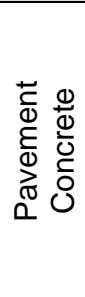 } & \multirow{2}{*}{ Cement } & \multirow{2}{*}{ Cement } & \multirow{2}{*}{2,060} & 220 & barge \\
\hline & & & & 96 & cement truck \\
\hline & Fly Ash & Coal Fly Ash & 846 & 215 & dump truck \\
\hline & PCC Agg & Virgin Aggregate & 17,756 & 9 & dump truck \\
\hline & Water in PCC & Water & 3,203 & 0 (onsite) & $\mathrm{n} / \mathrm{a}$ \\
\hline & \multicolumn{3}{|c|}{ Total Concrete to site } & 9.6 & mixing truck \\
\hline \multirow{5}{*}{ 兽 } & Cement & Cement & 394 & 425 & cement truck \\
\hline & Fly Ash & Coal Fly Ash & 90 & 47 & dump truck \\
\hline & PCC Agg & Virgin Aggregate & 2,947 & 4.6 & dump truck \\
\hline & Water in PCC & Water & 357 & 0 (onsite) & $\mathrm{n} / \mathrm{a}$ \\
\hline & \multicolumn{3}{|c|}{ Total Concrete to site } & 2.2 & mixing truck \\
\hline \multirow{7}{*}{$\begin{array}{l}\mathbb{D} \\
\stackrel{\Phi}{\mathbb{N}} \\
\infty\end{array}$} & \multirow{2}{*}{ RAP onsite } & RAP to recycling plant & 3,280 & 0 (onsite) & $\mathrm{n} / \mathrm{a}$ \\
\hline & & RAP from recycling plant to site & 3,280 & 0 (onsite) & $\mathrm{n} / \mathrm{a}$ \\
\hline & \multirow{2}{*}{ RCA onsite } & $\mathrm{RCA}$ to recycling plant & 3,246 & 0 (onsite) & $\mathrm{n} / \mathrm{a}$ \\
\hline & & RCA from recycling plant to site & 3,246 & 0 (onsite) & $\mathrm{n} / \mathrm{a}$ \\
\hline & \multirow{2}{*}{ RCA offsite } & RCA to recycling plant & 5,527 & 25 & dump truck \\
\hline & & RCA from recycling plant to site & 5,527 & 2.2 & dump truck \\
\hline & Base Agg & Gravel & 1,595 & 9.4 & dump truck \\
\hline \multirow{3}{*}{$\dot{0}$} & \multirow{2}{*}{ RCA } & RCA to recycling plant & 17,883 & 25 & dump truck \\
\hline & & RCA from recycling plant to site & 17,883 & 2.2 & dump truck \\
\hline & Virgin SCM & Gravel & 9,130 & 9.4 & dump truck \\
\hline \multirow{7}{*}{ 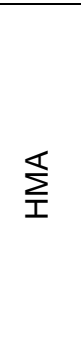 } & Asphalt binder & Bitumen & 73 & 73 & tanker truck \\
\hline & RAP binder & RAP & 4 & at plant & $\mathrm{n} / \mathrm{a}$ \\
\hline & RAS binder & RAS & 20 & at plant & $\mathrm{n} / \mathrm{a}$ \\
\hline & HMA Agg & Virgin Aggregate & 1,588 & at plant & $\mathrm{n} / \mathrm{a}$ \\
\hline & FRAP & FRAP & 269 & at plant & $\mathrm{n} / \mathrm{a}$ \\
\hline & RAS & RAS & 58 & at plant & $\mathrm{n} / \mathrm{a}$ \\
\hline & \multicolumn{3}{|l|}{ Total HMA to site } & 2.2 & mixing truck \\
\hline \multicolumn{6}{|c|}{ MAINTENANCE } \\
\hline \multirow{5}{*}{$\begin{array}{l}\frac{\Phi}{0} \\
\frac{0}{0} \\
\overline{0} \\
0\end{array}$} & Cement & Cement & 74 & $\begin{array}{c}220 \\
96\end{array}$ & $\begin{array}{c}\text { barge } \\
\text { cement truck }\end{array}$ \\
\hline & Fly Ash & Coal Fly Ash & 38 & 231 & dump truck \\
\hline & PCC Agg & Virgin Aggregate & 704 & 9 & dump truck \\
\hline & Water in PCC & Water & 124 & 0 (onsite) & $\mathrm{n} / \mathrm{a}$ \\
\hline & \multicolumn{3}{|c|}{ Total Concrete to site } & 9.6 & mixing truck \\
\hline \multirow{5}{*}{ 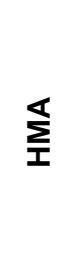 } & Asphalt binder & Bitumen & 880 & 84 & tanker truck \\
\hline & RAS & RAS & 360 & at plant & $\mathrm{n} / \mathrm{a}$ \\
\hline & FRAP & FRAP & 1,235 & at plant & $\mathrm{n} / \mathrm{a}$ \\
\hline & HMA Agg & Virgin Aggregate & 4,821 & at plant & $\mathrm{n} / \mathrm{a}$ \\
\hline & \multicolumn{3}{|l|}{ Total HMA to site } & 2 & mixing truck \\
\hline
\end{tabular}


Table C4. Beltline Analysis: PaLATE inputs for Planned data Virgin design

\begin{tabular}{|c|c|c|c|c|c|}
\hline \multirow{2}{*}{\multicolumn{2}{|c|}{ Material }} & \multirow{2}{*}{ PaLATE Process } & \multirow{2}{*}{ Input $\left(y d^{3}\right)$} & \multicolumn{2}{|c|}{ Transportation } \\
\hline & & & & Distance (mi) & Vehicle \\
\hline \multicolumn{6}{|c|}{ INITIAL CONSTRUCTION } \\
\hline \multirow{5}{*}{ 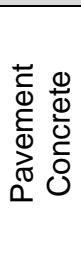 } & \multirow{2}{*}{ Cement } & \multirow{2}{*}{ Cement } & \multirow{2}{*}{2,906} & 220 & barge \\
\hline & & & & 96 & cement truck \\
\hline & PCC Agg & Virgin Aggregate & 17,756 & 9 & dump truck \\
\hline & Water in PCC & Water & 3,203 & 0 (onsite) & $\mathrm{n} / \mathrm{a}$ \\
\hline & \multicolumn{3}{|c|}{ Total Concrete to site } & 9.6 & mixing truck \\
\hline \multirow{4}{*}{ 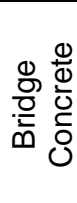 } & Cement & Cement & 483 & 425 & cement truck \\
\hline & PCC Agg & Virgin Aggregate & 2,947 & 4.6 & dump truck \\
\hline & Water in PCC & Water & 357 & 0 (onsite) & $\mathrm{n} / \mathrm{a}$ \\
\hline & \multicolumn{3}{|c|}{ Total Concrete to site } & 2.2 & mixing truck \\
\hline \multicolumn{2}{|c|}{ Base Agg } & Gravel & 13,647 & 9.4 & dump truck \\
\hline \multicolumn{2}{|c|}{ Subbase SCM } & Gravel & 27,014 & 9.4 & dump truck \\
\hline \multirow{3}{*}{$\sum_{I}^{\mathbb{I}}$} & Asphalt binder & Bitumen & 97 & 84 & tanker truck \\
\hline & HMA Agg & Virgin Aggregate & 1,9115 & at plant & $\mathrm{n} / \mathrm{a}$ \\
\hline & \multicolumn{3}{|l|}{ Total HMA to site } & 2.2 & mixing truck \\
\hline \multicolumn{6}{|c|}{ MAINTENANCE } \\
\hline \multirow{4}{*}{$\begin{array}{l}0 \\
\frac{\Phi}{0} \\
\frac{0}{0} \\
0\end{array}$} & Cement & Cement & 113 & 220 & barge \\
\hline & PCC Agg & Virgin Aggregate & 704 & 9 & dump truck \\
\hline & Water in PCC & Water & 124 & 0 (onsite) & $\mathrm{n} / \mathrm{a}$ \\
\hline & \multicolumn{3}{|c|}{ Total Concrete to site } & 9.6 & mixing truck \\
\hline \multirow{3}{*}{ 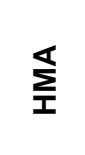 } & Asphalt binder & Bitumen & 880 & 87 & tanker truck \\
\hline & HMA Agg & Virgin Aggregate & 6,026 & at plant & $\mathrm{n} / \mathrm{a}$ \\
\hline & \multicolumn{3}{|l|}{ Total HMA to site } & 2 & mixing truck \\
\hline
\end{tabular}


Table C5. Beltline Analysis: PaLATE inputs for Constructed data Recycled design

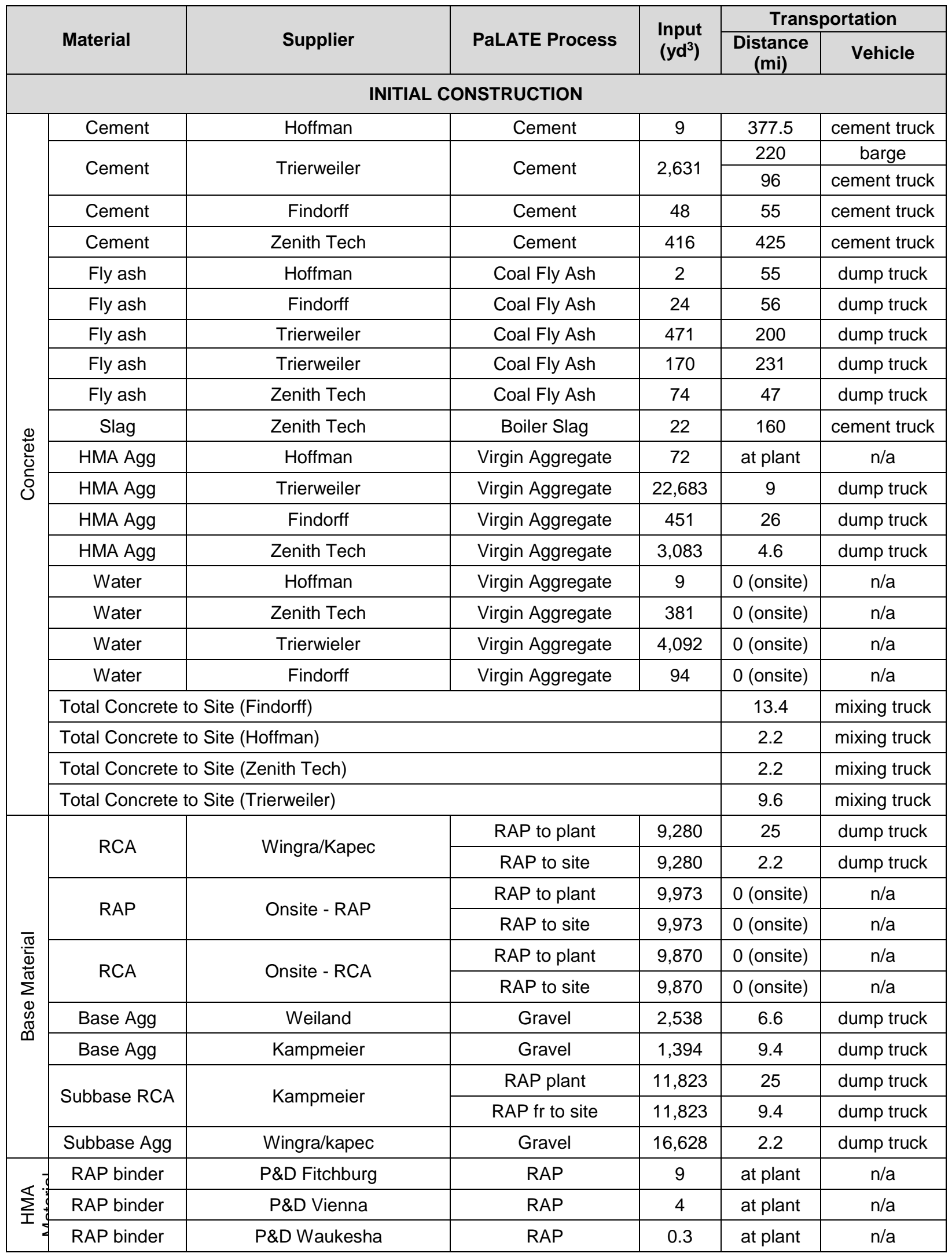




\begin{tabular}{|c|c|c|c|c|c|c|}
\hline & RAS binder & P\&D Fitchburg & RAS & 5 & at plant & $\mathrm{n} / \mathrm{a}$ \\
\hline & RAS binder & P\&D Vienna & RAS & 34 & at plant & $\mathrm{n} / \mathrm{a}$ \\
\hline & RAS binder & P\&D Waukesha & RAS & 2 & at plant & $\mathrm{n} / \mathrm{a}$ \\
\hline & Asphalt & CRM Milwaukee to Fitchburg & Bitumen & 109 & 87 & truck \\
\hline & Asphalt & CRM Milwaukee to Vienna & Bitumen & 162 & 84 & truck \\
\hline & Asphalt & CRM Milwaukee to Waukesha & Bitumen & 6 & 18 & truck \\
\hline & Asphalt & CRM Green Bay to Fitchbug & Bitumen & 19 & 144 & truck \\
\hline & FRAP & P\&D Fitchburg & FRAP & 230 & at plant & $\mathrm{n} / \mathrm{a}$ \\
\hline & FRAP & P\&D Vienna & FRAP & 272 & at plant & $\mathrm{n} / \mathrm{a}$ \\
\hline & FRAP & P\&D Waukesha & FRAP & 14 & at plant & $\mathrm{n} / \mathrm{a}$ \\
\hline & RAS & P\&D Vienna & RAS & 96 & at plant & $\mathrm{n} / \mathrm{a}$ \\
\hline & RAS & P\&D Fitchburg & RAS & 14 & at plant & $\mathrm{n} / \mathrm{a}$ \\
\hline & RAS & P\&D Waukesha & RAS & 4 & at plant & $\mathrm{n} / \mathrm{a}$ \\
\hline & HMA Agg & Herfel / Klahn & Virgin Aggregate & 829 & at plant & $\mathrm{n} / \mathrm{a}$ \\
\hline & HMA Agg & Capitol S\&G & Virgin Aggregate & 338 & at plant & $\mathrm{n} / \mathrm{a}$ \\
\hline & HMA Agg & Johnson & Virgin Aggregate & 18 & 14 & truck \\
\hline & HMA Agg & P\&D Vienna & Virgin Aggregate & 999 & at plant & $\mathrm{n} / \mathrm{a}$ \\
\hline & HMA Agg & P\&D Fitchburg & Virgin Aggregate & 0.96 & at plant & $\mathrm{n} / \mathrm{a}$ \\
\hline & HMA Agg & P\&D Waukesha & Virgin Aggregate & 28 & at plant & $\mathrm{n} / \mathrm{a}$ \\
\hline & \multicolumn{4}{|c|}{ Total HMA to Site (P\&D Fitchburg) } & 2 & truck \\
\hline & \multicolumn{4}{|c|}{ Total HMA to site (P\&D Vienna) } & 20 & truck \\
\hline & \multicolumn{4}{|c|}{ Total HMA to site (P\&D Waukesha) } & 69 & truck \\
\hline \multicolumn{7}{|c|}{ MAINTENANCE } \\
\hline \multirow{6}{*}{$\begin{array}{l}\frac{0}{0} \\
\frac{0}{0} \\
\overline{0}\end{array}$} & \multirow{2}{*}{ Cement } & \multirow{2}{*}{ Trierweiler } & \multirow{2}{*}{ Cement } & \multirow{2}{*}{74} & 220 & barge \\
\hline & & & & & 96 & cement truck \\
\hline & Fly Ash & Trierweiler & Coal Fly Ash & 38 & 231 & dump truck \\
\hline & PCC Agg & Trierweiler & Virgin Aggregate & 704 & 9 & dump truck \\
\hline & Water in PCC & Trierweiler & Water & 124 & 0 (onsite) & $\mathrm{n} / \mathrm{a}$ \\
\hline & \multicolumn{4}{|c|}{ Total Concrete to site (Trierweiler) } & 9.6 & mixing truck \\
\hline \multirow{5}{*}{$\sum_{i}^{\mathbb{I}}$} & Asphalt & CRM Milwaukee to Fitchburg & Bitumen & 880 & 84 & tanker truck \\
\hline & RAS & P\&D Fitchburg & RAS & 360 & at plant & $\mathrm{n} / \mathrm{a}$ \\
\hline & FRAP & P\&D Fitchburg & FRAP & 1,235 & at plant & $\mathrm{n} / \mathrm{a}$ \\
\hline & HMA Agg & P\&D Fitchburg & Virgin Aggregate & 4,821 & at plant & $\mathrm{n} / \mathrm{a}$ \\
\hline & \multicolumn{4}{|c|}{ Total HMA to site } & 2 & mixing truck \\
\hline
\end{tabular}


Table C6. Beltline Analysis: PaLATE inputs for Constructed data Virgin design

\begin{tabular}{|c|c|c|c|c|c|c|}
\hline & \multirow[b]{2}{*}{ Material } & \multirow[b]{2}{*}{ Supplier } & \multirow[b]{2}{*}{ PaLATE Process } & \multirow{2}{*}{$\begin{array}{c}\text { Input } \\
\left(\mathrm{yd}^{3}\right)\end{array}$} & \multicolumn{2}{|c|}{ Transportation } \\
\hline & & & & & $\begin{array}{c}\text { Distance } \\
(\mathrm{mi})\end{array}$ & Vehicle \\
\hline \multicolumn{7}{|c|}{ INITIAL CONSTRUCTION } \\
\hline \multirow{17}{*}{$\begin{array}{l}\frac{0}{d} \\
\frac{1}{U} \\
\frac{C}{0} \\
0\end{array}$} & Cement & Hoffman & Cement & 12 & 377.5 & cement truck \\
\hline & \multirow{2}{*}{ Cement } & \multirow{2}{*}{ Trierweiler } & \multirow{2}{*}{ Cement } & \multirow{2}{*}{3,273} & 220 & barge \\
\hline & & & & & 96 & cement truck \\
\hline & Cement & Findorff & Cement & 73 & 55 & cement truck \\
\hline & Cement & Zenith Tech & Cement & 512 & 425 & cement truck \\
\hline & HMA Agg & Hoffman & Virgin Aggregate & 72 & at plant & $\mathrm{n} / \mathrm{a}$ \\
\hline & HMA Agg & Trierweiler & Virgin Aggregate & 22,683 & 9 & dump truck \\
\hline & HMA Agg & Findorff & Virgin Aggregate & 451 & 26 & dump truck \\
\hline & HMA Agg & Zenith Tech & Virgin Aggregate & 3,083 & 4.6 & dump truck \\
\hline & Water & Hoffman & Virgin Aggregate & 9 & 0 (onsite) & $\mathrm{n} / \mathrm{a}$ \\
\hline & Water & Zenith Tech & Virgin Aggregate & 381 & 0 (onsite) & $\mathrm{n} / \mathrm{a}$ \\
\hline & Water & Trierwieler & Virgin Aggregate & 4,092 & 0 (onsite) & $\mathrm{n} / \mathrm{a}$ \\
\hline & Water & Findorff & Virgin Aggregate & 94 & 0 (onsite) & $\mathrm{n} / \mathrm{a}$ \\
\hline & \multicolumn{4}{|c|}{ Total Concrete to Site (Findorff) } & 13.4 & mixing truck \\
\hline & \multicolumn{4}{|c|}{ Total Concrete to Site (Hoffman) } & 2.2 & mixing truck \\
\hline & \multicolumn{4}{|c|}{ Total Concrete to Site (Zenith Tech) } & 2.2 & mixing truck \\
\hline & \multicolumn{4}{|c|}{ Total Concrete to Site (Trierweiler) } & 9.6 & mixing truck \\
\hline \multicolumn{2}{|c|}{ Base Agg } & Weiland & Gravel & 2,538 & 6.6 & dump truck \\
\hline \multicolumn{2}{|c|}{ Base Agg } & Kampmeier & Gravel & 1,394 & 9.4 & dump truck \\
\hline \multicolumn{2}{|c|}{ Subbase Agg } & Wingra/kapec & Gravel & 16,628 & 2.2 & dump truck \\
\hline & Asphalt & CRM Milwaukee to Fitchburg & Bitumen & 119 & 87 & truck \\
\hline & Asphalt & CRM Milwaukee to Vienna & Bitumen & 200 & 84 & truck \\
\hline & Asphalt & CRM Milwaukee to Waukesha & Bitumen & 8 & 18 & truck \\
\hline & Asphalt & CRM Green Bay to Fitchbug & Bitumen & 24 & 144 & truck \\
\hline & HMA Agg & Herfel / Klahn & Virgin Aggregate & 2,827 & at plant & $\mathrm{n} / \mathrm{a}$ \\
\hline & HMA Agg & Johnson & Virgin Aggregate & 18 & 14 & truck \\
\hline & HMA Agg & P\&D Vienna & Virgin Aggregate & 3070 & at plant & $\mathrm{n} / \mathrm{a}$ \\
\hline & HMA Agg & P\&D Fitchburg & Virgin Aggregate & 1973 & at plant & $\mathrm{n} / \mathrm{a}$ \\
\hline & HMA Agg & P\&D Waukesha & Virgin Aggregate & 115 & at plant & $\mathrm{n} / \mathrm{a}$ \\
\hline & \multicolumn{4}{|c|}{ Total HMA to Site (P\&D Fitchburg) } & 2 & truck \\
\hline & \multicolumn{4}{|c|}{ Total HMA to site (P\&D Vienna) } & 20 & truck \\
\hline & \multicolumn{4}{|c|}{ Total HMA to site (P\&D Waukesha) } & 69 & truck \\
\hline \multicolumn{7}{|c|}{ MAINTENANCE } \\
\hline \multirow{4}{*}{ 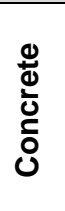 } & \multirow{2}{*}{ Cement } & \multirow{2}{*}{ Trierweiler } & \multirow{2}{*}{ Cement } & 113 & 220 & barge \\
\hline & & & & 113 & 96 & cement truck \\
\hline & PCC Agg & Trierweiler & Virgin Aggregate & 704 & 9 & dump truck \\
\hline & Water in PCC & Trierweiler & Water & 124 & 0 (onsite) & $\mathrm{n} / \mathrm{a}$ \\
\hline
\end{tabular}


Appendix C: Tables and Figures

\begin{tabular}{|c|c|c|c|c|c|c|}
\hline & \multicolumn{4}{|c|}{ Total Concrete to site (Trierweiler) } & 9.6 & mixing truck \\
\hline \multirow{3}{*}{ 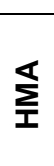 } & Asphalt & CRM Milwaukee to Fitchburg & Bitumen & 880 & 84 & tanker truck \\
\hline & HMA Agg & P\&D Fitchburg & Virgin Aggregate & 6,026 & at plant & $\mathrm{n} / \mathrm{a}$ \\
\hline & \multicolumn{4}{|c|}{ Total HMA to site } & 2 & mixing truck \\
\hline
\end{tabular}




\section{C.1.2 SimaPro Input Tables}

Table C7. Beltline Analysis: SimaPro inputs for Planned data Recycled design

\begin{tabular}{|c|c|c|c|c|}
\hline \multicolumn{5}{|c|}{ INITIAL CONSTRUCTION } \\
\hline \multicolumn{2}{|r|}{ Material } & SimaPro Process & Input (kg) & Unit \\
\hline \multirow{3}{*}{ 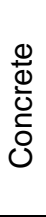 } & $\begin{array}{l}\text { Cement } \\
\text { with Fly Ash }\end{array}$ & $\begin{array}{c}\text { Cement, pozzolana and fly ash } 15-40 \% \text {, US only } \\
\text { \{US\}|production|Alloc Def, S }\end{array}$ & $4,019,293$ & $\mathrm{~kg}$ \\
\hline & PCC Agg & Gravel, crushed $\{$ RoW\}|production|Alloc Def, S & $23,477,192$ & $\mathrm{~kg}$ \\
\hline & $\begin{array}{l}\text { Water in } \\
\text { PCC }\end{array}$ & $\begin{array}{c}\text { Tap water }\{\text { RoW }\} \mid \text { tap water production, conventional treatment|Alloc } \\
\text { Def, S }\end{array}$ & $2,712,607$ & $\mathrm{~kg}$ \\
\hline \multirow{7}{*}{ 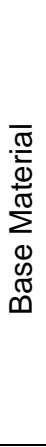 } & \multirow{2}{*}{ RAP onsite } & (Milling) Diesel $\{$ RoW $\} \mid$ petroleum refinery operation|Alloc Def, S & 1,256 & $\mathrm{~kg}$ \\
\hline & & Rock crushing $\{$ Row $\} \mid$ processing $\mid$ Alloc Def, S & $5,503,990$ & $\mathrm{~kg}$ \\
\hline & \multirow{2}{*}{ RCA onsite } & $\begin{array}{l}\text { Waste concrete gravel }\{\mathrm{CH}\} \mid \text { treatment of, recycling } \mid \text { Alloc Def, S / } \\
\text { Concrete block }\{\mathrm{RoW}\} \mid \text { production | Alloc Def, S }\end{array}$ & $5,535,413$ & $\mathrm{~kg}$ \\
\hline & & Rock crushing $\{$ Row $\} \mid$ processing $\mid$ Alloc Def, S & $5,535,413$ & $\mathrm{~kg}$ \\
\hline & \multirow{2}{*}{$\begin{array}{l}\text { RCA } \\
\text { imported }\end{array}$} & $\begin{array}{l}\text { Waste concrete gravel }\{\mathrm{CH}\} \mid \text { treatment of, recycling } \mid \text { Alloc Def, S / } \\
\text { Concrete block }\{\text { RoW }\} \mid \text { production | Alloc Def, S }\end{array}$ & $39,926,023$ & $\mathrm{~kg}$ \\
\hline & & Rock crushing $\{$ Row $\} \mid$ processing $\mid$ Alloc Def, S & $39,926,023$ & $\mathrm{~kg}$ \\
\hline & Base Agg & Gravel, crushed $\{$ RoW\}|production|Alloc Def, S & $13,135,545$ & $\mathrm{~kg}$ \\
\hline \multirow{5}{*}{ 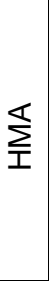 } & Binder & Bitumen adhesive compound, hot $\{$ RoW $\} \mid$ production|Alloc Def, S & 55,462 & $\mathrm{~kg}$ \\
\hline & RAP binder & Diesel $\{$ RoW $\} \mid$ petroleum refinery operation|Alloc Def, S & 9 & $\mathrm{~kg}$ \\
\hline & FRAP & Diesel $\{$ RoW $\} \mid$ petroleum refinery operation|Alloc Def, $S$ & 692 & $\mathrm{~kg}$ \\
\hline & RAS & Diesel $\{$ RoW $\} \mid$ petroleum refinery operation|Alloc Def, $S$ & 76 & $\mathrm{~kg}$ \\
\hline & HMA Agg & Gravel, crushed $\{$ RoW\}|production|Alloc Def, S & $1,800,590$ & $\mathrm{~kg}$ \\
\hline \multirow{2}{*}{ 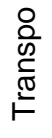 } & Truck & Transpork, single unit truck, diesel powered, US & $2,761,521$ & $\mathrm{tkm}$ \\
\hline & Barbe & Transport, barge, average fuel mix/US & 926,185 & tkm \\
\hline \multicolumn{5}{|c|}{ MAINTENANCE } \\
\hline \multirow{3}{*}{ 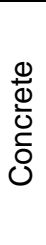 } & $\begin{array}{l}\text { Cement } \\
\text { with Fly Ash }\end{array}$ & $\begin{array}{l}\text { Cement, pozzolana and fly ash } 15-40 \% \text {, US only } \\
\text { \{US\}|production|Alloc Def, S }\end{array}$ & 134,338 & $\mathrm{~kg}$ \\
\hline & PCC Agg & Gravel, crushed $\{$ RoW\}|production|Alloc Def, S & 797,799 & $\mathrm{~kg}$ \\
\hline & $\begin{array}{l}\text { Water in } \\
\text { PCC }\end{array}$ & $\begin{array}{c}\text { Tap water }\{\text { RoW }\} \mid \text { tap water production, conventional treatment|Alloc } \\
\text { Def, S }\end{array}$ & 94,180 & $\mathrm{~kg}$ \\
\hline \multirow{4}{*}{ 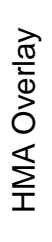 } & Binder & Bitumen adhesive compound, hot $\{$ RoW $\} \mid$ production|Alloc Def, S & 670,546 & $\mathrm{~kg}$ \\
\hline & RAS & Diesel $\{$ RoW $\} \mid$ petroleum refinery operation|Alloc Def, $S$ & 477 & $\mathrm{~kg}$ \\
\hline & FRAP & Diesel $\{$ RoW $\} \mid$ petroleum refinery operation|Alloc Def, $S$ & 3,173 & $\mathrm{~kg}$ \\
\hline & Other Agg & Gravel, crushed $\{$ RoW\}|production|Alloc Def, S & $9,753,361$ & $\mathrm{~kg}$ \\
\hline \multirow{2}{*}{ 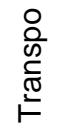 } & Truck & Transpork, single unit truck, diesel powered, US & 223,886 & $\mathrm{tkm}$ \\
\hline & Barge & Transport, barge, average fuel mix/US & 33,343 & $\mathrm{tkm}$ \\
\hline
\end{tabular}


Table C8. Beltline Analysis: SimaPro inputs for Planned data Virgin design

\begin{tabular}{|c|c|c|c|c|}
\hline \multicolumn{5}{|c|}{ INITIAL CONSTRUCTION } \\
\hline \multicolumn{2}{|r|}{ Material } & SimaPro Process & Input (kg) & Unit \\
\hline \multirow{3}{*}{$\begin{array}{l}0 \\
\frac{0}{0} \\
\frac{0}{0} \\
0\end{array}$} & Cement & Cement, Portland $\{$ US\}|production|Alloc Def, S & $4,019,293$ & $\mathrm{~kg}$ \\
\hline & PCC Agg & Gravel, crushed $\{$ RoW\}|production|Alloc Def, S & $23,477,192$ & $\mathrm{~kg}$ \\
\hline & $\begin{array}{l}\text { Water in } \\
\text { PCC }\end{array}$ & $\begin{array}{c}\text { Tap water }\{\text { RoW }\} \mid \text { tap water production, conventional treatment|Alloc } \\
\text { Def, } S\end{array}$ & $2,712,607$ & $\mathrm{~kg}$ \\
\hline \multicolumn{2}{|c|}{ Base Agg } & Gravel, crushed $\{$ RoW\}|production|Alloc Def, S & $64,100,970$ & $\mathrm{~kg}$ \\
\hline \multirow{2}{*}{ 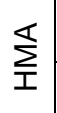 } & Binder & Bitumen adhesive compound, hot $\{$ RoW $\}$ |production|Alloc Def, $S$ & 96,178 & $\mathrm{~kg}$ \\
\hline & HMA Agg & Gravel, crushed $\{$ RoW\}|production|Alloc Def, S & $2,311,477$ & $\mathrm{~kg}$ \\
\hline \multirow{2}{*}{ 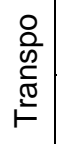 } & Truck & Transpork, single unit truck, diesel powered, US & $3,303,607$ & tkm \\
\hline & Barbe & Transport, barge, average fuel mix/US & $1,347,048$ & tkm \\
\hline \multicolumn{5}{|c|}{ MAINTENANCE } \\
\hline \multirow{3}{*}{$\begin{array}{l}\frac{0}{0} \\
\frac{0}{0} \\
0 \\
0\end{array}$} & Cement & Cement, Portland $\{$ US\}|production|Alloc Def, S & 134,338 & $\mathrm{~kg}$ \\
\hline & PCC Agg & Gravel, crushed $\{$ RoW\}|production|Alloc Def, S & 797,799 & $\mathrm{~kg}$ \\
\hline & $\begin{array}{l}\text { Water in } \\
\text { PCC }\end{array}$ & $\begin{array}{c}\text { Tap water }\{\text { RoW }\} \mid \text { tap water production, conventional treatment|Alloc } \\
\text { Def, } S\end{array}$ & 94,180 & $\mathrm{~kg}$ \\
\hline \multirow{2}{*}{ 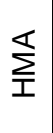 } & Binder & Bitumen adhesive compound, hot $\{$ RoW $\} \mid$ production|Alloc Def, S & 670,546 & $\mathrm{~kg}$ \\
\hline & Other Agg & Gravel, crushed $\{$ RoW\}|production|Alloc Def, S & $12,191,701$ & $\mathrm{~kg}$ \\
\hline \multirow{2}{*}{ 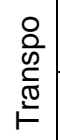 } & Truck & Transpork, single unit truck, diesel powered, US & 212,174 & tkm \\
\hline & Barge & Transport, barge, average fuel mix/US & 52,429 & tkm \\
\hline
\end{tabular}


Table C9. Beltline Analysis: SimaPro inputs for Constructed data Recycled design

\begin{tabular}{|c|c|c|c|c|}
\hline \multicolumn{5}{|c|}{ INITIAL CONSTRUCTION } \\
\hline \multicolumn{2}{|r|}{ Material } & SimaPro Process & Input (kg) & Unit \\
\hline \multirow{4}{*}{$\begin{array}{l}\frac{0}{0} \\
\frac{0}{0} \\
\overline{0} \\
0\end{array}$} & $\begin{array}{c}\text { Cement } \\
\text { with Fly Ash }\end{array}$ & $\begin{array}{c}\text { Cement, pozzolana and fly ash } 15-40 \% \text {, US only } \\
\text { \{US\}|production|Alloc Def, S }\end{array}$ & $4,394,146$ & $\mathrm{~kg}$ \\
\hline & $\begin{array}{l}\text { Cement } \\
\text { with Slag }\end{array}$ & $\begin{array}{c}\text { Cement, blast furnace slag 5-25\%, US only, }\{\text { US }\} \mid \text { production|Alloc } \\
\text { Def, S }\end{array}$ & 160,478 & $\mathrm{~kg}$ \\
\hline & PCC Agg & Gravel, crushed $\{$ RoW\}|production|Alloc Def, S & $29,811,630$ & $\mathrm{~kg}$ \\
\hline & $\begin{array}{l}\text { Water in } \\
\text { PCC }\end{array}$ & $\begin{array}{c}\text { Tap water }\{\text { RoW\}|tap water production, conventional treatment|Alloc } \\
\text { Def, S }\end{array}$ & $3,486,544$ & $\mathrm{~kg}$ \\
\hline \multirow{7}{*}{ 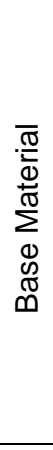 } & \multirow{2}{*}{ RAP onsite } & (Milling) Diesel $\{$ RoW\}|petroleum refinery operation|Alloc Def, S & 3,820 & $\mathrm{~kg}$ \\
\hline & & Rock crushing\{Row\}|processing $\mid$ Alloc Def, S & $16,737,604$ & $\mathrm{~kg}$ \\
\hline & \multirow{2}{*}{ RCA onsite } & $\begin{array}{c}\text { Waste concrete gravel }\{\mathrm{CH}\} \mid \text { treatment of, recycling|Alloc Def, S / } \\
\text { Concrete block }\{\text { RoW }\} \mid \text { production | Alloc Def, S }\end{array}$ & $16,833,357$ & $\mathrm{~kg}$ \\
\hline & & Rock crushing $\{$ Row $\} \mid$ processing|Alloc Def, $S$ & $16,833,357$ & $\mathrm{~kg}$ \\
\hline & \multirow{2}{*}{$\begin{array}{c}\mathrm{RCA} \\
\text { imported }\end{array}$} & $\begin{array}{c}\text { Waste concrete gravel }\{\mathrm{CH}\} \mid \text { treatment of, recycling } \mid \text { Alloc Def, S / } \\
\text { Concrete block }\{\mathrm{RoW}\} \mid \text { production | Alloc Def, S }\end{array}$ & $44,186,561$ & $\mathrm{~kg}$ \\
\hline & & Rock crushing\{Row\}|processing|Alloc Def, S & $44,186,561$ & $\mathrm{~kg}$ \\
\hline & Base Agg & Gravel, crushed $\{$ RoW\}|production|Alloc Def, S & $19,295,275$ & $\mathrm{~kg}$ \\
\hline \multirow{5}{*}{ 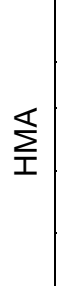 } & Binder & Bitumen adhesive compound, hot $\{$ RoW $\} \mid$ production|Alloc Def, S & 225,940 & $\mathrm{~kg}$ \\
\hline & RAP binder & Diesel $\{$ RoW\}|petroleum refinery operation|Alloc Def, $S$ & 15 & $\mathrm{~kg}$ \\
\hline & FRAP & Diesel $\{$ RoW\}|petroleum refinery operation|Alloc Def, S & 1,327 & $\mathrm{~kg}$ \\
\hline & RAS & Diesel $\{$ RoW $\} \mid$ petroleum refinery operation|Alloc Def, $S$ & 149 & $\mathrm{~kg}$ \\
\hline & HMA Agg & Gravel, crushed $\{$ RoW\}|production|Alloc Def, S & $4,482,395$ & $\mathrm{~kg}$ \\
\hline \multirow{2}{*}{ 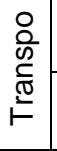 } & Truck & Transpork, single unit truck, diesel powered, US & $3,292,300$ & $\mathrm{tkm}$ \\
\hline & Barbe & Transport, barge, average fuel mix/US & $1,183,206$ & $\mathrm{tkm}$ \\
\hline \multicolumn{5}{|c|}{ MAINTENANCE } \\
\hline \multirow{3}{*}{$\begin{array}{l}\frac{\Phi}{0} \\
\frac{0}{0} \\
\frac{0}{0} \\
0\end{array}$} & $\begin{array}{c}\text { Cement } \\
\text { with Fly Ash }\end{array}$ & $\begin{array}{c}\text { Cement, pozzolana and fly ash } 15-40 \% \text {, US only } \\
\text { \{US\}|production|Alloc Def, S }\end{array}$ & 134,338 & $\mathrm{~kg}$ \\
\hline & PCC Agg & Gravel, crushed $\{$ RoW\}|production|Alloc Def, S & 797,799 & $\mathrm{~kg}$ \\
\hline & $\begin{array}{l}\text { Water in } \\
\text { PCC }\end{array}$ & $\begin{array}{c}\text { Tap water }\{\text { RoW }\} \mid \text { tap water production, conventional treatment|Alloc } \\
\text { Def, S }\end{array}$ & 94,180 & $\mathrm{~kg}$ \\
\hline \multirow{4}{*}{ 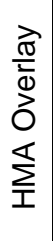 } & Binder & Bitumen adhesive compound, hot $\{$ RoW $\} \mid$ production|Alloc Def, S & 670,546 & $\mathrm{~kg}$ \\
\hline & RAS & Diesel $\{$ RoW $\} \mid$ petroleum refinery operation|Alloc Def, S & 477 & $\mathrm{~kg}$ \\
\hline & FRAP & Diesel $\{$ RoW $\} \mid$ petroleum refinery operation|Alloc Def, S & 3,173 & $\mathrm{~kg}$ \\
\hline & Other Agg & Gravel, crushed $\{$ RoW\}|production|Alloc Def, S & $9,753,361$ & $\mathrm{~kg}$ \\
\hline \multirow{2}{*}{ 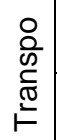 } & Truck & Transpork, single unit truck, diesel powered, US & 223,886 & $\mathrm{tkm}$ \\
\hline & Barge & Transport, barge, average fuel mix/US & 33,343 & tkm \\
\hline
\end{tabular}


Table C10. Beltline Analysis: SimaPro inputs for Constructed data Virgin design

\begin{tabular}{|c|c|c|c|c|}
\hline \multicolumn{5}{|c|}{ INITIAL CONSTRUCTION } \\
\hline \multicolumn{2}{|r|}{ Material } & SimaPro Process & Input (kg) & Unit \\
\hline \multirow{3}{*}{$\begin{array}{l}\frac{\Phi}{0} \\
\frac{0}{0} \\
0 \\
0\end{array}$} & Cement & Cement, Portland $\{U S\} \mid$ production|Alloc Def, S & $4,554,624$ & $\mathrm{~kg}$ \\
\hline & PCC Agg & Gravel, crushed $\{$ RoW\}|production|Alloc Def, S & $29,811,630$ & $\mathrm{~kg}$ \\
\hline & $\begin{array}{l}\text { Water in } \\
\text { PCC }\end{array}$ & $\begin{array}{c}\text { Tap water }\{\text { RoW\}|tap water production, conventional treatment|Alloc } \\
\text { Def, } S\end{array}$ & $4,150,647$ & $\mathrm{~kg}$ \\
\hline \multicolumn{2}{|c|}{ Base Agg } & Gravel, crushed $\{$ RoW\}|production|Alloc Def, S & $158,072,716$ & $\mathrm{~kg}$ \\
\hline \multirow{2}{*}{ 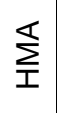 } & Binder & Bitumen adhesive compound, hot $\{$ RoW $\} \mid$ production|Alloc Def, S & 290,043 & $\mathrm{~kg}$ \\
\hline & HMA Agg & Gravel, crushed $\{$ RoW\}|production|Alloc Def, S & $5,463,400$ & $\mathrm{~kg}$ \\
\hline \multirow{2}{*}{ 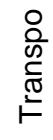 } & Truck & Transpork, single unit truck, diesel powered, US & $4,365,838$ & tkm \\
\hline & Barbe & Transport, barge, average fuel mix/US & $1,471,719$ & $\mathrm{tkm}$ \\
\hline \multicolumn{5}{|c|}{ MAINTENANCE } \\
\hline \multirow{3}{*}{$\begin{array}{l}\frac{\Phi}{0} \\
\frac{0}{0} \\
0 \\
0\end{array}$} & Cement & Cement, Portland $\{$ US\}|production|Alloc Def, S & 134,338 & $\mathrm{~kg}$ \\
\hline & PCC Agg & Gravel, crushed $\{$ RoW\}|production|Alloc Def, S & 797,799 & $\mathrm{~kg}$ \\
\hline & $\begin{array}{l}\text { Water in } \\
\text { PCC }\end{array}$ & $\begin{array}{c}\text { Tap water }\{\text { RoW }\} \mid \text { tap water production, conventional treatment|Alloc } \\
\text { Def, S }\end{array}$ & 94,180 & $\mathrm{~kg}$ \\
\hline \multirow{2}{*}{ 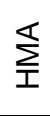 } & Binder & Bitumen adhesive compound, hot $\{$ RoW $\} \mid$ production|Alloc Def, S & 670,546 & $\mathrm{~kg}$ \\
\hline & Other Agg & Gravel, crushed $\{$ RoW\}|production|Alloc Def, S & $12,191,701$ & $\mathrm{~kg}$ \\
\hline \multirow{2}{*}{ 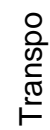 } & Truck & Transpork, single unit truck, diesel powered, US & 212,174 & tkm \\
\hline & Barge & Transport, barge, average fuel mix/US & 52,429 & $\mathrm{tkm}$ \\
\hline
\end{tabular}


Table C11. I-94 Analysis: SimaPro inputs for Recycled design

\begin{tabular}{|c|c|c|c|c|}
\hline \multicolumn{2}{|r|}{ Material } & SimaPro Process & Input (kg) & Unit \\
\hline \multirow{3}{*}{$\begin{array}{l}\frac{\emptyset}{0} \\
\frac{0}{0} \\
0 \\
0\end{array}$} & $\begin{array}{l}\text { Cement } \\
\text { with Fly Ash }\end{array}$ & $\begin{array}{c}\text { Cement, pozzolana and fly ash } 15-40 \% \text {, US only } \\
\{\text { US }\} \text { |production|Alloc Def, } S\end{array}$ & $7,034,918$ & $\mathrm{~kg}$ \\
\hline & PCC Agg & Gravel, crushed $\{$ RoW\}|production|Alloc Def, S & $24,929,956$ & $\mathrm{~kg}$ \\
\hline & $\begin{array}{l}\text { Water in } \\
\text { PCC }\end{array}$ & $\begin{array}{c}\text { Tap water }\{\text { RoW }\} \mid \text { tap water production, conventional treatment|Alloc } \\
\text { Def, } S\end{array}$ & $2,904,861$ & $\mathrm{~kg}$ \\
\hline \multirow{5}{*}{ 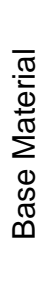 } & \multirow{2}{*}{ RAP onsite } & (Milling) Diesel $\{$ RoW $\} \mid$ petroleum refinery operation $\mid$ Alloc Def, $S$ & 3,967 & $\mathrm{~kg}$ \\
\hline & & Rock crushing $\{$ Row $\} \mid$ processing $\mid$ Alloc Def, S & $17,643,034$ & $\mathrm{~kg}$ \\
\hline & \multirow[t]{2}{*}{ RCA onsite } & $\begin{array}{c}\text { Waste concrete gravel }\{\mathrm{CH}\} \mid \text { treatment of, recycling|Alloc Def, S / } \\
\text { Concrete block }\{\mathrm{RoW}\} \mid \text { production | Alloc Def, S }\end{array}$ & $24,640,947$ & $\mathrm{~kg}$ \\
\hline & & Rock crushing\{Row\}|processing $\mid$ Alloc Def, S & $24,640,947$ & $\mathrm{~kg}$ \\
\hline & Base Agg & Gravel, crushed $\{$ RoW\}|production|Alloc Def, S & $40,024,297$ & $\mathrm{~kg}$ \\
\hline \multirow{3}{*}{ 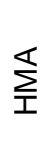 } & Binder & Bitumen adhesive compound, hot $\{$ RoW $\} \mid$ production|Alloc Def, S & $1,619,824$ & $\mathrm{~kg}$ \\
\hline & FRAP & Diesel $\{$ RoW $\} \mid$ petroleum refinery operation|Alloc Def, S & 833 & $\mathrm{~kg}$ \\
\hline & HMA Agg & Gravel, crushed $\{$ RoW\}|production|Alloc Def, S & $27,071,792$ & $\mathrm{~kg}$ \\
\hline$\stackrel{\frac{r}{c}}{\frac{\sigma}{\sigma}}$ & Bottom ash & \multicolumn{3}{|l|}{$\mathrm{n} / \mathrm{a}$ - byproduct } \\
\hline 岂 & $\begin{array}{l}\text { Foundry } \\
\text { sand }\end{array}$ & \multicolumn{3}{|l|}{$\mathrm{n} / \mathrm{a}$ - byproduct } \\
\hline \multicolumn{2}{|c|}{ Truck Transpo } & Transport, single unit truck, diesel powered, US & $7,396,069$ & tkm \\
\hline
\end{tabular}

Table C12. I-94 Analysis: SimaPro inputs for Virgin design

\begin{tabular}{|c|c|c|c|c|}
\hline \multicolumn{2}{|r|}{ Material } & SimaPro Process & Input (kg) & Unit \\
\hline \multirow{3}{*}{ 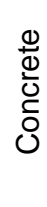 } & Cement & Cement, Portland $\{U S\} \mid$ production|Alloc Def, S & $7,034,918$ & $\mathrm{~kg}$ \\
\hline & PCC Agg & Gravel, crushed $\{$ RoW\}|production|Alloc Def, S & $24,929,956$ & $\mathrm{~kg}$ \\
\hline & $\begin{array}{l}\text { Water in } \\
\text { PCC }\end{array}$ & $\begin{array}{c}\text { Tap water }\{\text { RoW }\} \mid \text { tap water production, conventional treatment|Alloc } \\
\text { Def, } S\end{array}$ & $2,904,861$ & $\mathrm{~kg}$ \\
\hline \multicolumn{2}{|c|}{ Base Agg } & Gravel, crushed $\{$ RoW\}|production|Alloc Def, S & $82,308,278$ & $\mathrm{~kg}$ \\
\hline \multirow{2}{*}{ 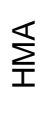 } & Binder & Bitumen adhesive compound, hot $\{$ RoW $\} \mid$ production|Alloc Def, S & $1,619,824$ & $\mathrm{~kg}$ \\
\hline & HMA Agg & Gravel, crushed $\{$ RoW\}|production|Alloc Def, S & $30,776,651$ & $\mathrm{~kg}$ \\
\hline \multirow{2}{*}{$\begin{array}{l}\text { 돓 } \\
\text { ह్ } \\
\text { జ్ }\end{array}$} & Granular fill & Gravel, crushed $\{$ RoW\}|production|Alloc Def, S & $214,612,273$ & $\mathrm{~kg}$ \\
\hline & Sand & Sand $\{R O W\} \mid$ gravel and quarry operation|Alloc Def, $S$ & $15,968,175$ & $\mathrm{~kg}$ \\
\hline \multicolumn{2}{|c|}{ Truck Transpo } & Transport, single unit truck, diesel powered, US & $14,023,946$ & $\mathrm{tkm}$ \\
\hline
\end{tabular}




\section{C.2 Figures}

\section{C.2.1 SimaPro Networks}

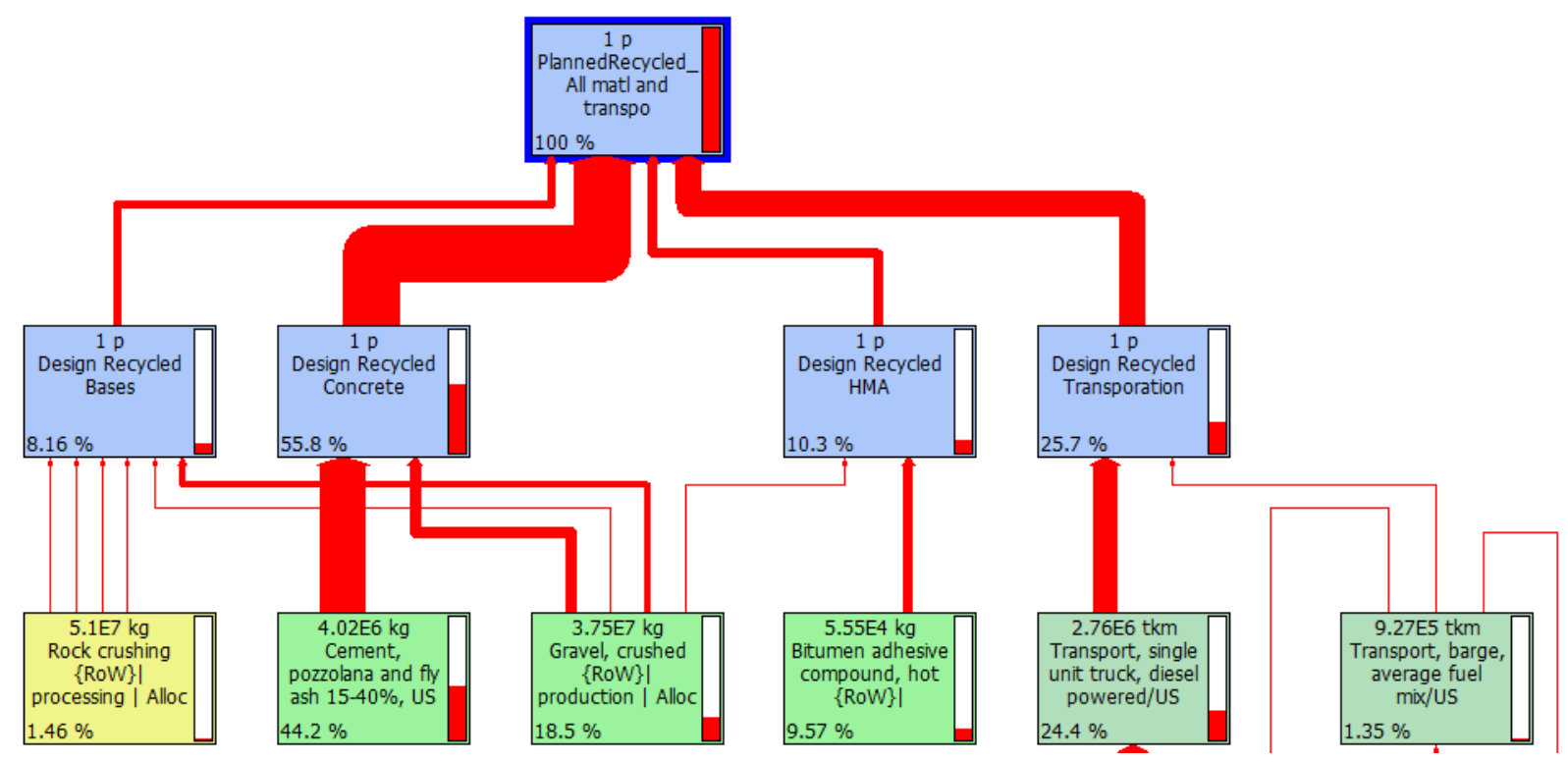

Figure C1. Beltline Analysis: SimaPro network of energy flows for Planned data Recycled design

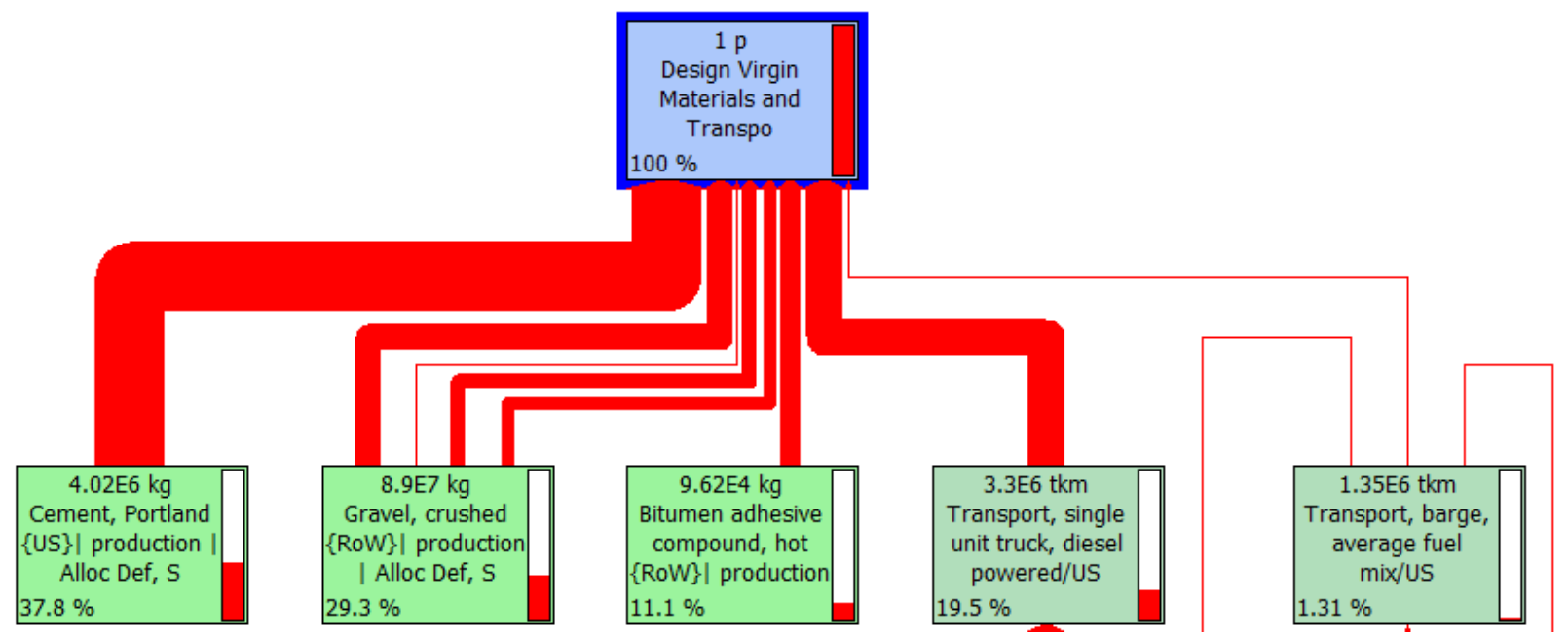

Figure C2. Beltline Analysis: SimaPro network of energy flows for Planned data Virgin design 


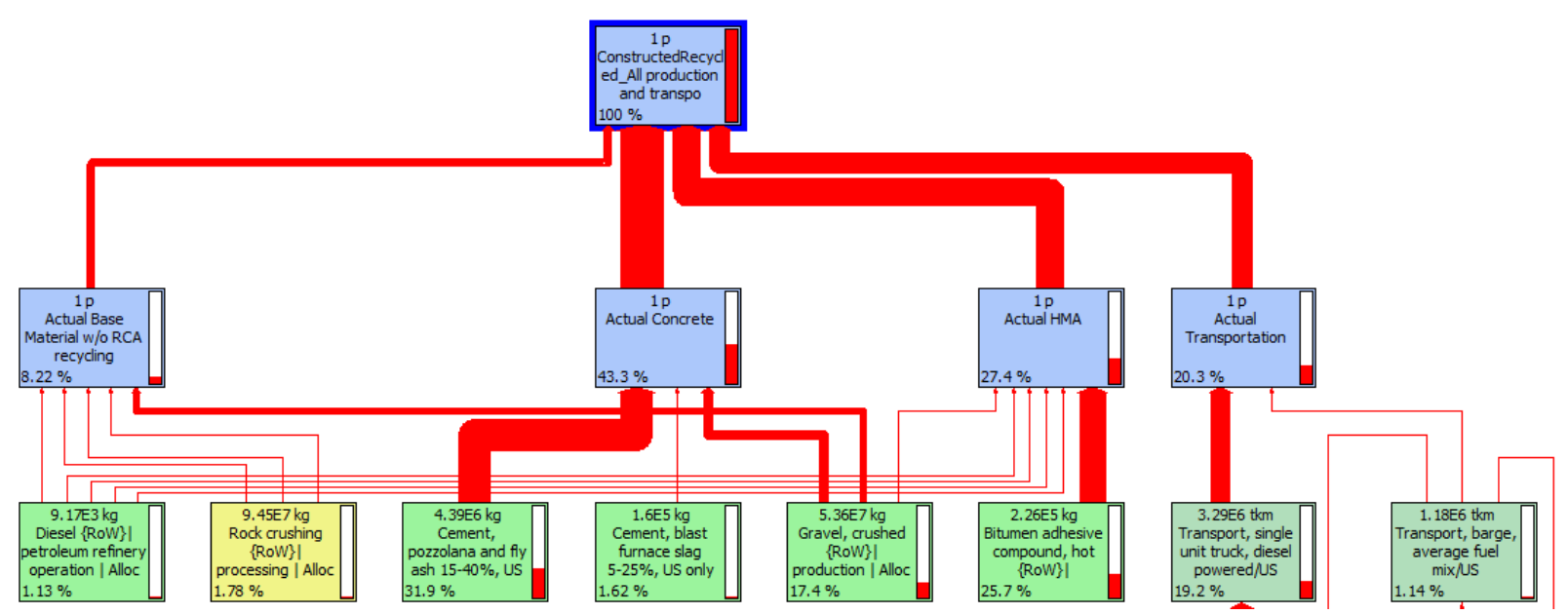

Figure C3. Beltline Analysis: SimaPro network of energy flows for Constructed data Recycled design

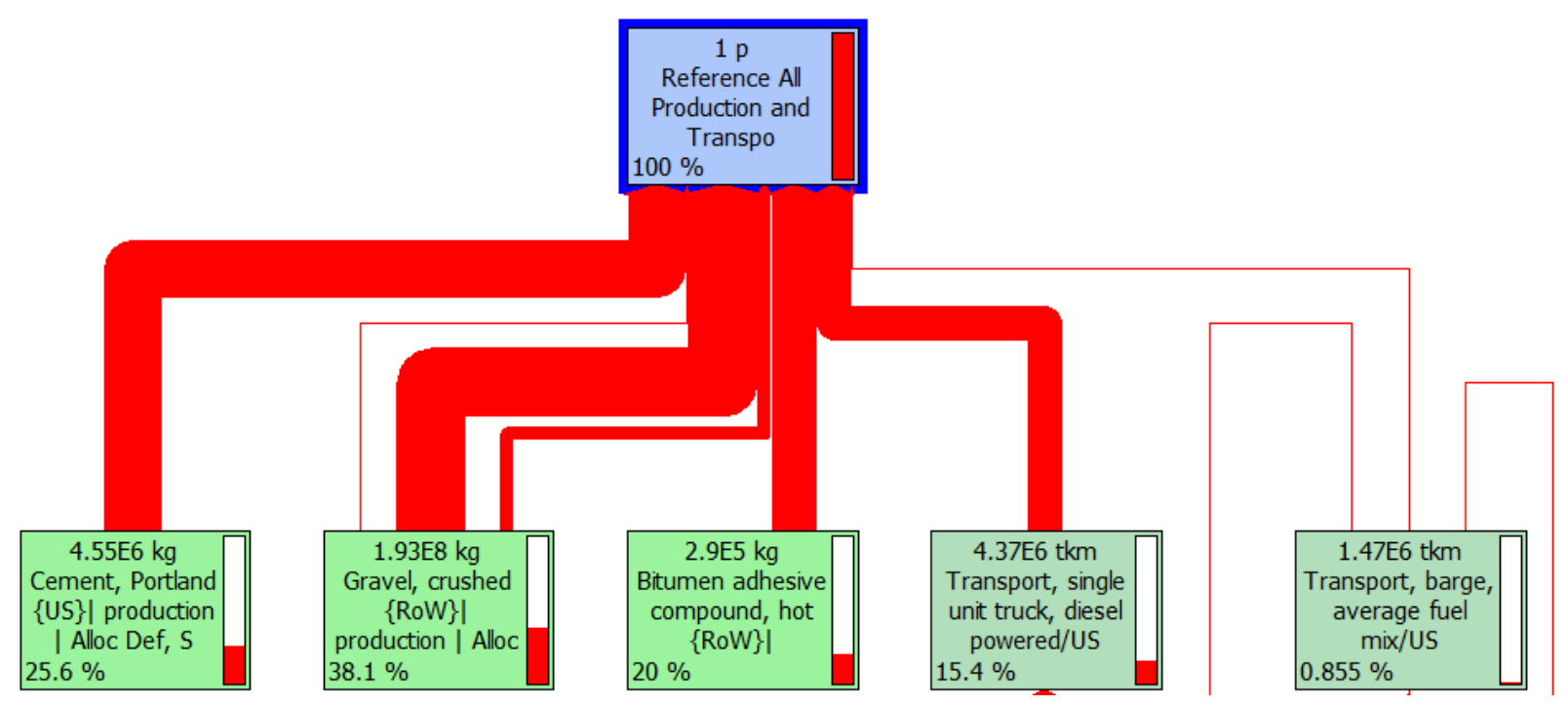

Figure C4. Beltline Analysis: SimaPro network of energy flows for Constructed data Recycled design 


\section{C.2.2 Site Photos}

\section{C.2.2.1 I-94 Reconstruction Photos}

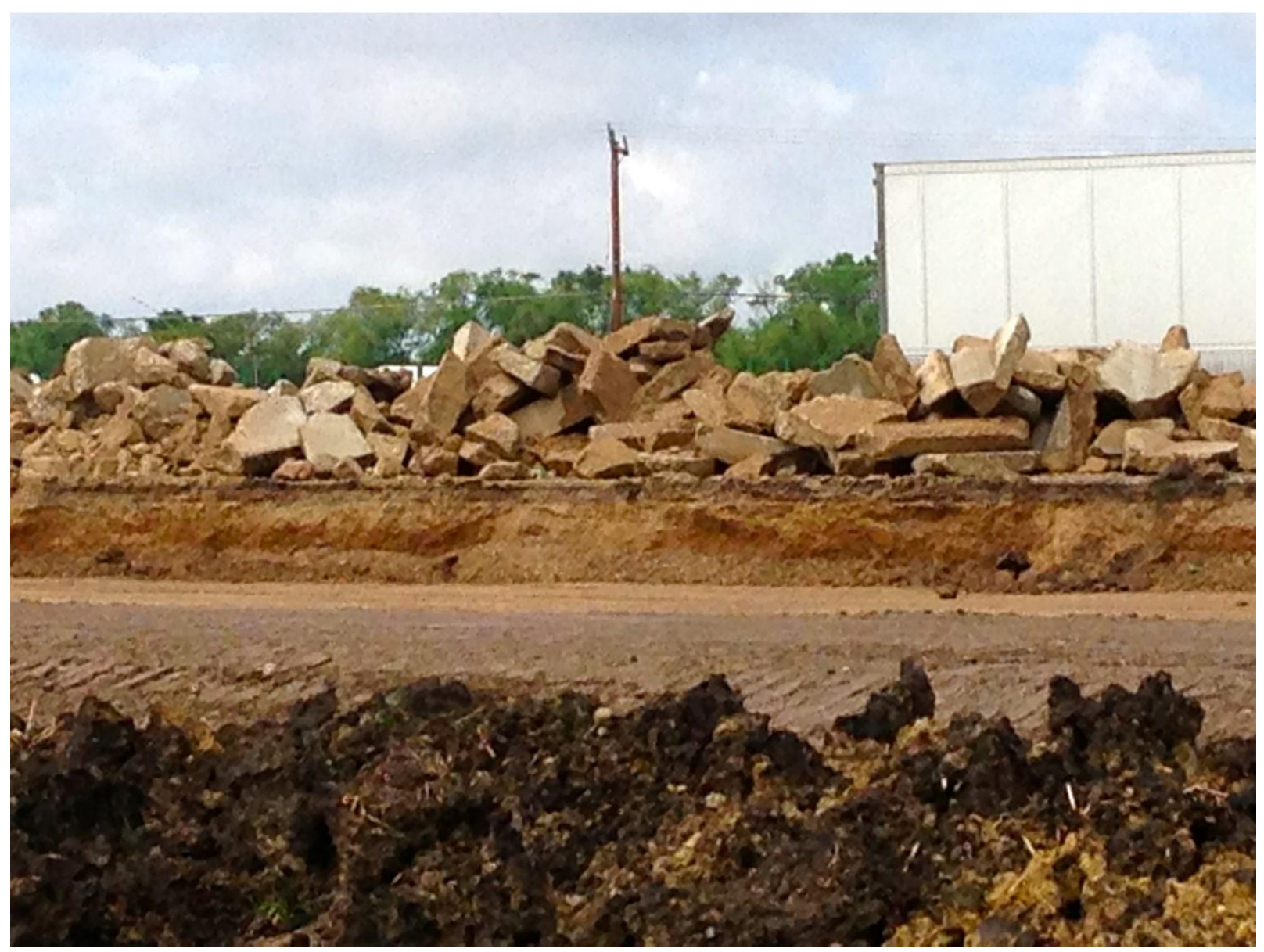

Figure C5. Demolished concrete pavement stockpiled onsite (June 2013) 


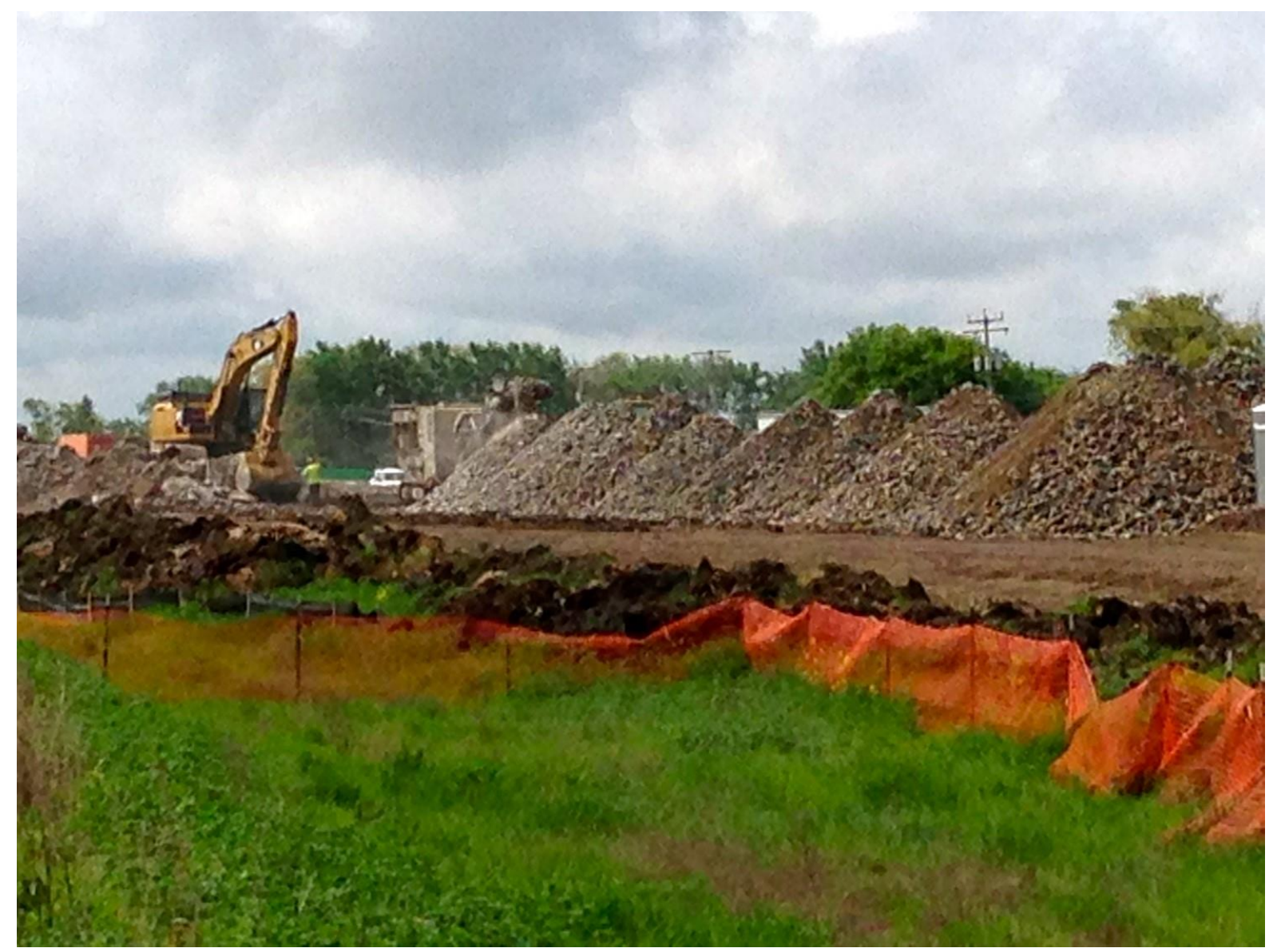

Figure C6. Photo of on-going concrete crushing for RCA; RCA stockpiled onsite (June 2013) 


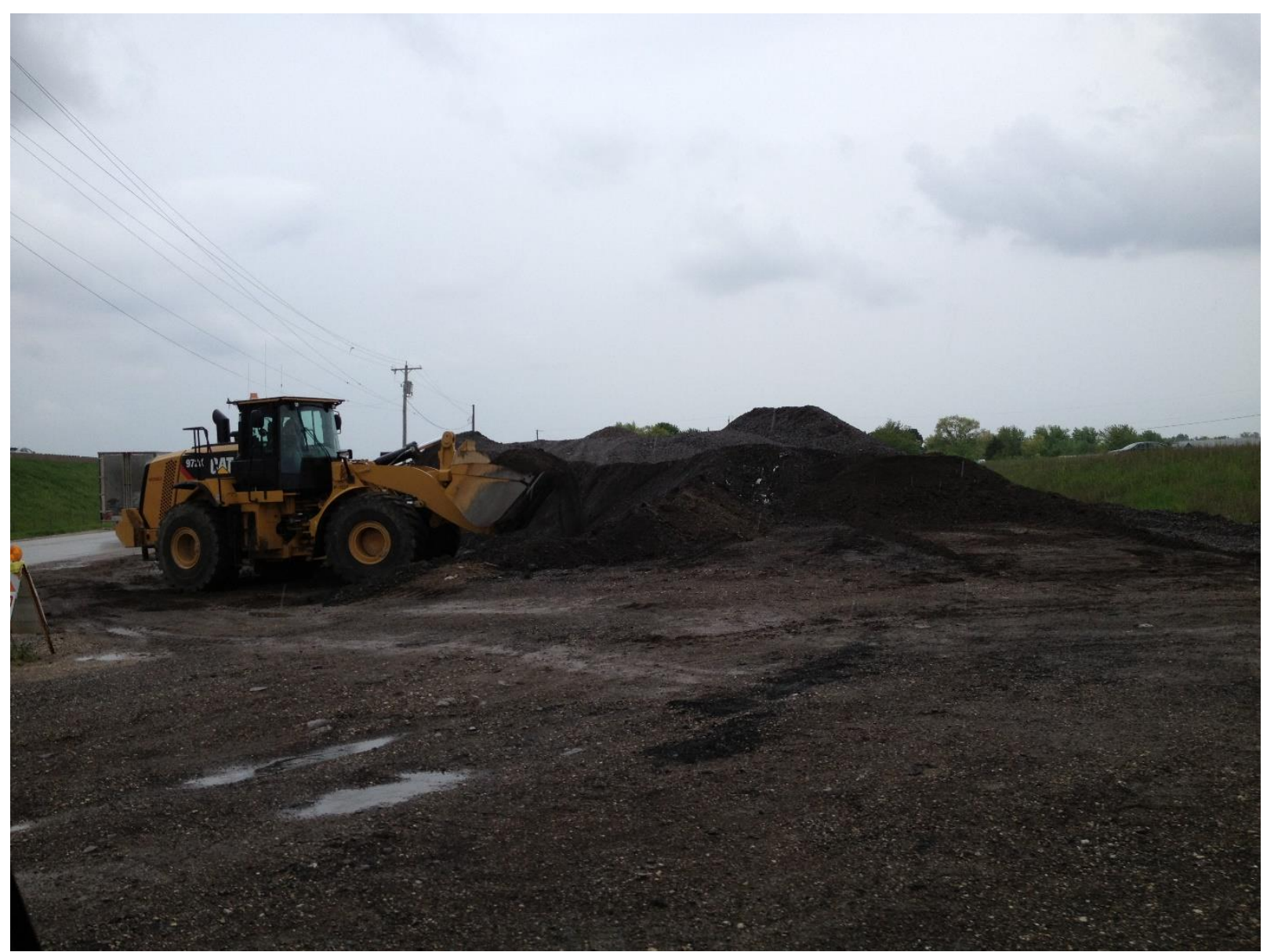

Figure C7. We Energies fly ash used in concrete mix; We Energies dug fly ash out from landfill nearby their coal power plant for use on the roadway (June 2013) 


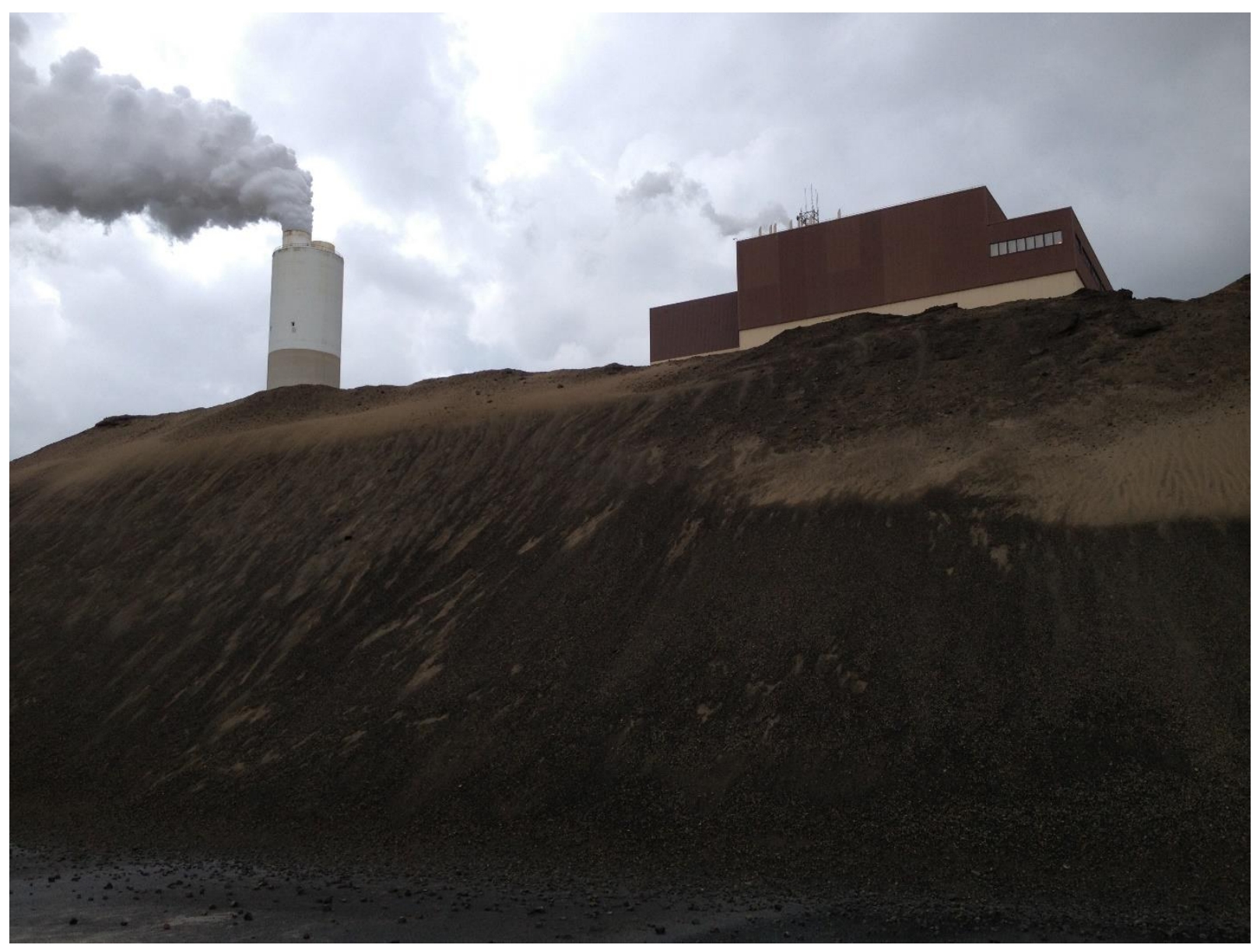

Figure C8. Bottom ash stockpiled at We Energies coal power plant (June 2013) 


\section{C.2.2.2 Beltline Reconstruction Photos}

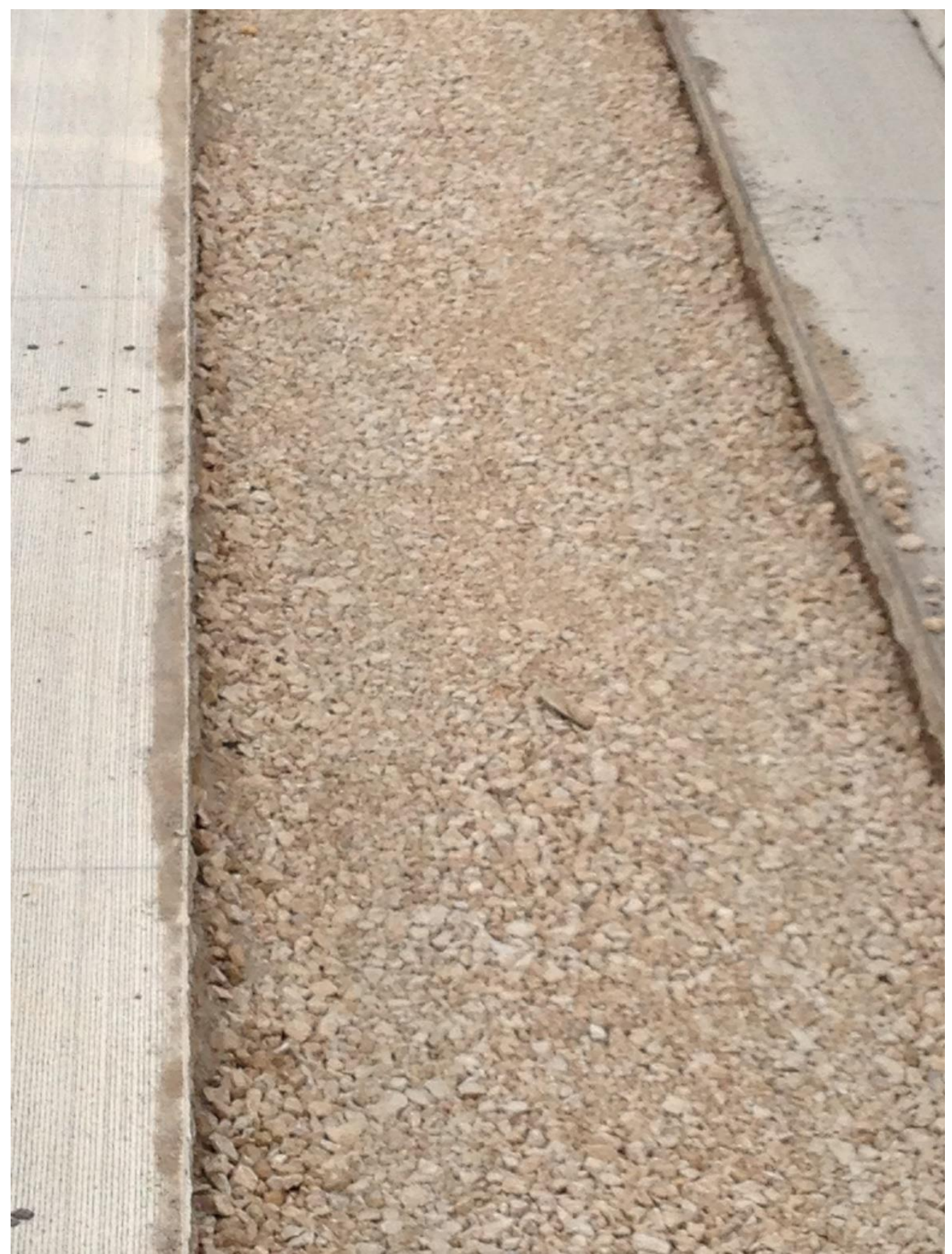

Figure C9. Base aggregate below concrete surface one-lane in width, consist of onsite RCA and RAP, imported RCA, and virgin aggregate (September 2015) 


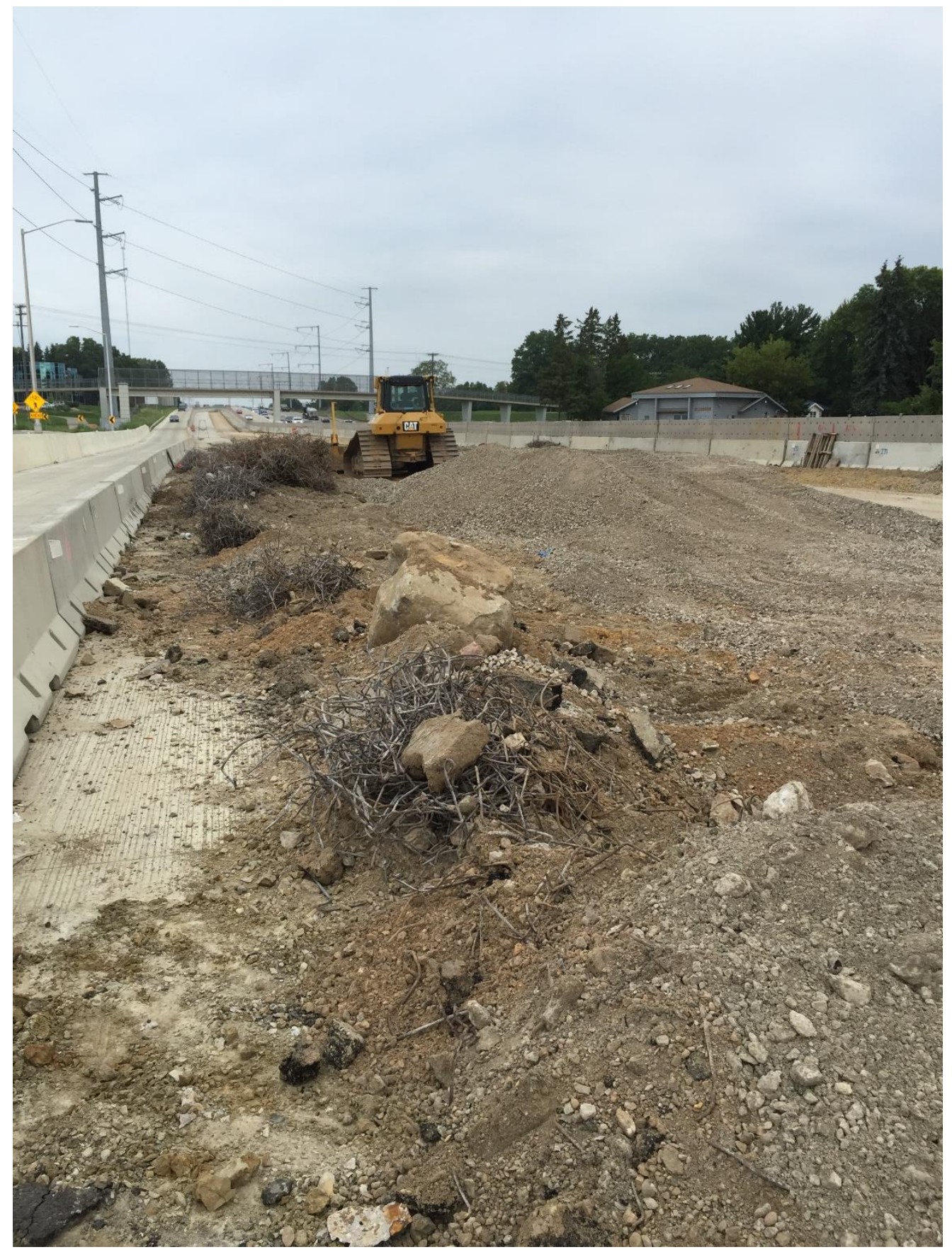

Figure $\mathrm{C} 10$. Onsite recycled pavement stockpiles; rebar is removed from existing pavement and discarded (September 2015) 


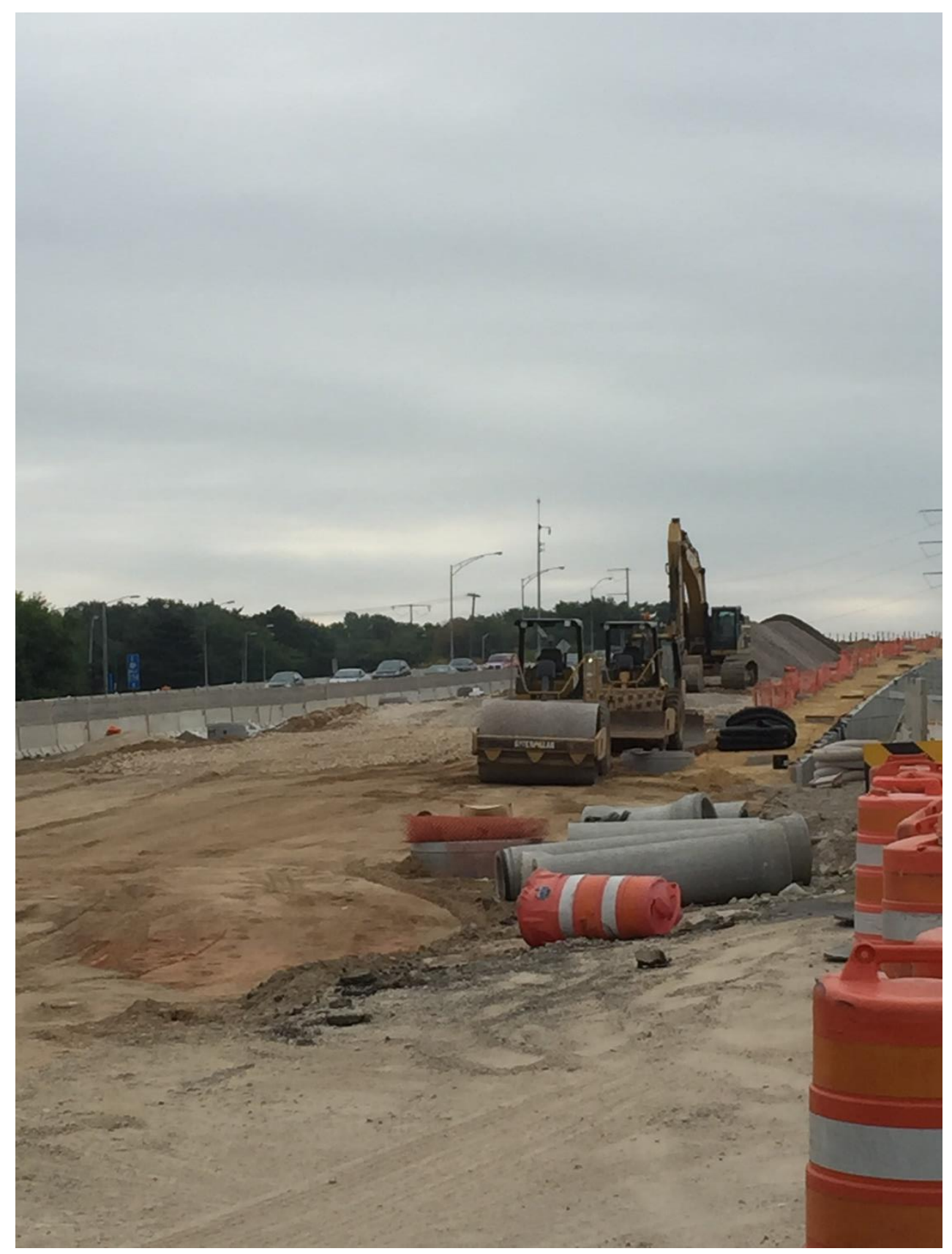

Figure C11. Construction of base course on one of project's bridges; aggregate is stockpiled in the background (September 2015) 


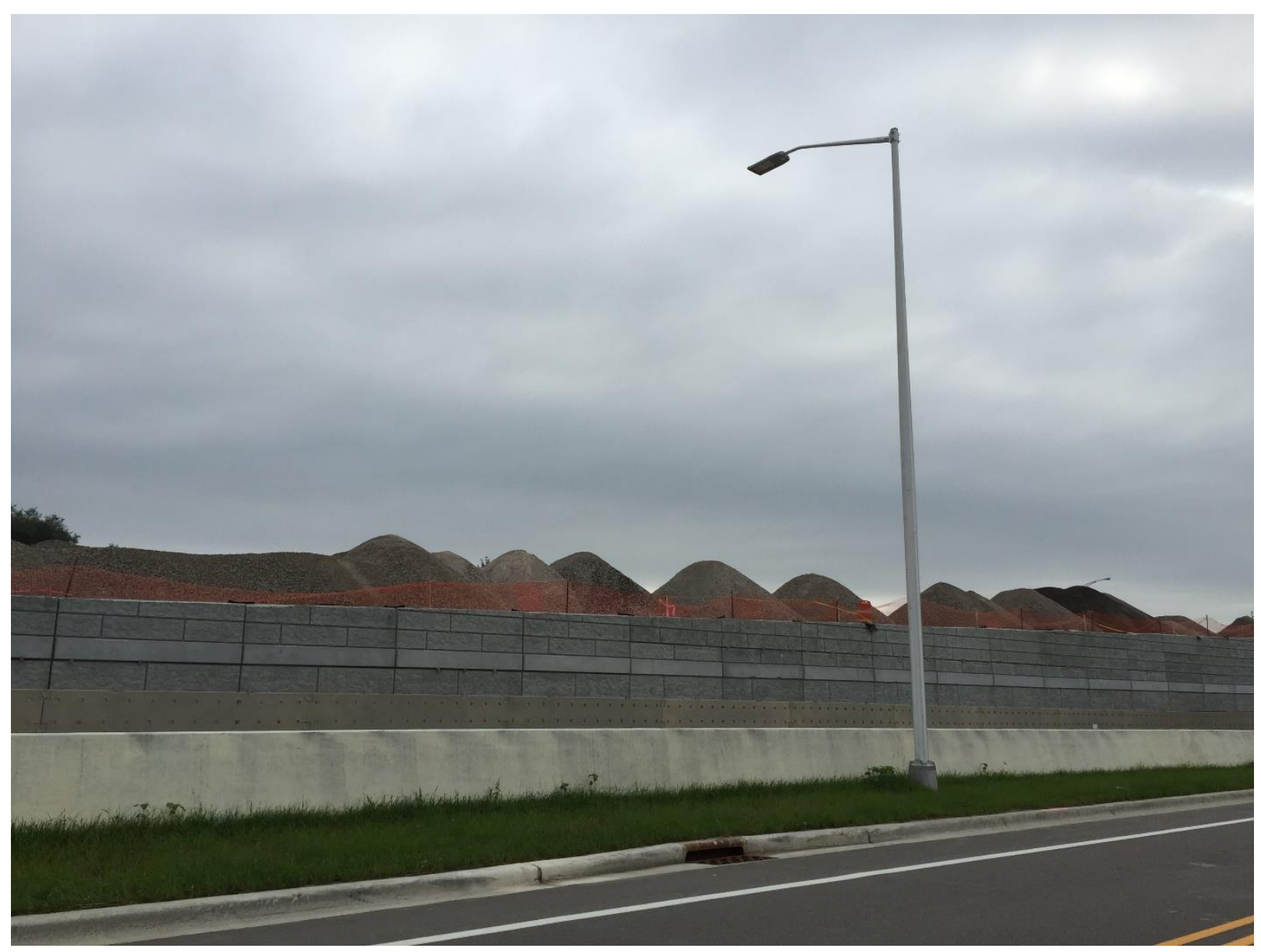

Figure C12. Recycled aggregate stockpiled onsite; space for stockpiling was sparse in urban environment and some piles were placed on bridge/ramp expansions (September 2015) 


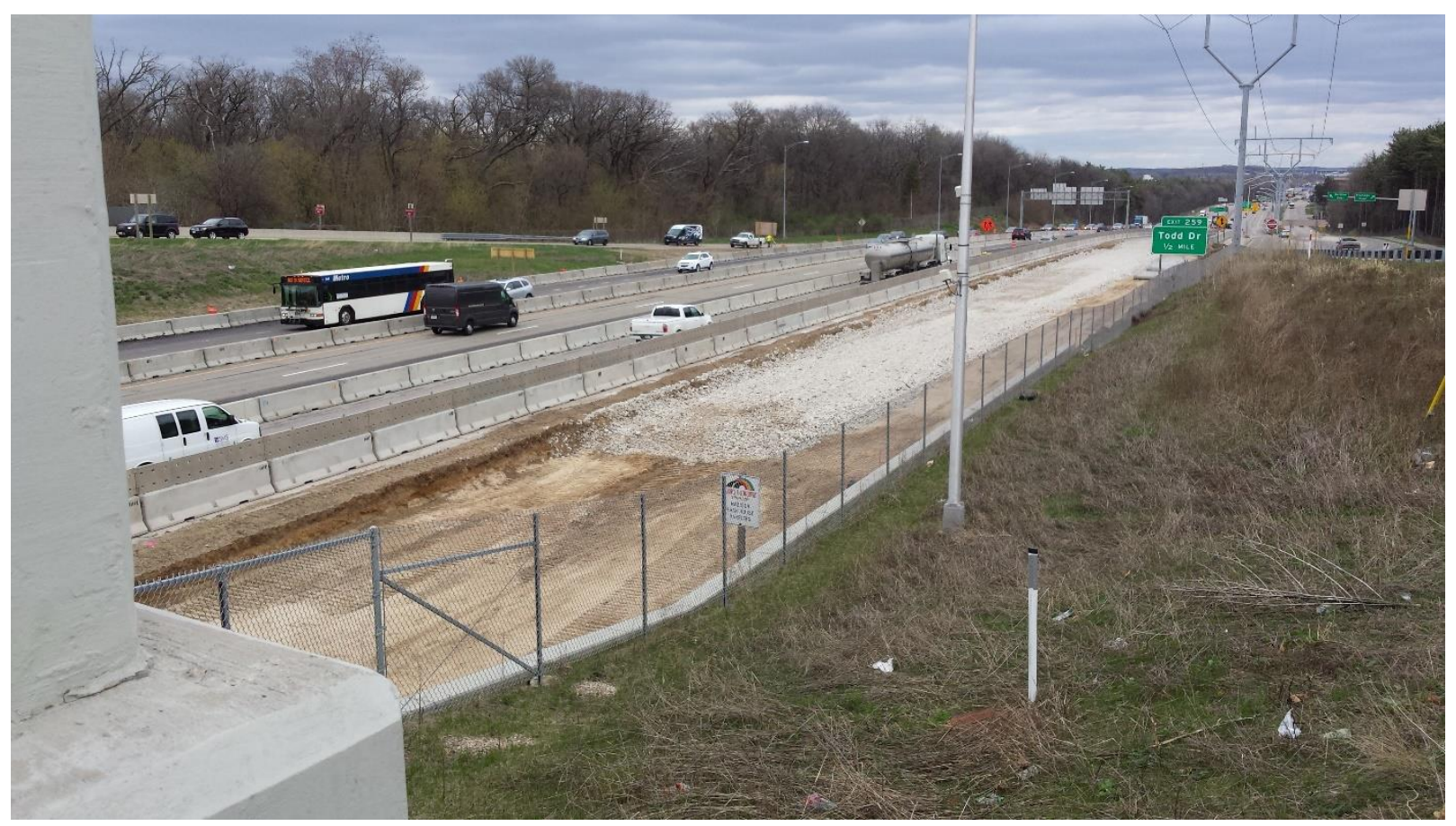

Figure C13. Aerial photo of eastbound Beltline reconstruction; base course is being placed (April 2015) 


\section{References}

AASHTO. (2008). Primer on Transportation and Climate Change.

ACAA. (2003). Fly Ash Facts for Highway Engineers (No. FHWA-IF-03-019). Federal Highway Administration. Retrieved from https://www.fhwa.dot.gov/pavement/recycling/fach00.cfm

ACAA. (2015). Beneficial Use of Coal Combustion Products: An American Recycling Success Story. The American Coal Ash Association. Retrieved from https://www.acaausa.org/Portals/9/Files/PDFs/Production-and-Use-Brochure.pdf

Adams, T., Bloom, E., Edil, T., Hanz, A., \& Schroeckenthaler, K. (2014). Cost-Effective Means of Managing Pavements in Poor Condition (No. CFIRE 05-0, MnDOT Contract N.o. 89264 Work Orde No. 5). National Center for Freight \& Infrastructure Research and Education (CFIRE). Retrieved from http://www.wistrans.org/cfire/research/projects/05-03/

Agri-footprint. (2015). Agri-footprint 2.0: Description of data.

Bloom, E., Del Ponte, K., Madras Natarajan, B., Pakes Ahlman, A., Edil, T., \& Whited, G. (In press). State DOT Life Cycle Benefits of Recycled Material in Road Construction. Presented at the Geo-Chicago 2016, Chicago, IL.

Bloom, E., Horstmeier, G., Pakes Ahlman, A., \& Edil, T. B. (2016). Assessing the Life Cycle Benefits of Recycled Material in Road Construction. Presented at the GeoChicago 2016, Chicago, IL.

Bloom, E., Pakes Ahlman, A., \& Edil, T. B. (In press). Life Cycle Assessment of Interstate 94 - A Case Study Report on the Successful Use of Recycled Materials in Highways. Wisconsin Department of Transportation.

Bozyurt, O., Tinjum, J. M., Son, Y.-H., Edil, T. B., \& Benson, C. H. (2012). Resilient modulus of recycled asphalt pavement and recycled concrete aggregate. Proc., GeoCongress 2012, GSP(225), 3901-3910. 
Chesner, W. H., Collins, R. J., \& MacKay, M. H. (1998). User Guidelines for Waste and By-Product Materials in Pavement Construction (No. FHWA-RD-97-148). Federal Highway Administration.

Chester, M. V., \& Horvath, A. (2009). Environmental assessment of passenter transportation should include infrastructure and supply chains. Environmental Research Letters, 4(2), 18.

Copeland, A. (2011). Reclaimed Asphalt Pavement in Asphalt Mixtures: State of the Practice (No. FHWA-HRT-11-021). Federal Highway Administration.

Cross, S. A., Chesner, W. H., Justus, H. G., \& Kearney, E. R. (2011). Life Cycle Environmental Analysis for the Evaluation of Pavement Rehabilitaiton Options. Presented at the 90th Annual Meeting of the Transporation Research Board, Washington, D.C.

DeCorla-Souza, P., Everett, J., Gardner, B., \& Culp, M. (1997). Total cost analysis: An alternative to benefit-cost analysis in evaluating transportation alternative. Transportation, 24(2), 107-123.

EarthShift. (2016). TRACI 2 Impact Assessment Method | EarthShift. Retrieved May 11, 2016, from http://www.earthshift.com/software/simapro/traci2

Edil, T. B. (2013). Characterization of recycled materials for sustainable construction. Proc. 18th ICSMGE. Retrieved from http://www.issmge.org/images/joomd/3195-3198.pdf

Edil, T. B., Tinjum, J. M., \& Benson, C. H. (2012). Recycled Unbound Materials (No. MN/RC 201235). Minnesota Department of Transportation.

Edil, T., Benson, C., Bin-Shafique, M., Tanyu, B., Kim, W.-H., \& Senol, A. (2002). Field evaluation of construction alternatives for roadways over soft subgrade. Transportation Research Record: Journal of the Transportation Research Board, (1786), 36-48.

FHWA. (1998). Life-Cycle Cost Analysis in Pavement Design (No. FHWA-SA-98-079). Federal Highway Administration. 
FHWA. (2004, August). RealCost User Manual. Retrieved June 3, 2015, from http://www.fhwa.dot.gov/infrastructure/asstmgmt/rc2100.cfm

FHWA. (2008). User Guideline for ByProducts and Secondary Use Materials in Pavement Construction (No. FHWA-RD-97-148). VA, U.S.A.: Federal Highway Administration.

FHWA. (2011). Work Zone Road User Costs: Concepts and Applications (No. FHWA-HOP-12005). U.S. Department of Transportation, Federal Highway Administration. Retrieved from http://www.ops.fhwa.dot.gov/wz/resources/publications/fhwahop12005/ fhwahop12005.pdf>

FHWA. (2014a). Concrete Pavement Rehabilitation Guide for Diamond Grinding. Retrieved June 3, 2015, from http://www.fhwa.dot.gov/pavement/concrete/diamond.cfm\#_Toc516391167 FHWA. (2014b). Life Cycle Assessment of Pavements (No. FHWA-HIF-15-001). Federal Highway Administration.

FHWA. (2016). User Guidelines for Waste and Byproduct Materials in Pavement Construction (No. FHWA-RD-97-148). Federal Highway Administration. Retrieved from http://www.fhwa.dot.gov/publications/research/infrastructure/structures/97148/index.cfm

Flexible Pavements of Ohio. (2015). Technical Bulletin: Cold Weather Paving. Retrieved from http://www.flexiblepavements.org/sites/www.flexiblepavements.org/files/cold_weather_p aving_tech_bull_rev27aug2015.pdf

Gambatese, J. A., \& Rajendran, S. (2005). Sustainable roadway construction: Energy consumption and material waste generation of roadways. In Construction Research Congress (Vol. 183). Retrieved from http://ascelibrary.org/doi/abs/10.1061/40754(183)21

Goedkoop, M., Oele, M., Leijting, J., Ponsioen, T., \& Meijer, E. (2016). Introduction to LCA with SimaPro. PRe Consulting.

Guthrie, W., Cooley, D., \& Eggett, D. (2007). Effects of Reclaimed Asphalt Pavement on Mechanical Properties of Base Materials. Transportation Research Record: Journal of the Transportation Research Board, 2005, 44-52. http://doi.org/10.3141/2005-06 
Hakkinen, T., \& Makela, K. (1996). Environmental adaption of concrete: Environmental impact of concrete and asphalt pavements. Technical Research Center of Finland (VTT).

Herrmann, I. T., \& Moltesen, A. (2015). Does it matter which Life Cycle Assessment (LCA) tool you choose? - a comparative assessment of SimaPro and GaBi. Journal of Cleaner Production, 86, 163-169. http://doi.org/10.1016/j.jclepro.2014.08.004

Horvath, A. (2007, June 5). PaLATE - Pavement Life-cycle Tool [UC Berkeley]. Retrieved March 24, 2015, from http://www.ce.berkeley.edu/ horvath/palate.html

Huang, Y., Galatioto, F., \& Parry, T. (2014). Road pavement maintenance life cycle assessment - A UK case studyO. Presented at the Internation Symposium on Pavement Life Cycle Assessment 2014, Davis, CA. Retrieved from http://www.ucprc.ucdavis.edu/pLCA2014/media/pdf/Papers/LCA14_UK\%20Case\%20Study\%20Pavement\%20Maintena nce.pdf

Huang, Y. H. (2003). Pavement Analysis and Design, 2nd Edition. New York: Prentice Hall.

Inamura, H., Piantanakulchai, M., \& Takeyama, Y. (1999). A life cycle inventory analysis of carbon dioxide for a highway construction project using input-output scheme: A case study of the tohoku expressway construction works. Graduate School of Information Sciences, Tohoku University.

Retrieved from https://www.researchgate.net/profile/Mongkut_Piantanakulchai/publication/252032139_A _Life_Cycle_Inventory_Analysis_of_Carbon_Dioxide_for_a_Highway_Construction_Proj ect_Using_Input-

Output_Scheme_A_Case_Study_of_the_Tohoku_Expressway_Construction_Works/link s/540d9adf0cf2f2b29a38bb87.pdf

ISO. (2006a). ISO 14040:2006, Environmental Management - Life cycle assessment - Principles and framework. International Organization for Standardization.

ISO. (2006b). ISO 14044:2006, Environmental Management - Life cycle assessment Requirements and guidelines. International Organization for Standardization. 
ISO. (2008). ISO 15686-5:2008, Buildings and constructed assesst - Service-life planning - Part 5: Life-cycle costing. International Organization for Standardization.

Janisch, D., \& Gaillard, F. (1998). Minnesota Seal Coat Handbook (No. Report MN/RC-1999-07). St. Paul: Minnesota Local Road Research Board, Minnesota DOT.

Johanneck, L., \& Khazanovich, L. (2010). Comprehensive Evaluation of Effect of Climate in Mechanistic-Empirical Pavement Design Guide Predictions. Transportation Research Record: Journal of the Transportation Research Board, 2170, 45-55. http://doi.org/10.3141/2170-06

Johnson, G. (2003). Minnesota's experience with thin bituminous treatments for low-volume roads. Transportation Research Board, 1819, 333-337.

Kibert, C. J. (2002). Policy instruments for a sustainable built environment. Journal of Land Use \& Environmental Law, 17(2), 379-394.

Korre, A., \& Durucan, S. (2009). Life Cycle Assessment of Aggregates (No. EVA 025). Waste \& Resources Action Programme (WRAP).

Lee, J., Edil, T. B., Benson, C. H., \& Tinjum, J. M. (2013). Building Environmentally and Economically Sustainable Transportation Infrastructure: Green Highway Rating System. Journal of Construction Engineering and Management, 139(12), A4013006: 1-10. http://doi.org/10.1061/(ASCE)CO.1943-7862.0000742

Lee, J., Edil, T., Tinjum, J., \& Benson, C. (2010). Quantitative Assessment of Environmental and Economic Benefits of Recycled Materials in Highway Construction. Transportation Research Record: Journal of the Transportation Research Board, 2158, 138-142. http://doi.org/10.3141/2158-17

MnDOT. (2014). Minnesota State Highway Investment Plan: 2014-2033. Retrieved March 20, 2016, from http://www.dot.state.mn.us/planning/mnship/>

Moreno Ruiz, E., Levova, T., Bourgault, G., \& Wenet, G. (2014). Documentation of changes implemented in ecoinvent version 3.1. Zurich: ecoinvent. 
Mroueh, U.-M., Eskola, P., \& Laine-Ylijoki, J. (2001). Life-cycle impacts of the use of industrial byproducts in road and earth construction. Waste Management, 21(3), 271-277.

Nathman, R. K. (2008). PaLATE User Guide, Example Exercise, and Contextual Discussion. University of Delaware, DE, U.S.A.

Noland, R. B., \& Hanson, C. S. (2015). Life-cycle greenhouse gas emissions associated with a highway reconstruction: a New Jersey case study. Journal of Cleaner Production, 107, $731-740$.

Pavement Interactive Consortium. (2008). Asphalt. Retrieved March 12, 2016, from http://www.pavementinteractive.org/article/materialsasphalt/

Pavement Interactive Consortium. (2009). Asphalt Concrete Base (ACB). Retrieved March 12, 2016, from http://www.pavementinteractive.org/article/pavement-typesasphalt-concretebase-acb/

Portland Cement Association. (2015). How Cement Is Made. Retrieved March 12, 2016, from http://www.cement.org/cement-concrete-basics/how-cement-is-made

PRe Sustainability. (2016). SimaPro, the world's leading LCA software. Retrieved May 10, 2016, from https://simapro.com/

Rebitzer, G., Ekvall, T., Frischknecht, R., Hunkeler, D., Norris, G., Rydberg, T., ... Pennington, D. W. (2004). Life cycle assessment. Environment International, 30(5), 701-720. http://doi.org/10.1016/j.envint.2003.11.005

Reyes-Ortiz, O., Berardinelli, E., Alvarez, A. E., Carvajal-Muñoz, J. S., \& Fuentes, L. G. (2012). Evaluation of Hot Mix Asphalt Mixtures with Replacement of Aggregates by Reclaimed Asphalt Pavement (RAP) Material. Procedia - Social and Behavioral Sciences, 53, 379_ 388. http://doi.org/10.1016/j.sbspro.2012.09.889

RMRC. (2010). Coal Bottom Ash/Boiler Slag. Retrieved June 17, 2015, from http://rmrc.wisc.edu/ug-mat-coal-bottom-ashboiler-slag/

RMRC. (2010). Coal Fly Ash. Retrieved June 17, 2015, from http://rmrc.wisc.edu/coal-fly-ash/ 
RMRC. (2010). Reclaimed Asphalt Pavement. Retrieved April 22, 2016, from http://rmrc.wisc.edu/ug-mat-reclaimed-asphalt-pavement/

RMRC. (2016). Material Tracking Tool. Retrieved August 4, 2016, from http://rmrc.wisc.edu/material-tracking-tool/

Rogbeck, J., \& Knutz, A. (1996). Coal bottom ash as light fill material in construction. Waste Management, 16(1), 125-128.

Soleimanbeigi, A., \& Edil, T. B. (2013). Evaluation of Shear Creep Response of Recycled Asphalt Shingle Mixtures. Presented at the Geo-Congress 2013, San Diego, CA.

Soleimanbeigi, A., Edil, T., \& Benson, C. (2013). Evaluation of Fly Ash Stabilization of Recycled Asphalt Shingles for Use in Structural Fills. Journal of Materials in Civil Engineering, 25, 94-104.

Strand Associates. (2014). Plan of Proposed Improvement: USH 18 (Design Plans). Wisconsin Department of Transportation.

Suh, S. (2010). CEDA 4.0 User's Guide. IERS, LLC.

Truitt, P. (2009). Potential for reducing greenhouse gas emissions in the construction sector. Washington, DC: U.S. Environmental Protection Agency.

Tsang, M. P., Bates, M. E., Madison, M., \& Linkov, I. (2014). Benefits and Risks of Emerging Technologies: Integrating Life Cycle Assessment and Decision Analysis To Assess Lumber Treatment Alternatives. Environmental Science \& Technology, 48(19), 1154311550. http://doi.org/10.1021/es501996s

U.S. EPA. (2015a). Resource Conservation and Recovery Act (RCRA) Laws and Regulations. Retrieved December 7, 2015, from http://www.epa.gov/rcra

U.S. EPA. (2015b). Sources of Greenhouse Gas Emissions. Retrieved August 3, 2016, from https://www3.epa.gov/climatechange/ghgemissions/sources/transportation.html

USEtox®. (2016). How to use USEtox characterization factors. Retrieved May 11, 2016, from http://www.usetox.org/faq-page/23-0\#t23n100 
Warner, J., \& Edil, T. (2012). An evaluation of reclaimed asphalt shingles for beneficial reuse in roadway construction. In Testing and Specification of Recycled Materials for Sustainable Geotechnical Construction. ASTM International. Retrieved from http://www.astm.org/DIGITAL_LIBRARY/STP/PAGES/STP154020120008.htm

Wen, H., Baugh, J., Edil, T., \& Wang, J. (2011). Cementitious High-Carbon Fly Ash Used to Stabilize Recycled Pavement Materials as Base Course. Transportation Research Record: Journal of the Transportation Research Board, 2204, 110-113. http://doi.org/10.3141/2204-14

WisDOT. (2007). I-94 North-South Freeway Project. Retrieved July 1, 2015, from http://projects.511wi.gov/i94northsouth/

WisDOT. (2014a). WisPave 4 User Manual. Wisconsin Department of Transportation. Retrieved from http://wisconsindot.gov/Documents/doing-bus/eng-consultants/cnsltrsrces/tools/qmp/wpmanual.pdf

WisDOT. (2014b, October 24). WisPave 4 User Manual. WisDOT. Retrieved from http://wisconsindot.gov/Documents/doing-bus/eng-consultants/cnsltrsrces/tools/qmp/wpmanual.pdf

WisDOT. (2015). Chapter 14: Pavement. Retrieved December 9, 2015, from http://wisconsindot.gov/Pages/doing-bus/eng-consultants/cnslt-rsrces/rdwy/fdm.aspx

WisDOT. (2015). Madison Beltline Study. Retrieved June 1, 2015, from http://wisconsindot.gov/Pages/projects/by-region/sw/madisonbeltline/default.aspx

WisDOT. (2015). Quality management program. Retrieved May 10, 2016, from http://wisconsindot.gov/Pages/doing-bus/eng-consultants/cnslt-rsrces/qmp/default.aspx WisDOT. (2015). Verona Road (US 18/151) Project. Retrieved June 1, 2015, from , http://projects.511wi.gov/veronard/ 
WisDOT. (2015). Wisconsin Department of Transportation - Average Unit Price List. Wisconsin $\begin{array}{llll}\text { Department of } & \text { Transportation. } & \text { Retrieved }\end{array}$ http://wisconsindot.gov/hcciDocs/contracting-info/average-unit-price.pdf

WisDOT. (2016a). Material recycling. Retrieved May 12, 2016, from http://wisconsindot.gov/Pages/aboutwisdot/performance/mapss/measures/preservation/recycling.aspx

WisDOT. (2016b). Section 10 Pavement Design. WisDOT Standard Specifications. Retrieved from http://wisconsindot.gov/rdwy/fdm/fd-14-10.pdf

WisDOT. (2016c). Section 301 General Requirements for Base Aggregates. WisDOT Standard Specifications. Retrieved from http://wisconsindot.gov/rdwy/stndspec/ss-03-01.pdf\#ss301

WisDOT. (2016d). Section 460 Hot Mix Asphalt Pavements. WisDOT Standard Specifications. Retrieved from http://wisconsindot.gov/rdwy/stndspec/ss-04-60.pdf\#ss460

Zapata, P., \& Gambatese, J. A. (2005). Energy Consumption of Asphalt and Reinforced Concrete Pavement Materials and Construction. Journal of Infrastructure Systems, 11, 9-20. 